University of Louisville

ThinkIR: The University of Louisville's Institutional Repository

Electronic Theses and Dissertations

$5-2005$

\title{
The Alternatives to detention program : assessment of one Kentucky county's efforts to deinstitutionalize status offenders.
}

Arthur Hayden

University of Louisville

Follow this and additional works at: https://ir.library.louisville.edu/etd

\section{Recommended Citation}

Hayden, Arthur, "The Alternatives to detention program : assessment of one Kentucky county's efforts to deinstitutionalize status offenders." (2005). Electronic Theses and Dissertations. Paper 590.

https://doi.org/10.18297/etd/590

This Doctoral Dissertation is brought to you for free and open access by ThinkIR: The University of Louisville's Institutional Repository. It has been accepted for inclusion in Electronic Theses and Dissertations by an authorized administrator of ThinkIR: The University of Louisville's Institutional Repository. This title appears here courtesy of the author, who has retained all other copyrights. For more information, please contact thinkir@louisville.edu. 


\title{
THE ALTERNATIVES TO DETENTION PROGRAM: ASSESSMENT OF ONE KENTUCKY COUNTY'S EFFORTS TO DEINSTITUTIONALIZE STATUS OFFENDERS
}

\author{
by \\ Arthur Hayden, Jr. \\ B.A., Kentucky State University, 1991 \\ M.S.W., University of Kentucky, 1997 \\ M.S., Eastern Kentucky University, 1998
}

\begin{abstract}
A Dissertation
Submitted to the Faculty of the

Graduate School of the University of Louisville

in Partial Fulfillment of the Requirements

for the Degree of
\end{abstract}

Doctor of Philosophy

Kent School of Social Work

University of Louisville

Louisville, Kentucky

and

College of Social Work

University of Kentucky

Lexington, Kentucky

May, 2005 
THE ALTERNATIVES TO DETENTION PROGRAM: ASSESSMENT OF ONE KENTUCKY COUNTY'S EFFORTS TO DEINSTITUTIONALIZE STATUS OFFENDERS

by

Arthur Hayden, Jr.

B.A., Kentucky State University, 1992

M.S.W., University of Kentucky, 1997

M.S., Eastern Kentucky University, 1998

A Dissertation Approved on

May, 2005

by the following Dissertation Committee:

Daniel P. Wulff, Ph.D.

Michael A. van Zyl, Ph.D.

Angela D. West, Ph.D.

Richard D. Sutphen, Ph.D.

Preston Elrod, Ph.D. 


\section{DEDICATION}

This dissertation is dedicated to the many individuals who have been supportive and instrumental to my successes along the way. I want to especially dedicate this to my parents whose love made this possible. 


\section{ACKNOWLEDGEMENTS}

I want to express my gratitude to my dissertation committee members, Drs. Daniel Wulff, Michael Adriaan van Zyl, Angela West, Richard Sutphen, and Preston Elrod for their assistance and support throughout this process. I also want to thank my son, Demarcus Hayden, for his patience as I have pursued my educational goals throughout the years. Special appreciation goes to my former supervisor, Harriette Swart, for her understanding and flexibility. Likewise, to my brother, Troy Hayden, whose technical savvy has saved me on more than one occasion. I would like to thank the Lexington, Fayette County Detention Alternatives coordinator, Mr. Wade Carpenter, for his assistance. Finally, I want to thank the many individuals with the Cabinet for Health \& Family Services, Department of Juvenile Justice, and Administrative Office of the Courts whose support and assistance made this endeavor possible. 


\title{
ABSTRACT \\ THE ALTERNATIVES TO DETENTION PROGRAM: ASSESSMENT OF ONE KENTUCKY COUNTY'S EFFORTS TO DEINSTITUTIONALIZE STATUS OFFENDERS
}

\author{
Arthur Hayden, Jr.
}

May, 2005

Since the beginning of the juvenile justice movement in the United States over a century ago, considerable debate has persisted among policymakers and practitioners concerning the causes of juvenile offending and the appropriate responses to control it. Although the juvenile justice system was conceived and developed to provide individualized, benevolent treatment to young offenders, the system has gradually shifted to resemble a more punitive, adult criminal justice model. While presently the system includes characteristics of both the juvenile and adult justice models, future directions are uncertain. This is problematic for young offenders who need and deserve more solicitous care in their rehabilitation.

This dissertation examines an alternative intervention used to respond to status offending in Lexington, Fayette County, Kentucky—-the Alternatives to Detention (ATD) program. While policymakers and practitioners generally agree on the causes of status offending such as child maltreatment and general family dysfunction, there is no consensus regarding how to appropriately respond. 
Thus, this evaluation is particularly salient given the continuing debate over how to respond to the unique challenges presented by this population.

The dissertation is divided into five chapters including an Introduction, Literature Review, Methodology, Results, and Discussion. Chapter One provides an introduction to the problem of juvenile offending, particularly status offending, and describes efforts to deinstitutionalize these youths in one Kentucky county by using the Alternatives to Detention (ATD) program. Chapter Two discusses the national, state, and Fayette County trends in juvenile offending, and pays particular attention to rising status offense trends. Based on the literature, Chapter Three defines the methodology used to evaluate the ATD program. The methodology includes a quasi-experimental, multiple-group pre/post-test design using chart review of existing Juvenile Court and ATD program records. Chapter Four includes data analyses using descriptive and inferential statistical procedures. The findings and implications for both the present study and future research in this area are discussed in Chapter Five with recommendations for program improvement.

Based on the goals of the ATD program, results indicate that (1) Fayette County, Kentucky is in compliance with deinstitutionalization mandates set forth by the Juvenile Justice and Delinquency Prevention Act (JJDPA), and (2) the program produced positive outcomes when used as a predispositional alternative to secure detention for status offenders because it (a) ensures youths' appearance in court, and it (b) provides enhanced safety to youths and the community through decreased offending. 
This goals-based evaluation of the ATD program will add to the existing knowledge base focusing on effective correctional interventions for youths. In addition, the evaluation of the ATD program will provide local juvenile justice policymakers and practitioners with substantive outcomes that can be used in ongoing discussions concerning best practice standards for status offenders, while fulfilling mandates to deinstitutionalize these youths. 


\section{TABLE OF CONTENTS}

ACKNOWLEDGEMENTS. ..iv

ABSTRACT. ..v

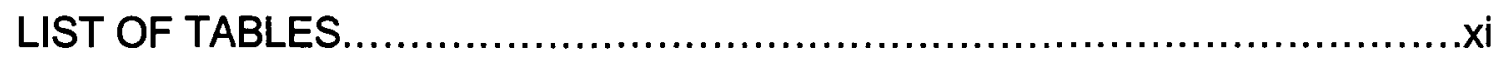

LIST OF FIGURES .........................................................

LIST OF APPENDICES ....................................................ii

INTRODUCTION.................................................................

Juvenile Justice System................................................

Historical Overview.........................................................

Juvenile and Family Courts............................................

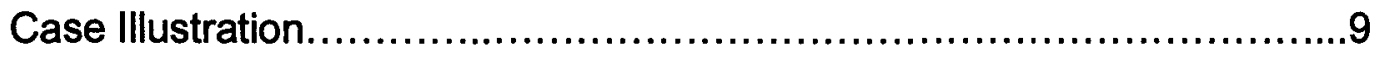

Study Purpose.............................................................11

ATD Programs..................................................... 13

Kentucky ATD Programs..............................................14

Fayette County ATD Program...........................................16

Goals and Objectives..................................................17

LITERATURE REVIEW.................................................. 19

Status Offenders..........................................................21

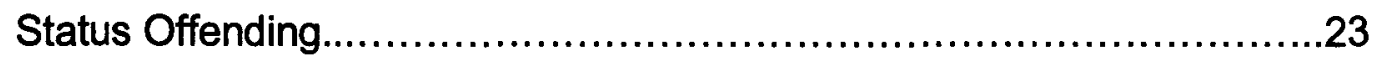

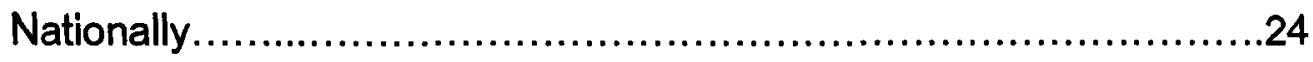


Kentucky.

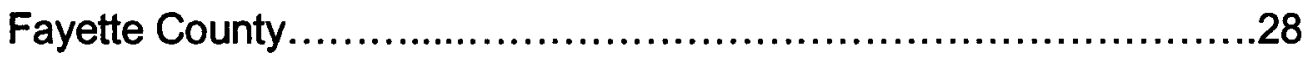

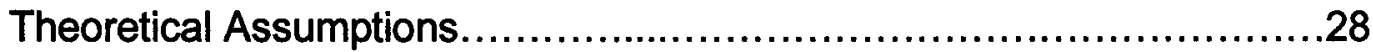

Program Evaluation......................................................32

Program Effectiveness and Recidivism...................................35

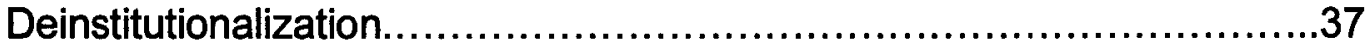

Research Questions....................................................41

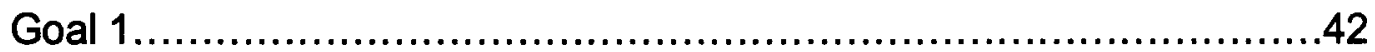

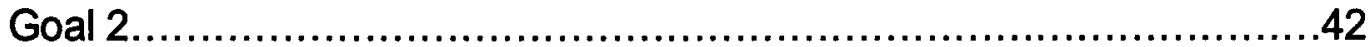

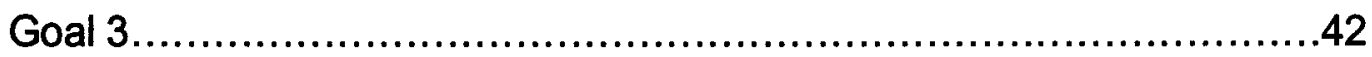

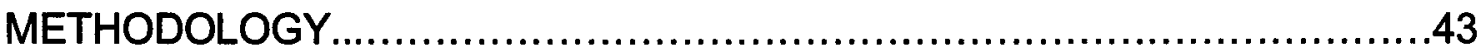

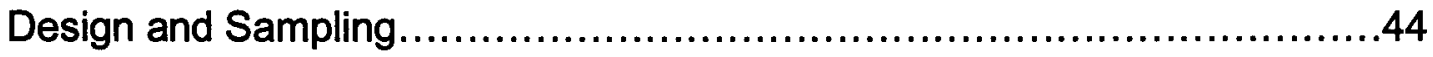

Research Design.......................................................45

Sample.................................................................... 48

Independent and Dependent Variables.....................................55

Variables Operationalized............................................52

Issues of Confidentiality...................................................54

Procedures for Collecting Data................................................54

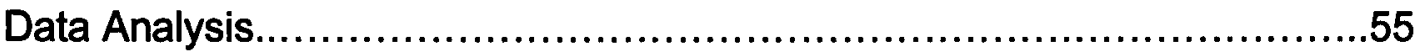

Dissemination of Findings................................................57

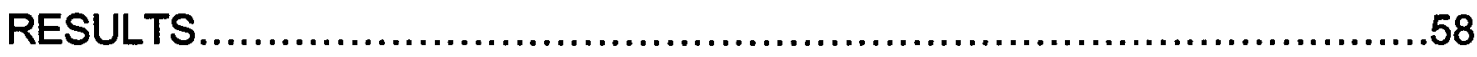

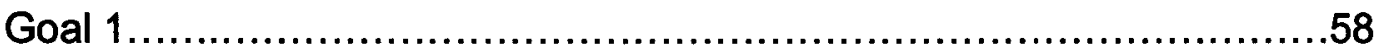

Placement Trends........................................................ 
Secure Detention........................................................ 58

Alternatives to Detention.................................................60

Placement Factors......................................................61

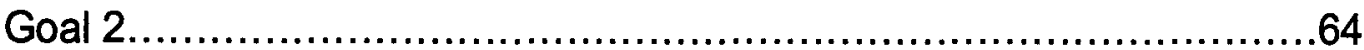

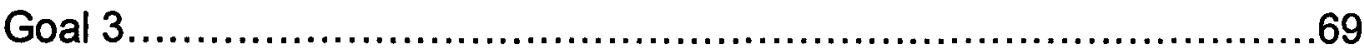

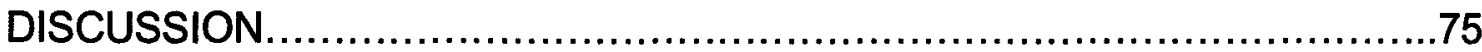

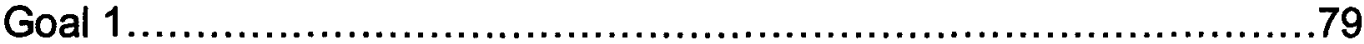

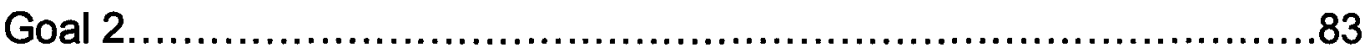

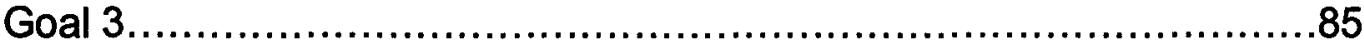

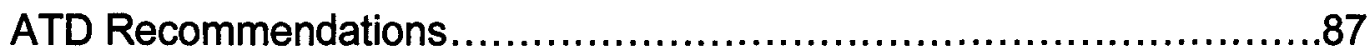

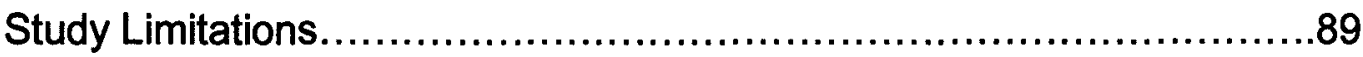

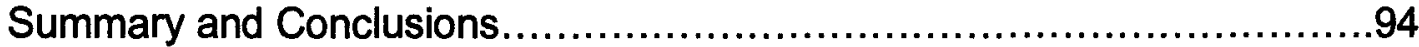

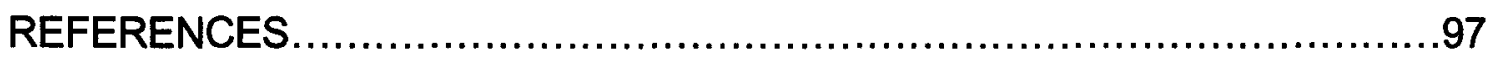

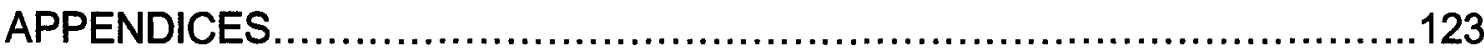

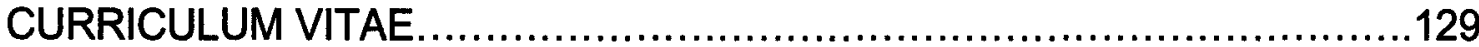




\section{LIST OF TABLES}

\section{TABLE}

PAGE

1. Number and Percentage of Subjects.

2. Mean Ages for Initial Court Contact, Initial Placement, and Number of Placement.

3. Crosstabulation for Placements by Offender Characteristics

4. Analysis of Variance by Ranks Between Placements for Age, Grade, and Number of Placements

5. Analysis of Variance by Ranks Between Placements for Contempt-FTA Charges and Recidivism.

6. Intercorrelations Between Number of Contempt-FTA Charges,

Recidivism, and Offender Characteristics.

7. Intercorrelations Between Number of Contempt-FTA Charges and Offender Characteristics.

8. Intercorrelations Between Number of Contempt-FTA Charges and Offender Characteristics by Placement Type. 68

9. Analysis of Variance by Ranks Between Placements for Status/Delinquent Charges and Recidivism.

10. Intercorrelations Between Status/Delinquent Charges, Recidivism, and Offender Characteristics.

11. Intercorrelations Between Status/Delinquent Charges and Offender Characteristics.

12. Intercorrelations Between Status/Delinquent Charges and Offender Characteristics by Placement Type. 


\section{LIST OF FIGURES}

1. Predispositional placement alternatives for status offenders in Fayette County.

2. Bar graph for status cases processed nationally in juvenile courts by type and year.

3. Bar graph for status and delinquent cases processed in juvenile courts in Kentucky

4. Line graph of status and delinquent cases processed in Fayette County juvenile court by year.

5. Pie chart for gender and race of subjects.

6. Pie chart for VCO status offender placements .59

7. Line graph for status offenders detained for contempt by year .60

8. Bar graph for contempt charges-FTA and recidivism by placement type.....65

9. Bar graph for status and delinquent charges and recidivism by placement type. 


\section{LIST OF APPENDICES}

\section{APPENDIX}

PAGE

A. Risk screening instrument..................................................

B. Offense risk or severity index................................................

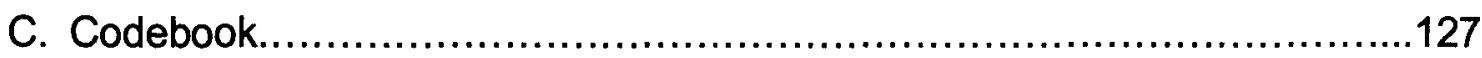


THE ALTERNATIVES TO DETENTION PROGRAM: ASSESSMENT OF ONE KENTUCKY COUNTY'S EFFORTS TO DEINSTITUTIONALIZE STATUS OFFENDERS

\section{CHAPTER ONE}

\section{INTRODUCTION}

Juvenile justice policymakers and practitioners have struggled since the inception of the juvenile justice system to figure out what policies and programs can be effective in controlling juvenile offending. These struggles have been exacerbated by a juvenile justice system with often competing and conflicting goals of treatment on the one hand, and punishment on the other. Wilson (1975) noted that he had never seen a root cause of offending or encountered a government program that successfully addressed juvenile offending. While over a century has passed since the first Juvenile Court was established, no consensus exists as to what works (Greve, 2001). Waggoner (1996) aptly observed that everyone complains about the juvenile justice system, but no one ever does anything about it.

As Crowe (2000) notes, there are wide disparities in opinions and theories that explain juvenile offending and how it should be treated. While Bernard (1992) suggests the trend has been to cycle between institutionalization and deinstitutionalization of the juvenile offender, Weijers (1999) asserts there is a foundational issue to consider in balancing and justifying punishment of children. 
Harris, Welsh, and Butler (2000, p. 359) state that the "American juvenile justice system was founded on internally conflicting value systems: the diminished responsibility and heightened malleability of youths versus individual culpability and social control of protocriminality." The uncertainties of the juvenile justice system have led some to believe that "nothing works" (Gibbons, 1999; Jackson, de Keijser, \& Michon, 1995; Olsson, 1996), or that the system is fundamentally flawed and should be overhauled or abolished altogether (Feld, 1997).

According to Fagan and Forst (1996), a major weakness in the juvenile justice system is that intervention efforts such as the Juvenile Court have not been grounded in the theories and causal assumptions that explain juvenile offending. The authors add that in many instances, intervention is often atheoretical because efforts are based on vision or zeal, and that programs for juvenile offenders must be grounded in theoretical assumptions that explain and predict human development and behavior to adequately address these issues. On the other hand, Ohlin (1998) notes that while many theories on offending have emerged, none of the theories adequately accounts for offending today. Matthews and Pitts (1998, p. 404) suggests that "what works" for juvenile offenders requires further identification of causal mechanisms and "their operation within different contexts." Therefore, further research is needed to determine what interventions are useful with juvenile offenders. According to Reid (2004), this can be accomplished through comparative approaches that examine different interventions simultaneously. 


\section{Juvenile Justice System}

\section{Historical overview.}

The history and evolution of the American juvenile justice system (see, for example, Harris et al., 2000; Krisberg, 1995; Ohlin, 1998; Olsson, 1996) helps explain the tensions within the system. According to Harris et al., (2000, p. 359), from its inception the primary focus of the system has been delinquency, "an amorphous construct that not only includes 'criminal' behavior but also an array of youthful actions that offend prevailing social mores." Yet, the meaning of delinquency and the methods for addressing it have differed across time (Harris et al., 2000).

While juvenile crime has been an issue of concern for centuries, the notion of juvenile justice has its traditions rooted in England beginning in the $15^{\text {th }}$ century. A precursor to the American juvenile justice system, the English Poor Laws system was developed in an effort to control the emigrant underclass with laws that mandated regulation of the poor, especially women and children, by local governments (Crowe, 2000; Driver, 1993; Platt, 1977). Yet, the result of these early efforts to control the poor ultimately contributed to childhood deviance and massive child abandonment with "bands of youths roaming the cities at night, engaging in thievery, begging, and other forms of misbehavior" (Krisberg \& Austin, 1993, p. 9). In 1553, the first "house of correction" was created to specifically address childhood deviance. The Bridewell and other houses of correction that followed incorporated ideologies of the poor house, work house, and penal institution. 
The $18^{\text {th }}$ and early $19^{\text {th }}$ centuries were a pivotal period of change in the perception of juvenile crime and treatment of juvenile offenders. Shore (2000) notes that the Report of the Committee for Investigating the Alarming Increase of Juvenile Crime in the Metropolis, published in 1816 by a group of religious and philanthropic social reformers, generated interest in these issues and led to extensive changes in social policy relating to women and children; these changes brought about a reconceptualization of juvenile justice. The new justice system "endorsed the removal of children from domestic situations considered 'unfit" (Shore, p. 23). While English common law recognized and preferred family control of children, formal methods were introduced to encourage lawful behavior through apprenticeship or "binding out," as well as institutionalization if necessary.

The juvenile justice system was also being developed in colonial America that reflected both the authority of English rule and local self-government. The first courts enforced English common law, statutory law, and the criminal code with modifications for local conditions. Similar to the English system, informal control by the family was favored. By the late $18^{\text {th }}$ century, colonial laws specified a need for formal control of wayward youths through apprenticeship. Forced labor of destitute children, particularly in a young industrial America, contributed to massive urban migration and a new challenge to control a “dangerous underclass" (Krisberg \& Austin, 1993).

Beginning in the $19^{\text {th }}$ century, institutional measures intended to control delinquency led to the establishment of the first American juvenile institution in 
1825, the House of Refuge, in New York. Because delinquency was associated with poverty, forced treatment to prevent "pauperism" was the goal of this early institution. Other efforts headed primarily by religious and charitable organizations continued to work toward this goal. However, by the late $19^{\text {th }}$ century, state governments had incrementally assumed these responsibilities as seen by the creation of the first reform school in Massachusetts in 1864, the Lyman School, and other correctional institutions that followed. Institutionalization of poor children continued until these practices were reversed by state law in Illinois beginning first in 1868 (Bernard, 1992).

These formal measures to address childhood deviance led to the first Juvenile Court in Chicago in 1899. Based on the doctrine of parens patriae in which the state had inherent power and responsibility for the welfare of children, the first Juvenile Court was founded on the concept of control and rehabilitation through individualized justice. This philosophical goal shaped the early procedural and substantive differences between the adult and juvenile justice systems by focusing on the "best interests" of juvenile offenders. Specifically, a separate and independent court was established for children with special legal and social procedures to govern the adjudication and disposition of juvenile matters. Moreover, children were to be separated from adults in courts and institutional programs. Probation programs were developed to assist the court with these matters. The core of this rehabilitative model included two related claims: young offenders were misguided children rather than responsible wrongdoers, and the sole purpose of state intervention was to promote their 
welfare through rehabilitation (Scott \& Steinberg, 2003).

By the mid-20 ${ }^{\text {th }}$ century, criticisms concerning the effectiveness of the Juvenile Court model to rehabilitate young offenders ushered in important formal changes. Regulatory frameworks were established that combined dispositions with interventions intended to prepare young offenders for conventional adult roles (Scott \& Steinberg, 2003). In a series of landmark United States Supreme Court decisions (e.g., In re Gault (1967), In re Winship (1970), McKeiver v. Pennsylvania (1976)), Juvenile Courts were prompted to become more formal and similar to the adult criminal courts in areas such as due process. States also began to reclassify status offenders into a separate jurisdictional class (Matthews, 2000). Two significant federal laws affecting status offenders were instituted during this time. The Juvenile Delinquency Prevention and Control Act (1968), and the Juvenile Justice and Delinquency Prevention Act (1974); the latter mandated deinstitutionalization of status offenders and non-offenders such as neglected or dependent children from secure lock-up.

Criticisms concerning the juvenile justice system persisted into the late $20^{\text {th }}$ century. Public perceptions of higher crime rates contributed to additional procedural and substantive changes designed to "get tough" with juvenile crime. In many jurisdictions, certain juvenile offenses were no longer handled in Juvenile Court, but instead handled in adult criminal court through mandatory or automatic waiver, and sentencing became more punitive and less discretionary.

During the last decade, ideological shifts calling for a more "balanced approach" have surfaced in juvenile justice. These changes seek to incorporate 
the early ideals of rehabilitation through individualized justice with current principles of restorative justice. A "balanced approach" incorporates characteristics of both the juvenile and adult justice models including accountability, competency development, and community protection (Maloney, Romig \& Armstrong, 1988; Pranis, 1998; Snyder \& Sickmund, 1999), and seeks to repair damages, reestablish dignity, and reintegrate young offenders (Center for Peacekeeping and Conflict Studies, 2003).

The frustration surrounding the juvenile justice system persists in part due to policies that inadequately address the root causes of juvenile offending. Good intentions grounded in the past and carried forward to today have not controlled offending, nor have modern policies that have shifted away from early rehabilitative ideals toward more consequentialist or retributive philosophies. Explanations offered by Bernard (1992), Weijers (1999), and others suggest that problems will persist until policymakers and practitioners fully implement a more balanced approach.

\section{Juvenile and Family Courts}

The first Juvenile Court introduced in Illinois in 1899 was conceived as a treatment court intended "to provide for the care, protection, and wholesome moral, mental, and physical development of children" (Boisvert \& Wells, p. 230, 1980). However, the Juvenile Court has gradually shifted to adopt an authoritative interventionist approach in efforts to maintain control of an increasing number of juvenile offenders (Colley \& Culbertson, 1988). Yet, according to Zimring (2000, p. 2487), "the saga of the status offender was one of 
the greatest failings of the interventionist theory of juvenile courts." Because the Juvenile Court has become increasingly overburdened and unable to effectively manage juvenile offenders, family courts ${ }^{1}$ have been created in many jurisdictions to respond to the complex issues facing them and their families. While the family court concept dates back to the 1960s, the emergence of family courts have dramatically risen over the past two decades (Belou, 2004). Unified family courts, which combine all the elements of traditional juvenile and family courts, seek to provide comprehensive services to juveniles and their families with the assistance of support personnel and social service workers. The concept of family and unified family courts is one that a single, highly trained judge handles all matters relating to a family. Often, the court's jurisdiction includes marital actions, juvenile proceedings, adoptions, paternity actions, civil commitments, orders of protection, and criminal cases stemming from domestic violence. In 1994 the American Bar Association adopted a resolution calling for the use of the unified family courts model (Barnes, 1996; Gibeaut, 1997).

In Fayette County the Juvenile and Family Courts consider not only the offense and offending history, but the contexts in which offending occurs. Individual, family, neighborhood, and larger community factors must be considered when dispensing justice to those who offend. These issues are particularly relevant for status offenders and their families who present unique challenges to the juvenile justice system because of problems such as

\footnotetext{
${ }^{1}$ Family Court became a permanent part of the Kentucky Constitution in November, 2002. Previously, status offenders were under the jurisdiction of District Court, Juvenile Division. Presently, they are under the Circuit Court, Family Division. Some status offenders with active cases processed prior to the Family Court remain in District Court.
} 
chronic mental illness, substance abuse, domestic violence, child maltreatment, poverty, neighborhood violence, inadequate social opportunities, and general social malaise that influence juvenile justice clients. These issues have been well-documented in the literature (see, for example, Birkbeck \& LaFree, 1993; Brezina, 1998; Hoffman, 2003; Kierkus \& Baer, 2002; St. C. Levy, 1997). As one ATD program notes (Ed Necco and Associates, 2002), juvenile justice officials must often confront these realities in determining whether to send a juvenile home or use secure detention. While punishment of status offenders through incarceration remains a contentious issue, it is likely to continue. According to Steinhart (1996, p. 96), "the challenge...is to provide help without adequate service options in a policy environment that seems to favor incarceration as a tool for the control of youthful misconduct." The ATD program was developed with recognition that offending is related to numerous, complex circumstances, and that juvenile offenders often can benefit from interventions that provide a continuum of care based on specific circumstances for each individual offender.

\section{Case Illustration}

A 15-year-old, Caucasian female sits restlessly with her mother in a waiting room outside the Juvenile Court while she awaits the bailiff to call her name. The waiting room is crowded but quiet. The Juvenile Court docket is long and time-consuming. But the juvenile is accustomed to the procedures as she has been here before. On this day, the status offender is being arraigned for habitual truancy after missing $\mathbf{3 0}$ days of school. Normally timid, she tries to convince herself that the judge will be lenient. After all, she's only charged 
with a status offense and not more serious offenses like many of the other juveniles. The juvenile recognizes some of them-a classmate, a good friend, and a neighbor. She acknowledges them with a nod but doesn't want to become involved. She knows they are delinquents. However, she knows the judge will not be pleased to see her either. This is the eighth time she has been to court: four previous charges of running away from home, one charge of beyond parental control, one misdemeanor shoplifting charge, and truancy. The judge has warned her several times before that if she comes back to court, she's "going to be sorry." She has been seeing a therapist sporadically for a few months. She hopes the judge will take into consideration that she is on medication for depression. A social worker meets briefly with she and her mother to gather information to present to the judge. "The judge is not happy today," the social worker whispers. "She'll probably put you in detention for violating court orders to attend school," she warns. The mother says very little. She is exhausted from dealing with her daughter's perpetual misbehavior. "I've told her a million times to go to school and stay out of trouble, but she won't listen." The social worker is very familiar with this case. Several of the children in this family have been through court. The social worker knows that these circumstances only add to the judge's disdain. The mother struggles as a single parent of six. The family is poor, violence is commonplace in the neighborhood, and education isn't a priority. As the social worker carries on small talk with the family, a juvenile exits the courtroom in an outrage. Slamming the door, he exclaims, "I hate that bitch!" 
His mother tries to calm him to no avail. The young man hurls out more expletives. The bailiff rushes out to get him. "Hey, you! Get back in here! The judge heard that!" he yells. Others in the waiting room take notice. Chatter erupts, and it becomes apparent that many in the waiting room are now on edge. Most know that some judges are notoriously firm, but these thoughts are usually placed somewhere in the far recesses of their young minds. She knows though, because she has been in detention numerous times, and spent some time in foster care as an alternative to detention. She hopes that this time will be different. The young man never exits the courtroom. Everyone realizes that the judge has put him in lockdown. "You're next," the social worker says. She begins to sob.

\section{Study Purpose}

The purpose of this study was to evaluate the efficacy of the Alternatives to Detention (ATD) program used with juvenile offenders in Lexington, Fayette County, Kentucky. Specifically, this study assessed the outcomes of deinstitutionalization of status offenders from secure lock-up using the ATD program between September 1, 2001 (ATD implementation date) and July 1, 2003, the last date the reviewer had permission from the court to access records. Enumerated by the federal Juvenile Justice and Delinquency Prevention Act ${ }^{2}$ (JJDPA) of 1974 and by state statute in the Kentucky Unified Juvenile Code ( $\S$ 600.010 et. seq.) in 2000 , the ATD program was implemented to provide for a continuum of services that conforms to federal and state mandates to remove

\footnotetext{
${ }^{2}$ The JJDPA includes other provisions or "core protections" including removal from adult jail lockup, "sight and sound" separation from adults, and reduction in disproportionate minority confinement. States are required to maintain these protections to receive federal funding.
} 
status offenders from secure detention and correctional facilities. As noted by Holden and Kapler (1995, p. 9), "deinstitutionalization of status offenders remains a central theme in juvenile justice...the survival of a state's [deinstitutionalization] policy likely will depend in large part on how firmly it has become in laws, policies, and practices."

Revisions to the Kentucky Unified Juvenile Code during the 2000 session of the state General Assembly were the initial steps necessary to bring this state into compliance with the JJDPA enacted over two decades earlier. These revisions were in response to the Kentucky Juvenile Justice Advisory Committee Annual Report in 1999 and a federal consent decree that determined detention was used too often to punish status offenders in Kentucky contrary to the legislative mandates. According to the Annual Report, the rate for secure detention of status offenders was 26.64 per 100,000 individuals, and well above the de minimis or minimal rate of 5.8 per 100,000 required to be in full compliance with the JJDPA. Additionally, detention costs were not justified for the types of offenses committed. Use of secure detention for nonserious public offenders and status offenders was projected to cost on average $\$ 100$ per day per individual--substantially greater costs overall when compared to community-based alternatives (Kentucky Department of Public Advocacy, 2000).

Based on these findings, the state legislature enacted statutes barring status offenders (including those facing contempt charges without a Valid Court $\mathrm{Order}^{3}$ ) from being detained in secure jails and correctional facilities. Consequently, the

\footnotetext{
${ }^{3}$ A Valid Court Order is specified in state statute (K.R.S. 600.020). It is an order issued by a judge to a juvenile with specific terms acknowledged by the juvenile. The VCO is a statutory exception that allows for use of secure detention for status offenders who violate an order.
} 
Alternatives to Detention program was developed statewide to comply with the federal and state mandates. Presently, while services for status offenders remain under the jurisdiction of Kentucky's child welfare system, ${ }^{4}$ Department for Community Based Services (DCBS), the ATD program used for both status offenders and delinquents is overseen by Kentucky's Department of Juvenile Justice (DJJ).

\section{ATD Programs}

According to the Juvenile Research and Statistics Association (JRSA, 2003), alternatives to secure confinement of juvenile offenders represent a response to the varying needs of youths who enter the juvenile justice system and are consonant with the desire of many juvenile justice systems to steer juveniles away from secure confinement unless such confinement is necessary. Although public safety is always a primary concern, most juvenile justice professionals realize that less serious juvenile offenders seem to benefit more from nonsecure placements or programs. Therefore, alternatives to secure detention (a) create a continuum of services; (b) offer programs that are not secure because of the belief that not all youths need to be in a highly secured environment; (c) promote the perception that for certain youths a nonsecure environment is more likely to be rehabilitative; and (d) reduce the number of juveniles placed in secure institutions. ATD programs are funded primarily by the federal Formula Grants Program of the JJDPA (Nelson, 1982).

\footnotetext{
${ }^{4}$ The Department for Community Based Services (DCBS) is the state agency statutorily mandated to provide services to status offenders. In Fayette County, a county agency, Division of Youth Services (DYS), also provides these services. However, DYS does not provide services to status offenders probated or committed to the state.
} 


\section{Kentucky ATD Programs}

Similarly, Kentucky Department of Juvenile Justice (DJJ) policy states that the Alternatives to Detention (ATD) program "provide[s] a comprehensive continuum of community based programs for youths who require varying levels of custody and supervision on a temporary basis pending further legal action or until the conclusion of a court ordered disposition" (2002, Alternatives to Detention section, ๆ 3). This continuum of proper placement includes the following objectives: (1) to provide community based programming for nonviolent, at-risk juveniles that will effectively protect the community, and reserve secure detention resources for violent, serious offenders; (2) to ensure the juvenile's arrest-free return to court using a less restrictive form of community supervision which is comparably as effective as secure detention; (3) to prevent unnecessary disruptions of a juvenile's school and family life; (4) to prevent nonviolent juveniles from exposure to more sophisticated, delinquent youths; (5) to begin assessments and interventions that will facilitate a successful disposition of the youth's case if the youth is later adjudicated on the charges; (6) to eliminate the use of secure detention for other than public safety reasons including situations where youths have unsuitable homes, parents refuse to assume responsibility, or parents cannot be located; and (7) to provide cost effective options that prevent the need to construct costly detention centers (Diloreto, 2002).

The goals of the predispositional ATD program as specified by the Kentucky Department of Juvenile Justice (DJJ, 2003) include (a) to ensure that youths appear at court appearances prior to disposition, and (b) to ensure that both the 
public safety and the safety of youths is preserved, and that youths are placed in the least restrictive, most appropriate placement possible pending final disposition of the case (see, Standards of Practice \$1102). Kentucky statute (K.R.S. $§ 610.265)$ currently permits secure detention of status offenders awaiting a detention hearing, out-of-state runaways, or those in violation of a Valid Court Order (VCO) when the following conditions are met: (1) the court affirms the requirements for a VCO were established at the time the original order was signed; (2) probable cause has been found that the juvenile violated the order; and (3) an agency such as the Department for Community Based Services (DCBS) or DJJ reviews the behavior and circumstances for the juvenile's appearance before the court, determines whether all dispositions other than secure detention have been exhausted or are inappropriate, and submits recommendations to the court concerning the juvenile (Robinson \& Arnold, 2000). Otherwise, secure detention of status offenders is prohibited. Furthermore, youths under the age of 14 generally are not placed in secure detention.

The ATD coordinator relies upon an assessment tool (See Initial Detention Risk Screening Instrument, Appendix A, and Offense Risk or Severity Index, Appendix B) to assess the appropriateness of seeking a nonsecure placement for status offenders. Unless a juvenile has previous placement disruptions in the ATD program, or is inappropriate due to factors such as flight risk, aggressive behavior, severe mental health issues, lack of placement to justify secure detention, or scores too high on the assessment tool, nonsecure 
placement is required. Youths must also meet any criteria established by the private provider such as age or gender restrictions. Juvenile judges may refer youths to the ATD program, but the final decision to place the juvenile rests with the coordinator. Although judicial permission is not required when a youth pending disposition is placed in an alternative program, judges are informed of the ATD decision. When a youth is sentenced to detention, judicial approval is required for an alternative placement. Once placed, youths may move up or down the custody continuum based upon compliance or noncompliance with program rules. A youth can begin detention in a secure setting, be moved to a shelter setting, and finally be placed on home detention. Likewise, a youth placed on home detention who fails to follow the conditions of home detention may be placed in secure detention. An administrative hearing is conducted and a court hearing is not required (Diloreto, 2002).

\section{Fayette County ATD Program}

While the ATD program is used both pre and post adjudication, it is most often used as a predispositional alternative. In Fayette County, Kentucky, the program is typically used for status offenders facing contempt of court charges that result from violating valid court-ordered terms (VCO), or for failure to appear for court proceedings (W. Carpenter, ${ }^{5}$ personal communication, February 13 , 2003). According to DJJ policy, the ATD program "is appropriate for status offenders and nonviolent public offenders who are at risk of reoffending or not reappearing for court dates if not supervised...[and] are appropriate for youth that would, absent the availability of the ATD program, be securely detained" (2003,

\footnotetext{
${ }^{5}$ Wade Carpenter is the ATD coordinator for Lexington, Fayette County, Kentucky.
} 
Alternatives to Detention section, ๆ 3). All ATD services in Fayette County are contracted to private vendors and placements range from lesser restrictive alternatives including court resource foster homes, staff-secure shelter, and home detention, to more restrictive institutions such as residential facilities and secure confinement. Services provided to youths and their families vary among the private vendors and generally include temporary supervisory foster care, inhome crises intervention, home detention tracking, electronic monitoring, mentoring, and educational programs. Figure 1 displays the placement process for status offenders who are facing secure detention.

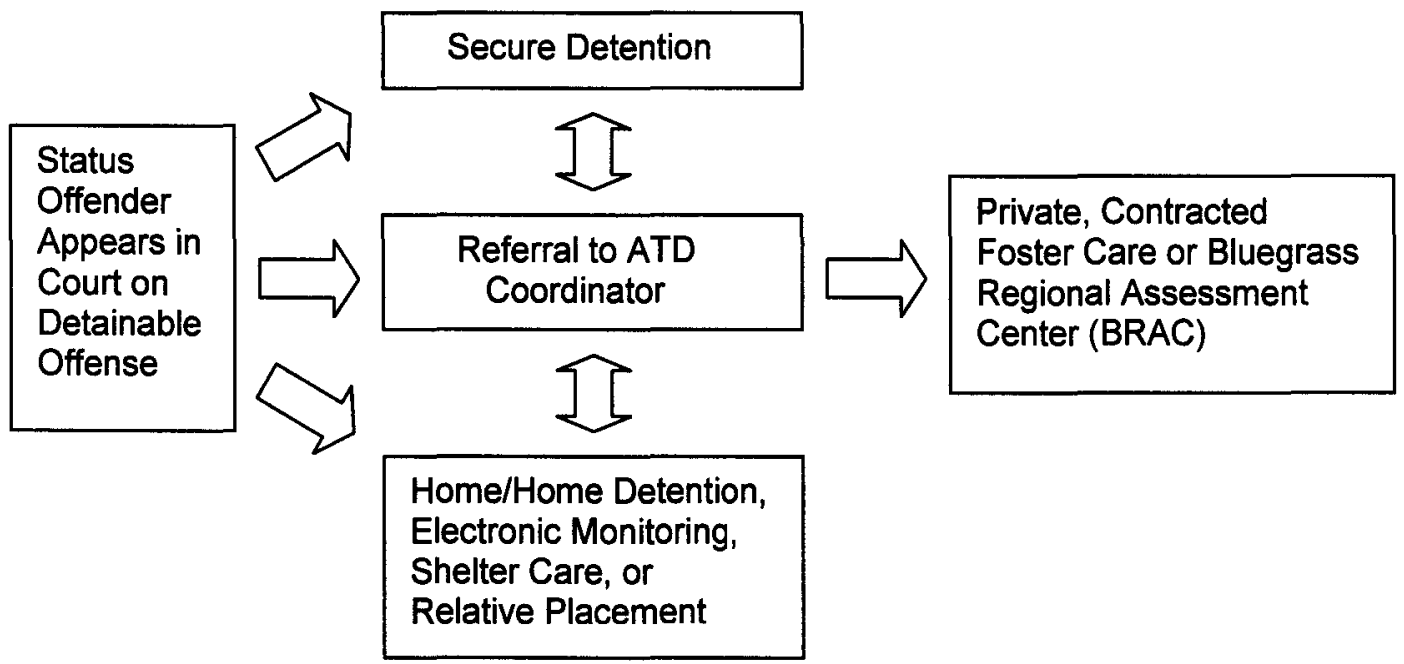

Figure 1. Predispositional placement process for status offenders facing secure detention in Fayette County.

\section{Goals and Objectives}

This study was a goals-based program evaluation of the predispositional Alternatives to Detention (ATD) program used with status offenders in Fayette County, Kentucky. Goals-based evaluations assess the extent that programs meet predetermined goals and objectives, and determine the appropriateness or 
inappropriateness of the specified goals of a program based on what the program intends to accomplish (McNamara, 1998). As noted by the President's Crime Prevention Council (1997), setting goals and evaluating them periodically to determine if the goals and supporting strategies are effective is "clearly the basis for formulating a comprehensive...prevention plan" for juvenile justice (see Evaluate section, $\mathbb{\Upsilon} 2$ ).

By conducting a goals-based evaluation of the ATD program in Fayette County, Kentucky, the current status of efforts to achieve the goal of full deinstitutionalization of status offenders can be assessed. Therefore, this study assessed: (1) utilization of the ATD Program to determine use/compliance with JJDPA and state mandates to use nonsecure detention alternatives for status offenders; (2) youth's cooperation with the judicial process by determining the effect of the ATD program on ensuring court appearances of status offenders (judicial cooperation); and (3) public and youth safety by determining the effect of the ATD program on reoffending (public and youth safety). 


\section{CHAPTER TWO}

\section{LITERATURE REVIEW}

The literature is replete with prior research on juvenile justice. Previous studies are useful for understanding juvenile offending and justice system efforts to control it. Often researched is the relationship between offending behavior and demographic characteristics such as age (Morse, 1997; O'Mahoney, 2000; Steinberg \& Cauffman, 1999), gender (Federle, 2000; MacDonald \& Chesney, 2001; Mazerolle, Brame, Paternoster, Piquero, \& Dean, 2000; Sarri, 1983), and ethnicity (Bishop \& Frazier, 1996; Feld, 1999; Kurtz, Giddings, \& Sutphen, 1993; Markowitz \& Jones-Brown, 2000; Pinderhughes, 1997). Interventions used with offenders have also been widely researched including probation (Albonetti \& Hepburn, 1997; Elrod \& Minor, 1992; Petersilia, 1995), residential treatment (Asarnow, Aoki, \& Elson, 1996; Gordon, Moriarty, \& Grant, 2000; Joshi \& Rosenberg, 1997; Lyons, Libman-Mintzer, Kisiel, \& Shallcross, 1998), incarceration (Bazemore \& Dicker, 1996; Levitt, 1998; Rossner, 1988), and others (Eddy, Reid, \& Fetrow, 2000; Schwartz, Jackson-Beeck, \& Anderson, 1984; Terry-McElrath, McBride, Vanderwaal, \& Ruel, 2002). Additionally, many theoretical explanations for offending are noted such as environmental, social, and mental health causes (Agnew, Brezina, Wright, \& Cullen, 2002; Bazemore, 2001; Gibson, Wright, \& Tibbetts, 2000; Lexcen \& Redding, 2000; Redding, 
2000; Shelton, 2002; Van-Voorhis, Mathers, \& Garner, 1988; Wright, Cullen, \& Miller, 2001). Other research has examined the issue of recidivism or repeat offending (Benda, 1987; Fendrich \& Archer, 1998; Minor, Hartmann, \& Terry, 1997; Wade, 1998).

Although there is copious literature on juvenile delinquency, the literature focusing on status offenders is limited. While numerous articles and studies concerning status offenders appeared in the literature circa the implementation of the JJDPA (see, for example, Alder, 1984; Boisvert \& Wells, 1980; Gilman, 1976; Kelley, 1983; Martin \& Snyder, 1976; Rausch, 1983; Rubin, 1977; Schneider, 1984; Spergel, Reamer, \& Lynch, 1981; Thomas, 1976), fewer present-day studies have concentrated on status offending. Explanations offered for the lack of attention to status offenders include perceptions that these offenses are less serious; resource and funding priorities; and conceptual, philosophical, and legal debates within the juvenile justice system concerning status offenders in general (Abadinsky, 1976; Feld, 1999; Harris, Welsh, \& Butler, 2000; Logan \& Rausch, 1985; Ohlin, 1998; Russell \& Sedlak, 1993). The research that has examined status offenders has focused primarily on social and environmental factors that contribute to status offending (Hull, 1994; Yoder, Whitbeck, \& Hoyt, 1999), the association between status offending and the development of delinquent careers (Jonson-Reid \& Barth, 2000; LeBlanc \& Biron, 1980; Rankin \& Wells, 1985; Rojek \& Erickson, 1982; Sheldon, Horvath, \& Tracy, 1989), and the differences and similarities between status and delinquent offenders (Benda, 1987; Bishop \& Frazier, 1996; Famularo, Fenton, Kinscherff, Barnum, Bolduc, \& Bunschaft, 
1992; Famularo, Kinscherff, Fenton, \& Bolduc, 1990; Kakar, 1996).

\section{Status Offenders}

Status offenders, unlike public offenders or delinquents, have engaged in behavior that if committed as an adult would not be illegal. Status offenses are those acts prohibited by state statute that apply only to minors under age 18 and include truancy, running away, incorrigibility or beyond control, and in some jurisdictions, miscellaneous offenses such as tobacco and curfew violations. In many states, liquor law violations are also considered status offenses for individuals under age 21. Under Kentucky law (Kentucky Unified Juvenile Code, KRS $600.20(58)$ ), a status offense action is defined as "any action brought in the interest of a child who is accused of committing acts, which if committed by an adult, would not be a crime. Such behavior shall not be considered criminal or delinquent and such children shall be termed status offenders."

Status offenders are often processed informally through diversion or other nonadjudicative alternatives (Sickmund, 2000). In some jurisdictions, status offenses are handled entirely by child welfare agencies, or may be processed in Family Courts; in others, these behaviors have become criminalized and they are handled in Juvenile Courts. This is particularly true for chronic status offenders (i.e., juveniles who frequently offend, and who often have serious emotional and behavior problems) who place tremendous strain on the Juvenile Court and community resources (Holden \& Kapler, 1995).

According to Colley and Culbertson (1988, p. 55), while the law is "quite clear" concerning the relationship between status and criminal behavior, many 
courts rely upon contempt power to "secure criminal convictions of minors who engage in noncriminal behavior" due to unique challenges status offenders pose (see, for example, Bazemore, 1994; Beger, 1994a; Colley \& Culbertson, 1988; Pillick, 1985). In addition to legal problems, these challenges include a multitude of individual and family issues, child maltreatment, substance abuse, domestic violence, and mental health (Ireland, Smith, \& Thornberry, 2002; Katner, 2000; Lemmon, 1999; Rosenblatt, Rosenblatt, \& Biggs, 2002; Sexton, 1998).

Perhaps no offenders present more of challenge to the juvenile justice system than status offenders. The Juvenile Court has long recognized that the conduct of these offenders is primarily related to family dysfunction. Numerous studies have examined the unique and complex issues facing status offenders and their families. For example, Riley, Greif, Caplan, and MacAulay (2004, p. 139) found that status offending was related to "parents' inabilities to cope with their children's mental health concerns, cultural differences, divorce-related issues, and inappropriate boundaries." Child maltreatment is also frequently associated with offending. Zingraff, Leiter, Myers, and Johnsen (1993) found a significant relationship between maltreatment and youthful problem behavior, while Kakar (1996) found that 95 percent of status offenders were victims of sexual abuse. Similarly, Whitbeck, Hoyt, and Yoder (1999) noted that runaways often leave abusive and neglectful homes. Hull $(1994$, p. 93) characterized these runaways as "refugees from a million private wars being waged across America - a ragtag army of the abused and the ignored drifting aimlessly like a flotsam out of sundered families." According to Allison, Crawford, Leone, 
Trickett, Perez-Febles, Burton, and LeBlanc (1999), poor parental monitoring, quality of parenting, lack of attachment, and lack of family commitment are strong indicators of substance abuse by juveniles. Wyman (1997) noted that family substance abuse is a significant predictor of substance abuse among status offenders.

\section{Status Offending}

Although there is some disagreement concerning the trends in juvenile offending (Fendrich \& Archer, 1998; McCord, Widom, \& Crowell, 2001; O'Conner \& Treat, 1996; Olsson, 1996; Wade, 1998; Waggoner, 1996), the United States Department of Justice (DOJ) reports that offending rates have remained persistently high. ${ }^{6}$ Across all categories of offending, the greatest increase reported by DOJ has been the 101 percent increase in status cases processed by the Juvenile Courts between 1989-1998. A 1-day detention count of juveniles in 1995 revealed that status offenders accounted for nearly 34 percent of the incarcerated population (Annie E. Casey Foundation, 2002). The most recent 1-day count data from 1997 revealed that status offenders accounted for 10 percent of the incarcerated population. ${ }^{7}$

Despite the seriousness of the juvenile offending problem, most of the efforts and financial resources directed at solving the problem have been restricted primarily to one intervention-incarceration (Greenwood, Model, Rydell, \& Chiesa, 1996). While Sickmund (2003) found that formal probation was the most likely disposition in most adjudicated status cases between 1989-1998,

\footnotetext{
${ }^{6}$ Data available from the Bureau of Justice Statistics, http://www.ojp.usdoj.gov/bjs

7 Data represents both public and private facilities.
} 
placement in "correctional" facilities was also used frequently as a disposition (Snyder \& Sickmund, 1999). Correctional facilities vary from programs that operate similar to prisons to those that are more residential. The authors report that in 1997 , approximately 6,877 status offenders were in either public or private placements; status offenders remain in placement longer than delinquents.

Because of increasing numbers of status cases, changes in child welfare and juvenile justice policy, and frustration among juvenile justice policymakers and practitioners that "nothing works", there continues to be an over-reliance on detention (particularly using the contempt powers of the court) to punish status offenders (Beger, 1994b). This trend persists despite legal mandates to use least restrictive alternatives, and disagreement concerning the effectiveness of detention for juvenile offenders (Greve, 2001; Krisberg \& Austin, 1993; Levitt, 1998; Ross, Armstrong, \& Conger, 2002; Rossner, 1988). As a result, juvenile offending and disagreement over appropriate responses to control it remains clearly "one of today's most pressing social problems" (Smith \& Stern, 1997, p. 382).

\section{Nationally.}

Juvenile offending continues at alarmingly high rates despite the considerable expenditures to control it over the past several decades. In 1996, Juvenile Courts processed 161,900 status and 1.8 million delinquency cases (Snyder \& Sickmund, 1999). The most recent data from 2000 indicates that 156,313 status (Stahl, Kang, \& Wilt, 2003) 1.6 million delinquency cases (Puzzanchera, Stahl, Finnegan, Tierney, \& Snyder, in press) were processed in 
Juvenile Courts. These statistics are quite significant compared to the 79,000 status and 896,000 delinquency cases that were processed in Juvenile Courts a decade earlier (OJJDP, 2000). Although ten-year arrest trends indicate only a slight increase of 3.4 percent in juvenile offending across all categories between 1991-2000 (FBI Uniform Crime Reports, 2000), Juvenile Court statistics indicate a 101 percent increase in status and 44 percent increase in delinquency cases processed by the Juvenile Courts from the previous decade (Snyder \& Sickmund). These data include all cases known to the Juvenile Courts (i.e., arrests, private complaints, and referrals).

A large number of status offenders continue to be formally processed nationally in Juvenile Courts despite the significant difference between the number of delinquent and status offenses committed and less formal methods often used with status offenders. As seen in Figure 2, the total number of status cases formally processed in the Juvenile Courts in 1997 increased significantly compared to 1988. In 1997, 52 percent of status and 57 percent of delinquent cases were formally processed by Juvenile Courts (Office of Juvenile Justice and Delinquency Prevention, 2000). As noted by Hund (1998), the actual number of status offenders is likely higher than recorded numbers due to variations in data collection methods used to records these statistics. 


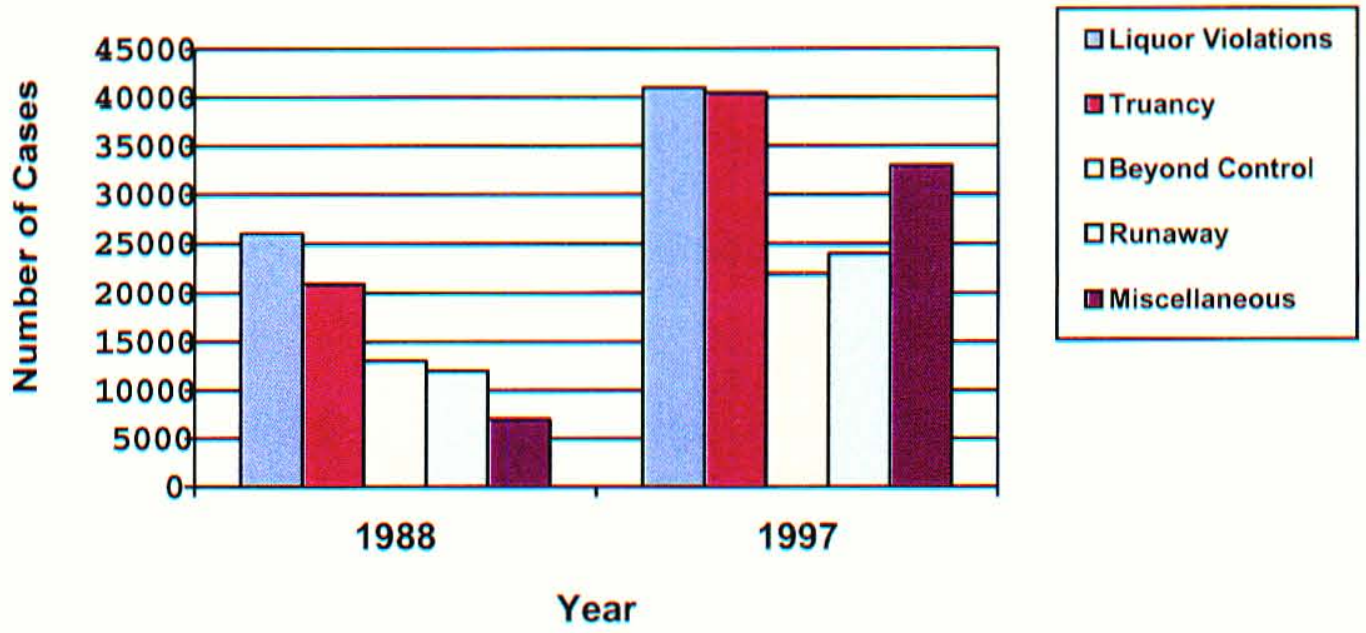

Figure 2. Status cases processed nationally in juvenile courts by type and year ${ }^{8}$

A profile of status offenders has emerged based on demographic characteristics as reported in national data. Stahl, Sickmund, Finnegan, Snyder, Poole, and Tierney (1999) report that of the 161,900 status offense cases petitioned in Juvenile Courts in 1996, males accounted for nearly 59 percent of those cases and females 41 percent. Liquor and miscellaneous offenses were most common among males, while truancy and runaway offenses were most common among females. When race was considered, Caucasians accounted for nearly 78 percent of status offense cases and minorities 22 percent. Liquor and truancy offenses were most common among Caucasians, while truancy and miscellaneous offenses were most common among minorities. Fifty-five percent of the status offenders were 15 years of age or younger and 45 percent over 16 years old. Truancy was most common among younger youths and liquor offenses among older youths.

\footnotetext{
${ }^{8}$ Data available from the Bureau of Justice Statistics, http://www.ojp.usdoj.gov/bjs
} 


\section{Kentucky.}

Offending in Kentucky is similar to that reported nationally. Juvenile arrests for all offenses increased between 1985-1995 (Curra, 1996), but have since declined. Review of arrest data reported in the Kentucky Annual Crime Reports for the period 1995-1999 indicated that there were 21,895 juvenile arrests in 1995 compared to 11,496 arrests in 1999 (a 49 percent decrease). Similarly, while the total number of cases processed by the Juvenile Courts for all offenses decreased between 1996-2001, an average of 41,751 cases were disposed of each year during this period throughout the state (Kentucky Court of Justice, 2003). Status offending in Kentucky has differed from national reports as it has remained constant. As seen in Figure 3, there were 5,199 status and 19,081 delinquent cases processed in 2003 compared to 5,173 status and 19,517 delinquent cases in 1997 (C. Allen, ${ }^{9}$ personal communication, July 29, 2004). This represents a 12.7 percent increase in status cases.

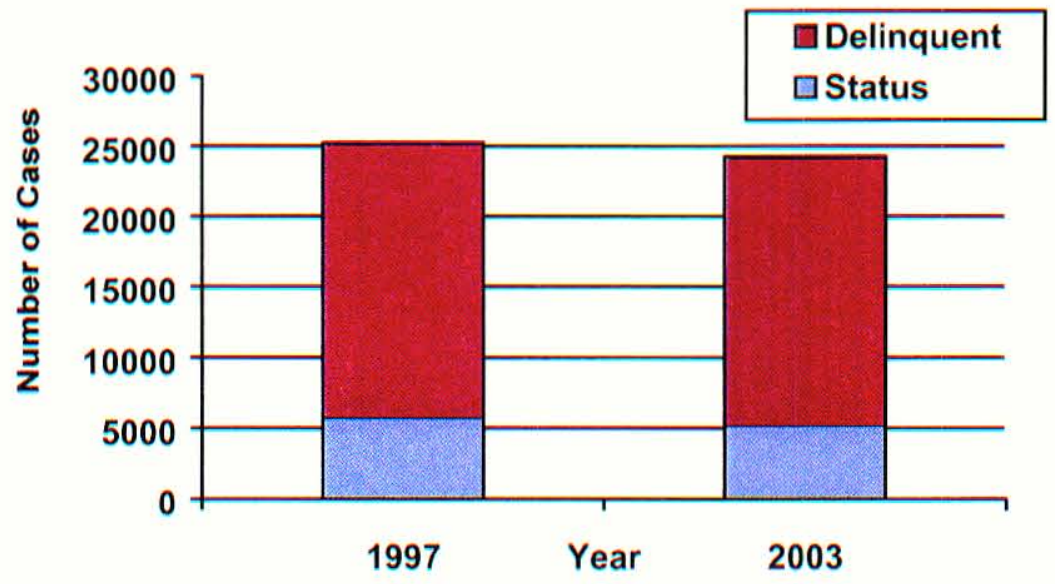

Figure 3. Status and delinquent cases processed in juvenile courts in Kentucky by year.

\footnotetext{
${ }^{9}$ Chad Allen is a statistician with the Kentucky Administrative Office of the Courts (AOC).
} 


\section{Fayette County.}

Similar to national and statewide trends in Kentucky, data for Fayette County indicate that there has been a significant decline in the number of delinquency cases formally processed in the Juvenile Court during the past 7 years.

However, only a slight decline has been observed in the number of status cases formally processed (see Figure 4). During fiscal year 1995 (beginning July 1), 281 status and 1,998 delinquency cases were processed compared to 127 status and 988 delinquency and cases in fiscal year 2003 (Kentucky Court of Justice, 2003). The number of status cases processed was roughly one-quarter of the number of delinquency cases processed.

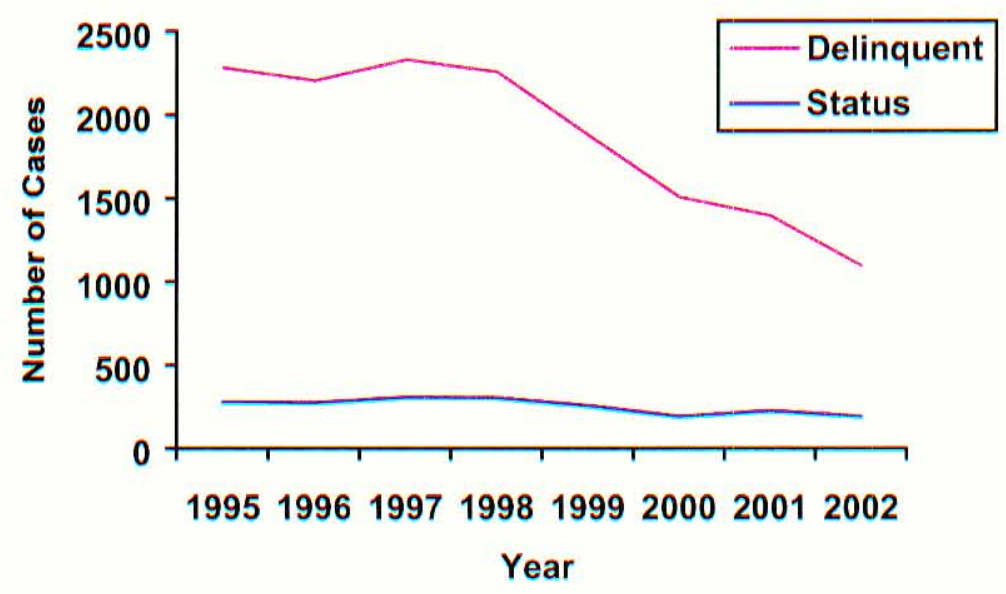

Figure 4. Status and delinquent cases processed in Fayette County juvenile court by year. ${ }^{10}$

\section{Theoretical Assumptions}

Theories help to explain or predict problematic behavior of status offenders.

${ }^{10}$ Data available from the Kentucky Court of Justice, www.kycourts.net 
Theories include systemic (macro-level), individual (micro-level), or a combination of both (Norkus, 2000; Yamaguchi, 1998). DeMelo (1999) distinguishes eight categories of criminological theories including Early Schools (e.g., Classical, Positive, and Chicago), Rational, Biological and Physiological, Psychological and Psychiatric, Sociological (i.e., crime and social structure, and crime and social process), Peacemaking, and Radical, Feminist, and Conflict. Hund (1998) identifies three theories that are most often cited to explain offending: learning, conflict, and control. Among others, these theories are useful in efforts to prevent juvenile offending.

Learning theory suggests that problematic behavior is a learned response from social, environmental, and personal experiences. These factors provide youths with opportunities to learn antisocial behaviors. Reinforcement, either positive or negative, contributes to the learning experiences. Conflict theory suggests that groups are in competition, and that hostility results when those with control restrict opportunities and decision-making of those without power; hostility is manifested as antisocial behavior. Control theory suggests that youths' ties or bonds give motivation to conform to social expectations. These bonds include attachment, involvement, commitment, and belief. Absence of any of these bonds diminishes capacity for control and decreases desire for conformity.

Numerous studies have focused on macro-level theories to explain offending and to guide intervention efforts. For example, Hagan, Cho, Jensen, and King (1997) note that the most effective interventions have been those that consider offending across multiple contexts such as family, school, community, 
and peer associations. Similarly, Elrod and Minor (1992) posit that lack of social integration between juveniles and primary socialization institutions such as family, school, and the community, combined with strong ties to negative peers, increases the likelihood of antisocial behavior. They state that the result of a failure to bond to these primary institutions, coupled with close negative peer interaction, reduces juveniles' stakes in conformity to conventional standards of conduct.

Matthews and Pitts (1998) suggest that a wide range of social and structural factors must be considered. These authors contend that juvenile offending is primarily an urban phenomena associated with poverty and weakened social institutions such as neighborhood groups and households. Monahan (1994) claims that there are strong correlates between family instability such as lack of parental supervision and offending. However, the author cautions that although there are many correlates to consider, two problems "keep us from knowing which factor really matters as a cause and which is irrelevant...one problem is that each factor relates not only to the [behavior] but to other sociological factors as well...[and] the second problem is that it is sometimes hard to tell which came first, the sociological factor or the [behavior]" (p. 64).

Smith and Stern (1997) emphasize social learning and the restraining effect of parental attachment and involvement on deviant behavior by focusing upon how family interaction patterns are learned and maintained. The authors maintain that there is overwhelming empirical evidence that links affective and control aspects of family socialization with law-breaking. They contend that 
family socialization is influenced by contextual issues including disadvantaged neighborhoods, economic hardship, stress and social isolation, and family disruption. The authors note that social disorganization helps explain how parenting in high-risk neighborhoods affects both control and affective dimensions of parenting-predictive factors of deviant behavior.

Micro-level theories have also been cited to explain offending behavior and to guide intervention. For example, biological and psychological theories distinguish between child and adult behavior. Developmental psychology suggests that children move through a sequence of stages with changes in operational processes, legal reasoning, internalization of social and legal expectations, and ethical decision-making. Therefore, the ability of an adolescent to exercise self-control (i.e., short-term versus long-term temporal perspectives, attitudes toward risks, impulsivity) is markedly different from an adult. Gibbs, Giever, and Martin (1998) suggest that self-control theory helps explain how juveniles' impulsivity, insensitivity, and risk-taking characteristics are compatible with attributes of wayward behavior.

Micro-macro theory integration involves more complex assumptions concerning the nature and causes of offending. For example, social disorganization theory (macro) introduced by Shaw and McKay (1942), and selfcontrol theory (micro) introduced by Gottredson and Hirschi (1990), can be integrated to "clarify how macro-social characteristics such as poverty, population heterogeneity, and residential mobility affect the possible consequences of juveniles' [individual] alternative choices of action" (Yamaguchi, 1998, p. 164). 
These linkages may better express the interdependence among variables.

Deterrence is an important consideration for policymakers and practitioners who struggle to find an appropriate balance between punishment and rehabilitation of juvenile offenders. Deterrence is a criminological theory that suggests individuals can be prevented from committing crime by fear of the potential consequences of punishment (Wikipedia, 2004). Studies have examined deterrence and youthful misconduct. A study conducted by Murray and Cox (1979) was one of the first to measure the deterrent effect of the sanctions of the criminal justice system on individuals. In their study of young criminals in Chicago in the 1970s, the authors identified a strong "suppression effect" in that delinquents sentenced to jail or stronger interventions subsequently committed less crime than their counterparts who received softer, alternative treatment. Similarly, in a study using state juvenile corrections census data, Levitt (1998) determined that juvenile offending is responsive to harsher sanctions. Conversely, findings from a study conducted by Johnson, Simons, and Conger (2004) suggest that justice system involvement with youths is positively related to later crime and deviant peer associations, and therefore, inconsistent with deterrence theory. Wilson (1983) suggests that personal morality and internal inhibitions against misconduct as a result of this morality is more likely the major deterrents to misbehavior.

\section{Program Evaluation}

The literature is useful for understanding and designing an effective program evaluation as undertaken in this study. Patton (1982) identifies 33 common 
evaluation methodologies including cost/benefit analysis, effectiveness evaluation, needs assessment, process evaluation, outcomes evaluation, formative evaluation, summative evaluation, and goals-based evaluation to name a few. A review of the literature finds numerous evaluations of criminal and juvenile justice programs (Bonta, 2000; Garcia, 2004; Harris, 1999; Pandiani, 1998; Presser \& Van-Voorhis, 2002), as well as other program evaluations (Chess, 2000; Lipsey, 2001; Peterson, 2002; Worthen, 2001). However, according to Wright and Jaworsky (1998), these evaluations are often lacking due to the use of nonexperimental methods and "disparity in consensus on such key points as definitions of recidivism, common instruments for testing, and length of tracking periods. A standard evaluation tool that measures effectiveness, efficiency, and program outcomes does not exist" (see \ Evaluating outcomes).

According to Poulin, Harris, and Jones (2000), program evaluation and development is an ongoing process in which formal, informal, and often unstated goals should be considered when measuring program success. Program evaluations are essential for three reasons: (1) to hold programs accountable for meeting their objectives, and to make better decisions about program planning or operations; (2) to improve programs by identifying strengths and weaknesses, create safer practices, enhance competence, and establish quality assurance; and (3) to market program effectiveness, develop a track record of success, and to advocate for social policy (Priest, 2001). In other words, "programs want and need to be able to tell their story" (Kalishman, 2002, p. 229) 
as a means to test value and impact, and to improve the program through systematic review. This is particularly important, according to Sanders (2001, p. 364), when "lives are at stake...[and] several viable options" are available. As noted by Petrosino, Turpin-Petrosino, and Finckenauer (2000, p. 354), "not only could ineffective programs divert money and attention from more successful interventions, they could also cause more harm than good." For juvenile justice and child welfare organizations such as the Department of Juvenile of Justice (DJJ) or Department for Community Based Services (DCBS), program evaluation is necessary "to demonstrate the effective impact they have on the communities they serve, and to be accountable for the efficient use of limited resources" (Ristau, 2001, p. 555). Such is the case for evaluating the ATD program.

Rossi, Freeman, and Lipsey (1999) state that many criteria are relevant in assessing program performance. These criteria include legal requirements, stated goals and objectives, customary practices, and costs. Similarly, Poulin and Orchowsky (2003) identify the following steps for an appropriate juvenile justice program evaluation: (1) define the problem; (2) implement evidencebased programming; (3) develop program logic; (4) identify measures; (5) collect and analyze data; (6) report findings; and (7) reassess program logic. These criteria help define evaluation questions specific to the program and to the circumstances of the evaluation. The evaluation of the predispositional ATD program was guided by these steps. It is intended that the findings of the evaluation will add to the knowledge base concerning juvenile justice issues (specifically interventions for status offenders) and program evaluations in 
general. As a result, policymakers and practitioners will have a clearer view of the progress made toward deinstitutionalization of status offenders from secure detention in Fayette County, Kentucky, while more fully understanding the benefits of the program as specified by its goals as an alternative to secure detention.

\section{Program Effectiveness and Recidivism}

Many disciplines including social work and criminology rely upon recidivism to evaluate program effectiveness (Benda, 1987; Myner, Santman, Cappelletty, \& Perlmutter, 1998; Patrick, Marsh, Bundy, Mimura, \& Perkins, 2004). Recidivism generally refers to rearrest or reoffending. However, according to Petersilia (1996, p. 382), "despite the recognized importance of recidivism for criminal justice policy and practice, it is difficult to measure because there is no uniformly accepted definition for the term....What has resulted is a research literature that contains vastly different conventions-different outcomes, different time periods, and different methodologies."

In juvenile justice the focus is primarily on program recidivism (Quist \& Matshazi, 2000). Numerous studies have examined program recidivism as an indicator of program success or failure. In a statewide assessment of juvenile offenders in Oregon (Oregon Youth Authority, 2002), recidivism was defined as an occurrence of offense referrals within a specified time frame. Greenwood (1994) defined recidivism as rearrest, reconviction, or reincarceration of youths within a specified time period. Kelley, Kennedy, and Homant (2003) defined recidivism based on formal juvenile court petitions. Roy (1995) defined 
recidivism as new offenses, rearrests, or reconvictions during and subsequent to program release. Quist and Matshazi (2000) defined recidivism as the number of offenses following program participation.

Albonetti and Hepburn (1997) note that recidivism studies fall into several different categories based on different measures. Recidivism can be measured in terms of the proportion of offenders who reoffend within a specified time frame. Recidivism is often examined in relationship to offender characteristics such as gender or ethnicity, or to the prevention effects of certain interventions such as probation or incarceration (see, for example, Kowalski \& Caputo, 1999; Lipsey, Wilson, \& Cothern, 2000; MacKenzie, 1999). Recidivism is also frequently examined in context with arrests, prosecutions, convictions, and institutionalization to quantify reoffending (see, for example, Barton \& Butts, 1990; Bourque, Cronin, Pearson, Felker, Han, \& Hill, 1996; Delaware Statistical Analysis Center, 1999; Greenwood \& Turner, 1993; Minor, Wells, Soderstrom, Bingham, \& Williamson, 1999; Skonovd \& Krause, 1991). The period for measuring recidivism varies, but is generally 6 months or longer (Carney \& Buttell, 2003; Bullis, Yovanoff, \& Havel, 2004; Josi \& Sechrest, 1999; Katsiyannis, Zhang, Barrett, \& Flaska, 2004; MacKenzie \& Brame, 2001). Because there are different measures for recidivism, there is disagreement whether recidivism should be the only outcome measure (Matthews \& Pitts, 1998). However, many programs continue to rely upon recidivism as the "most important and frequently exclusive indicator of effectiveness" (Jackson, de Keijser, \& Michon, 1995, p. 45). 
For this study, recidivism was determined by calculating the offense difference between the number of charges prior to placement minus the number of charges after placement. Based on a numerical index, a decline in offenses indicated a decrease in reoffending or recidivism, and escalation in offenses indicated an increase. Reliance upon subsequent offending to measure program success is useful as a conservative estimate of recidivism (K. Minor, ${ }^{11}$ personal communication, April 28, 1998). Therefore, both pre and post-placement offenses were considered for a more thorough view of reoffending.

\section{Deinstitutionalization}

Relatively little is known about the benefits of detention alternatives for status offenders, particularly given the lack of current research and the recent implementation of the program in Fayette County, Kentucky. While prior research has examined various programs used with delinquent offenders (see, for example, Bourque, Cronin, Pearson, Felker, Han, \& Hill, 1996; Castellano \& Soderstrom, 1992; Deschenes \& Greenwood, 1996; Greenwood \& Turner, 1987; Lindner, 1981; MacKenzie \& Souryal, 1994; National Council on Crime and Delinquency, 1999; Pabon, 1983; Roy, 1997; Sheldon, 1999) few studies have specifically addressed the effects of alternatives to secure confinement on status offenders (see, for example, Benda, 1987; Logan \& Rausch, 1985; Spergel, Reamer, \& Lynch, 1981). Of the various interventions used, studies offered mixed results concerning program effectiveness in areas such as reducing recidivism and improving the behavior of program participants.

Perhaps the most thorough research to date on juvenile detention has been

\footnotetext{
${ }^{11}$ Kevin Minor is a professor of Criminal Justice at Eastern Kentucky University, Richmond, Ky.
} 
the Juvenile Detention Alternatives Initiative (JDAI), a multi-year, multi-site project initiated in 1992 by the Annie E. Casey Foundation. The purpose of the JDAI was to determine if more effective and efficient systems could be developed to accomplish the purposes of secure detention for many youths who pose little risk of committing new offenses before their court dates or for failing to appear for court. The JDAI was conceived in part based on successes in juvenile detention reform in Broward County (Fort Lauderdale), Florida. According to the Annie E. Casey Foundation (1999), three JDAl sites ${ }^{12}$ completed the initiative's implementation phase including Cook County (Chicago), Illinois; Multnomah County (Portland), Oregon; and Sacramento County (Sacramento), California. The four objectives of JDAI included: (1) to eliminate the inappropriate and unnecessary use of secure detention; (2) to minimize failures to appear and the incidence of delinquent behavior; (3) to redirect public finances from building new facility capacity to responsible alternative strategies; and (4) to improve conditions in secure detention facilities. Results of this initiative indicated that in these jurisdictions detention alternatives could be used with "the right kids at the right level" (p. 15) without increasing the number of youths failing to appear for court, or increased levels of crime.

Similarly, in their study of youth crime and detention rates in two jurisdictions, Feldman, Males, and Schiraldi (2001) sought to determine whether it was possible to divert juvenile offenders from secure detention into communitybased programs without increasing the crime rate. Focusing on the neighboring

\footnotetext{
${ }^{12}$ Two additional sites, Milwaukee, Wisconsin and New York City, New York were also included in the study.
} 
jurisdictions of Washington, D.C. and the state of Maryland (both of which have struggled with detention issues), Feldman et al. compared 1990s arrest and detention data from both jurisdictions gathered from agency records, reports, and interviews. The authors found that despite similarities between the two jurisdictions on legal and procedural issues, the jurisdictions differed significantly on the use of detention. Specifically, Maryland increasingly relied upon detention while the use of detention significantly declined in Washington, D.C. Despite the increased use of detention in Maryland, however, offending rates during this period were significantly higher than in Washington, D.C. Thus, "more detention for low-level offenses is not associated with greater public safety and may occupy system resources that would be better focused on the relatively few youths...who commit serious, violent offenses" (p. 14).

Bakal (1998) and Loughran (1997) revisited the decision to deinstitutionalize juvenile offenders in separate articles on detention reform in Massachusetts (the first state to institute such reform in the 1970s). One area of interest, community integration, mandated use of community-based programs for offenders in lieu of incarceration. Describing this model, Bakal states:

We saw delinquency as a social, familial, and community phenomenon with community solutions as the means to treat and prevent youth delinquency. Delinquent youths were not only lawbreakers and victimizers but also victims themselves. We saw how they got caught in a vicious cycle of abuse, neglect, violence, rejection, and punishment. Our reform goals were to educate the public about the plight of children of the poor, about the need to 
develop programs and services closer to home, and about how to avoid negative labeling when youths become adjudicated.... (p. 113)

Despite the many innovative and successful programs implemented as part of the Massachusetts reform and the national policy of deinstitutionalization that followed, Bakal (1998) found that the strategy failed. Problems noted by the author included community resistance, public fear of increasing youth crime, social disorganization, family breakdown, fragmented reform, and inadequate resources.

Conversely, Loughran (1997) points to the success of the "Massachusetts Experiment." Based on findings from a study conducted by the National Council on Crime and Delinquency (1999), the author found that Massachusetts had the lowest recidivism rate of states included in the study, and that the communitybased system was more cost-effective than institutionalization. Loughran states that the success of this approach was due in part to the "ability to move youth back and forth on the continuum of services" based on their needs (p. 210). However, funding issues and a "get tough" approach to juvenile offending resulted in reduction of the community-based initiative in favor of institutionalization. Miller (1991) (the architect of the deinstitutionalization movement begun in Massachusetts) suggests that the juvenile justice system is traditionally nonreformable. He states that "the removal of status offenders from reform schools and detention centers didn't lower the total numbers of juveniles in institutions" (p. 12), they were simply relabeled and the institutions renamed to justify their continued usage. 


\section{Research Questions}

The JJDPA passed in 1974 specifies the primary goal of such programs as deinstitutionalization of status offenders from secure lock-up. This goal was based on the perception that status offenders engage in behaviors that are lowrisk compared to delinquents, and that alternatives should be developed that can more appropriately address these behaviors. In other words, the punishment should fit the behavior. However, despite alternative interventions for juvenile offenders, offending persists at high levels. According to national data, the number of status offenses processed by Juvenile Courts compared to other offenses have risen most dramatically over the past decade. These trends, coupled with policy changes and increasing frustration that nothing seems to work, have resulted in the reliance on detention to address these behaviors.

With the Valid Court Order exception, many status offenders are placed into secure confinement. Yet, according to Gorod (2000), punishment is not an effective method to correct the behavior of most status offenders due to the complex education, mental health, and family issues facing the child. Further, DeJong (1997) suggests that incarceration of naïve offenders has a criminogenic effect and is unrealistic. These punitive, knee-jerk reactions may be nonproductive and create even more problems for these youth (Sheldon, 1999).

This study evaluated the predispositional ATD program used for status offenders in Fayette County, Kentucky and was designed to answer the following questions based on the following program goals. In addition, recommendations were made to further develop the ATD program based on the specified goals. 
Goal 1: The ATD program will reduce the placement of status offenders in secure detention (Deinstitutionalization).

What are the demographics or offender characteristics of status offenders in Juvenile Court in Fayette County? What are the placement trends for status offenders in Fayette County? Have placement trends changed since implementation of the ATD program? Is placement related to offender characteristics? What factors influenced these placements?

Goal 2: The ATD program will ensure the court attendance of youths (Judicial Cooperation).

What is the relationship between offender characteristics and judicial cooperation? Has the ATD program improved judicial cooperation from status offenders? Does judicial cooperation differ based on the type of placement used with status offenders? What differences existed in judicial cooperation from pre to post placement? Does recidivism based on judicial cooperation differ for status offenders based on placement type?

Goal 3: The ATD program will ensure the safety of the public and youths (Public and Youth Safety).

What is the relationship between offender characteristics and public and youth safety? Has the ATD program improved public and youth safety for status offenders? Does public and youth safety differ based on type of placement used? What differences existed in public and youth safety from pre to post placement? Does recidivism based on public and youth safety differ for status offenders based on placement type? 


\section{CHAPTER THREE}

\section{METHODOLOGY}

Distinguishing between status offenders or delinquents has been an ongoing challenge in the juvenile justice system. Spergel, Reamer, and Lynch (1981) question the validity of using fixed distinctions, and suggest that juveniles should be classified according to the types of offenses committed during their entire offending careers. The fact is that many youths engage in both types of offending or straddle the fence between status and delinquent offending.

In Fayette County the classification of the offender is determined by the most serious offense that is adjudicated. If a juvenile is adjudicated for both status and delinquent offenses, the delinquent offense generally determines their classification, the court in which the juvenile will be processed, and the agency that will be assigned to provide services. Juveniles who encounter status charges while on probation for a delinquent offense most often remain classified as delinquent offenders, whereas, status offenders who are adjudicated for delinquent charges while on supervision ${ }^{13}$ for status offenses are typically reclassified as delinquents. Because the Juvenile Court in Fayette County relies upon the "best interest" standard, exceptions are sometimes made concerning classification for the purposes of intervention. In other words, status offenders who commit delinquent offenses may not be reclassified as delinquents based on

${ }^{13}$ Fayette County uses the term supervision in lieu of probation for status offenders. 
treatment needs. Status offenders are generally processed in the Family Court unless delinquent charges are pending; otherwise, they are processed in Juvenile Court with delinquent offenders based on Kentucky statutes. At the time this study was initiated all juveniles were processed in the Juvenile Court.

The Juvenile Court considers many factors in determining the category of offender such as the present charge before the court, the juvenile's age, their functioning capacity, the social environment in which they live, and family dynamics. For purposes of this study, a status offender was defined as a juvenile who had been adjudicated for a status offense and placed on Valid Court Orders (VCO). In most instances, these youths were either placed on supervision or already on supervision for previous status offense adjudications. Delinquents, those who were adjudicated for both types of offenses (unless amended to a status offense), and youths who were already on delinquent probation were excluded. Since use of secure detention is generally prohibited for status offenders, only youths who appeared on a detainable offense of contempt of court for violating a VCO were considered.

\section{Design and Sampling}

The study was a goals-based evaluation of the predispositional ATD program used for status offenders in Lexington, Fayette County, Kentucky. Only data concerning this county were assessed on request of the Department of Juvenile Justice, the agency that administers the program. Chart review of existing records maintained by the ATD program, Juvenile Court, and Juvenile Detention was conducted to assess current deinstitutionalization efforts (Goal 1), 
judicial cooperation (Goal 2), and public and youth safety (Goal 3) as defined by the ATD program goals. Review of ATD program and Juvenile Court records was limited to status offenders who appeared in court on a charge of contempt for violating Valid Court Orders that occurred on or after September 1, 2001 (ATD program implementation date). Review of the records was discontinued on July 1,2003 , the last date the reviewer had permission from the court to access records.

\section{Research Design}

The Office of Juvenile Justice and Delinquency Prevention (OJJDP) determines state compliance with JJDPA mandates based on statewide data. According to the Kentucky Department of Public Advocacy (2000), while Kentucky was within acceptable limits for deinstitutionalization in 1999, the state fell short of full compliance. Therefore, to assess Lexington, Fayette County's current deinstitutionalization efforts (Goal 1), both aggregate and unit record ${ }^{14}$ data were used. Aggregate data were first obtained from Juvenile Detention records (i.e., Monthly Admission/Release Report) to identify detention use trends for status offenders following implementation of the ATD program. Unit record data including demographic information, offense and placement history, and placement decision factors (e.g., prior failed ATD placements, mental health issues, placement availability) were obtained for each subject ( $N=$ 61), when available, from ATD program and Juvenile Court records. This analysis was useful for identifying placement trends for status offenders, and for

\footnotetext{
${ }^{14}$ Unit record approaches offer flexibility to track successes over time for individuals, and can be aggregated for multiple comparisons when reporting needs change (United States Department of Education, 1998).
} 
generating additional ideas for further utilizing the ATD program to decrease the number of status offenders securely detained in Fayette County, Kentucky.

To assess judicial cooperation (Goal 2) and public and youth safety (Goal 3) for status offenders in Fayette County, a quasi-experimental, multiple-group design was used. Specifically, the design was a nonequivalent, pre/post-test design that compared three placement groups of status offenders: those placed in (a) ATD program only, (b) secure detention only, and (c) other placements such as home detention, shelter care, or with relatives (miscellaneous category). For the miscellaneous group, ATD and/or secure detention placements may have also occurred. The design was selected based on the lack of ability to randomize the subjects in the placement groups, and therefore, the groups were presumed to be nonequivalent. The ATD program group was identified as the treatment group, and secure detention and miscellaneous groups were used for comparison. The three groups were selected based on the placement options that were typically used when status offenders appeared in court on the detainable offense of contempt of court. According to Diem (2002), quasi-experimental designs are under-utilized evaluation methods that are useful in providing important evidence of program impacts.

To assess judicial cooperation (Goal 2), the number of adjudicated ${ }^{15}$ offenses for contempt of court for failure to appear (FTA) was used. Youths who

\footnotetext{
${ }^{15}$ Adjudicated offenses were used as opposed to arrests for two important reasons. First, most status offenders are processed through court by means other than an arrest-typically, by summons due to a referral or private complaint. Second, adjudication ensures only those youths who are found guilty or acknowledge guilt are considered.
} 
fail to appear in court throughout the judicial process are charged with contemptFTA. Similarly, to assess public and youth safety (Goal 3), adjudicated status and delinquent offenses were used. For both goals, group comparisons of the data included pre and post-placement measures prior and after an initial placement intervention. The preplacement measure consisted of the number of charges recorded for the subjects in the 6 months prior to the initial placement that occurred following implementation of the ATD program. The post-placement measure consisted of charges recorded for the 6 months after the initial placement. These measures were selected based on the time frame available to inspect court records.

Only youths with placements prior to January 1, 2003 were included in the analysis. (This date was selected to ensure equivalency in the pre/post measures because data were not available for inspection beyond July 1, 2003.) When multiple placements occurred, charges subsequent to the initial placement were recorded as part of the post-placement measure. Additionally, because judges consider offending during previous placements when making subsequent placement decisions, a during-placement measure was included. However, due to variability in length of placements beyond the researcher's control (e.g., length of placements varies based on factors such as judges' discretion, placement disruption, and point of placement during the judicial process), no similar parameters could be established (i.e., 6 months) for this measure. Therefore, any charges that occurred during placement(s) within the study period were recorded for this measure. Thus, the total number of adjudicated contempt-FTA 
and status/delinquent charges for each placement group could be used to determine if statistically significant differences existed between the placement groups prior, during, and after placement. Recidivism for each placement group was calculated based on offense difference in the number of contempt-FTA and status/delinquent charges (i.e., number of charges committed prior to placement minus the number of charges committed after placement) for each group. Based on ATD program goals, it was anticipated that the ATD program would be as useful as secure detention in ensuring judicial cooperation of status offenders and public and youth safety, while proving more useful than using miscellaneous placements.

Although it is important to consider power analysis and sample size calculation in the proper design of experiments, these techniques were not necessary in this study. All available cases were used involving status offenders who appeared in Juvenile Court on the detainable offense of contempt during the study period.

\section{Sample}

Of the cases initially identified for this study $(N=99)$ from Department for Community Based Services (DCBS), ATD program, and Juvenile Court records, 38 were excluded due to pending matters in Juvenile Court, unavailability of the case record for inspection, or failure to meet design specifications (e.g., the juvenile was on delinquent probation). Therefore, a total of 61 cases were used in this study. Offense, placement, and demographic information for the subjects including age (initial court contact and initial placement), ethnicity, gender, grade, 
school type attended, living arrangement, number of placements, and placement type were gathered from these records. Of the number of subjects included in this study, females accounted for 57.4 percent $(n=35)$ and males 42.6 percent ( $n=26)$ of the subjects; minorities accounted for 54.1 percent $(n=33)$, and Caucasians 45.9 percent $(n=28)$. Figure 5 shows subjects' gender and race characteristics.

\section{Minority Males}

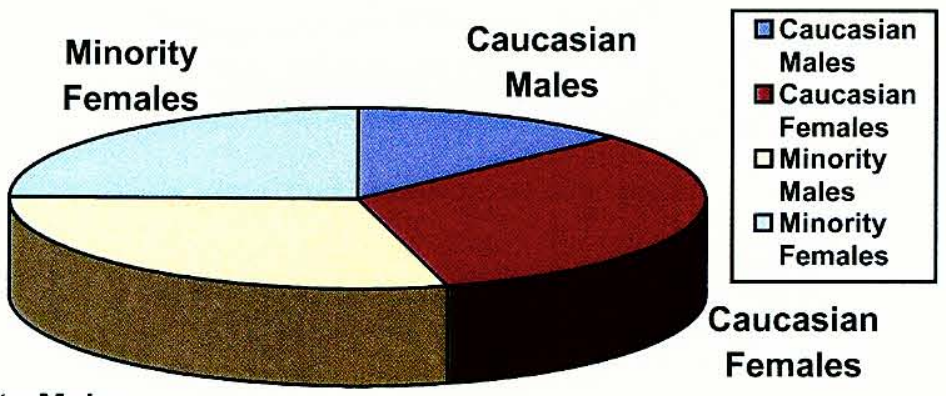

Figure 5. Gender and race of subjects $(\mathrm{N}=61)$

The mean age of subjects at initial court contact was 14.18 years and 15.03 years at initial placement. The mean number of placements was 2.44. The mean grade at initial court contact was 7.93 and 8.51 at initial placement. A majority of subjects ( $n=51,83.6 \%$ ) had living arrangements other than with both parents. Most subjects were enrolled in high school, grades 9-12 $(n=31$, $50.8 \%)$, and attended traditional school $(n=46,75.4 \%)$. Fifty-two percent ( $n=$ 32) of the subjects were age 14 or younger at initial court contact and 70.5 percent $(n=43)$ were age 14 or younger at initial placement. Most subjects ( $n=$ $38,62.3 \%)$ had two or more placements. Seventy percent $(n=43)$ of the subjects had 2 or more charges prior to initial placement compared to 29.5 
percent $(n=18)$ with only 1 charge. Twenty-six percent of the subjects $(n=16)$ experienced secure detention only; thirty-one percent $(n=19)$ ATD placements only; and forty-three percent $(n=26)$ had miscellaneous placements such as shelter care or home detention. As seen in Table 1, subjects were more evenly distributed with respect to ethnicity and moderately distributed with respect to gender. Data were less evenly distributed based on subjects' living arrangement, age, school type attended, and placement type.

Table 1.

Number and Percentage of Subjects ( $N=61$ )

\begin{tabular}{lcc}
\hline Characteristics & Number $(n)$ & Percent (\%) \\
\hline Gender & 26 & 42.6 \\
$\quad$ Male & 35 & 57.4 \\
Female & 33 & 54.1 \\
Ethnicity & 28 & 45.9 \\
$\quad$ Minorities & & \\
Caucasians & 32 & 52.4 \\
Age Initial Court Contact & 29 & 47.6 \\
10-14 & & \\
15-17 & 18 & 29.5 \\
Age Initial Placement & 43 & 70.5 \\
12-14 & & \\
15-17 & 10 & 16.4 \\
Living Arrangement & 51 & 83.6 \\
Both Parents & & \\
Other & 26 & 42.6 \\
Grade & 31 & 50.8 \\
6-8 & 4 & 6.6 \\
9-12 & & \\
Not Enrolled & 46 & 75.4 \\
School Type & 11 & 6.0 \\
Traditional & 4 & 6.6 \\
Alternative & 19 & 31.1 \\
Not Enrolled & 16 & 26.2 \\
Placement Type & 26 & 42.6 \\
ATD & & \\
Secure & & \\
Miscellaneous & & \\
\hline
\end{tabular}


Means data for subjects based on age (initial court contact and initial placement) and number of placements indicated insignificant differences. However, males were older and experienced more placements than females. Minorities were older at initial court contact but there were no significant difference in age between minorities and Caucasians at initial placement. However, minorities had more placements than Caucasians. Only minor differences were noted for grade, school type attended, and living arrangement. Most noticeable was that subjects not enrolled in school tended to be older at initial placement and had fewer placements compared to those who were enrolled. Similarly, subjects enrolled in alternative school programs were slightly older than those who attended traditional school programs both at initial court contact and at placement and experienced fewer placements. Subjects who lived with both parents were younger at initial court contact, older at initial placement, and had fewer placements than subjects who lived in other arrangements. When placement type was considered, subjects with ATD placements were older than subjects with other placements both at initial court contact and at placement, and experienced fewer placements.

Table 2.

Mean Age and Number of Placements for Subjects $(N=61)$

\begin{tabular}{lccc}
\hline & Court Contact & \multicolumn{2}{c}{ Age } \\
Characteristics & & & \#Placements \\
Gender & 13.97 & 14.97 & \\
$\quad$ Females & 14.46 & 15.12 & 2.34 \\
$\quad$ Males & & & 2.58 \\
Ethnicity & 14.30 & 15.03 & \\
$\quad$ Minorities & 14.40 & 15.04 & 2.58 \\
$\quad$ Caucasians & & &
\end{tabular}


Table 2. (Continued)

Mean Age and Number of Placements for Subjects $(N=61)$

\begin{tabular}{|c|c|c|c|}
\hline Characteristics & Court Contact & Placement & \#Placements \\
\hline \multicolumn{4}{|l|}{ Grade } \\
\hline $6-8$ & 13.38 & 14.27 & 1.65 \\
\hline $9-12$ & 14.77 & 15.45 & 1.65 \\
\hline Not Enrolled & 14.75 & 16.75 & 1.25 \\
\hline \multicolumn{4}{|l|}{ School Type } \\
\hline Traditional & 14.13 & 14.98 & 1.67 \\
\hline Alternative & 14.33 & 15.20 & 1.55 \\
\hline \multicolumn{4}{|l|}{ Living Arrangement } \\
\hline Both Parents & 13.90 & 15.10 & 1.50 \\
\hline Other & 14.27 & 14.93 & 1.73 \\
\hline \multicolumn{4}{|l|}{ Placement Type } \\
\hline ATD & 14.84 & 15.26 & 1.58 \\
\hline Detention & 13.75 & 14.94 & 2.00 \\
\hline Miscellaneous & 13.92 & 14.92 & 3.35 \\
\hline
\end{tabular}

\section{Independent and Dependent Variables}

The independent variables in this study included offender characteristics such as age (initial court contact and initial placement), ethnicity, gender, grade, and living arrangement. Independent variables also included total number of placements and placement type. The dependent variables included the number of contempt-FTA charges adjudicated (judicial cooperation variable), the number of status/delinquent offenses adjudicated (public and youth safety variable), and recidivism (as measured by offense difference).

\section{Variables Operationalized}

- Age is a numerical value of time since birth to the present expressed in years.

- Adjudication is a finding of guilt by a judge or acknowledgement of guilt by a juvenile offender. 
- Arraignment is the initial appearance in court for a charge.

- Contempt of court results from failure to obey a court order or failure to appear for court proceedings.

- Living Arrangement refers to the living situation of the subject at the time of first placement and includes both parents, mother, father, relative, or nonrelative.

- Delinquent offenses are illegal acts that apply to juveniles for which an adult could be criminally prosecuted such as theft, robbery, and murder.

- Disposition is the final sentencing.

- Ethnicity is the identified race of the subject such as Caucasian, AfricanAmerican, and Hispanic.

- Gender is the sex of the subject as either male or female.

- Grade is the year in school of the subject expressed numerically from 1 through 12 at the time of placement or not enrolled.

- Juvenile refers to youths under the age of 18 who are subject to the jurisdiction of the Juvenile Court or Family Court.

- Placement type includes ATD Program, secure detention, or a combination of placements such as home detention and secure detention (miscellaneous category).

- Recidivism was determined in this study by calculating offense difference between offenses committed prior to placement minus offenses committed after placement.

- Status offenses are illegal acts for juveniles only and consist of truancy, 
running away, and beyond control.

\section{Issues of Confidentiality}

This study involved chart review of existing records of the ATD program, Juvenile Court, and Juvenile Detention. The study was nonevasive, and did not require permission from the subjects whose records were reviewed. Because juveniles' records are confidential, approval to conduct this study was obtained from the Department for Community Based Services (DCBS, agency statutorily mandated to provide services to this population); Department of Juvenile Justice (DJJ, agency that administers the ATD program); and the Family Court in Fayette County, Kentucky. Approval to conduct this study was also obtained from the Institutional Review Board (IRB) of the University of Louisville. Confidentiality of the information was preserved by ensuring that no personally identifiable information on the subjects was reported. Juvenile Court records maintained by the court clerk were reviewed according to procedures specified by that office. Data were recorded in a Codebook (see Appendix B) developed and safeguarded by the researcher; it was destroyed upon conclusion of this study.

\section{Procedures for Collecting Data}

Subjects were determined based on records maintained by the ATD program coordinator and the Department for Community Based Services (DCBS). Once identified, records were cross-referenced with official Juvenile Court dockets maintained by the DCBS to ensure the youths were classified as status offenders. For purposes of this study, a status offender was defined as a youth who had been adjudicated for a status offense and placed on Valid Court 
Orders (VCO). Offenders considered as delinquents were excluded. Because the use of secure detention is generally prohibited for status offenders, only youths who appeared in court on the detainable offense of contempt for violating a VCO were considered; placement via the ATD program or other alternative resulted. Data obtained from three sources including the ATD program, Juvenile Court, and Juvenile Detention records were used to assess the following ATD program goals: (1) deinstitutionalization of status offenders from secure detention; (2) judicial cooperation; and (3) public and youth safety as specified elsewhere in this study.

\section{Data Analysis}

To complete this goals-based evaluation of the ATD program, secondary data analysis was conducted based on chart review of existing records maintained by the ATD program coordinator, Juvenile Court, and Juvenile Detention. Aggregate data obtained from Juvenile Detention Monthly Admission/Release Reports were used first to identify trends in the use of secure detention of status offenders. Both ATD program and Juvenile Court records were used to report demographic information, offense and placement history, and placement decision factors for each subject. The data were then aggregated for group comparisons in evaluating judicial cooperation (Goal 2), and public and youth safety (Goal 3). Because little was known about the parameters of the variables of interest in the population and the data was of low quality from small samples (Dallal, 2000, ๆ Parametric and nonparametric methods), nonparametric statistics were used. Nonparametric tests make less stringent demands of the 
data, and unlike standard parametric procedures, do not require that the observations be drawn from a normally distributed population. However, there are disadvantages to using nonparametric procedures. As there are no parameters to describe, it is more difficult to make quantitative statements about the actual difference between populations. These procedures also are less powerful than standard parametric tests in detecting existing differences (Dallal, 2000).

Statistical analyses conducted for this study included correlational procedures and tests of significant difference. To assess the significance of relationships, the chi-square $\left(x^{2}\right)$ test of association and Cramer's $V$ statistics, eta $(\eta)$ and Spearman's rho $(\rho)$ statistics were used. Specifically, chi-square and Cramer's $V$ were used together to explore relationships between nominal-level variables including offender characteristics and placement type. The Cramer's $V$ statistic was used to provide an index of strength of association between the variables based on chi-square. Similarly, the eta correlation was used to examine relationships between nominal-level offender characteristics and judicial cooperation (as measured by contempt-FTA charges) and public and youth safety (as measured by status/delinquent charges) based on placement type. Eta-squared $\left(\eta^{2}\right.$, also called the correlation ratio) provides an index of strength of association between the variables based on the eta coefficient. While eta is typically used with analysis of variance (ANOVA), it can be a useful coefficient outside this context (Garson, 2005). The Spearman's rank correlation was used as the nonparametric equivalent to the standard correlation coefficient to 
examine the relationships between ordinal-level offender characteristics and judicial cooperation and public and youth safety based on placement type. To assess differences between multiple, independent groups, the Kruskal-Wallis analysis of variance by ranks test was used as the nonparametric equivalent to the one-way analysis of variance (ANOVA). The Kruskal-Wallis test was used to assess group differences for judicial cooperation and public and youth safety based on placement type.

\section{Dissemination of Findings}

This study was completed to partially fulfill requirements for a Ph.D. in social work at the University of Louisville. The results will be published for the dissertation and may be published in a professional journal. Results were also provided to the Department of Juvenile Justice and Cabinet for Health and Family Services as requested by their respective Institutional Review Boards. 


\section{CHAPTER FOUR}

\section{RESULTS}

To conduct this goals-based assessment of the ATD program in Fayette County, both descriptive and inferential statistics were used. Descriptive statistics were used to give details concerning the placements for status offenders, and inferential statistics were used to make comparisons based on those placements according to specific program goals. Correlations were also computed to assess the potential relationships between variables included in this study.

Goal 1: The ATD program will reduce the placement of status offenders in secure detention (Deinstitutionalization).

Data from the Juvenile Court, Juvenile Detention Center, and ATD program were used to evaluate deinstitutionalization in Fayette County following the implementation of the ATD program. Specifically, data were analyzed to determine placement trends for status offenders, and to assess the extent to which offender characteristics were associated with the type of placements used with status offenders.

\section{Placement Trends}

Secure detention.

For status offenders included in this study $(N=61)$ charged with contempt for 
violating a Valid Court Order (VCO), Juvenile Court records indicated that 31.1 percent $(n=19)$ had ATD placements compared to 26.2 percent $(n=16)$ with secure detention placements. More subjects $(n=26,42.6 \%)$ experienced miscellaneous placements such as home detention or shelter care than either detention or ATD placements. Generally, status offenders were referred for nonsecure placement, although these placements did not always occur. Based on Juvenile Detention Center records (Juvenile Detention Monthly Admission/Release Reports) no status offenders were securely detained contrary to the VCO exception permitted by JJDPA since the ATD program was implemented in September, 2001. Figure 6 represents placements used with status offenders.

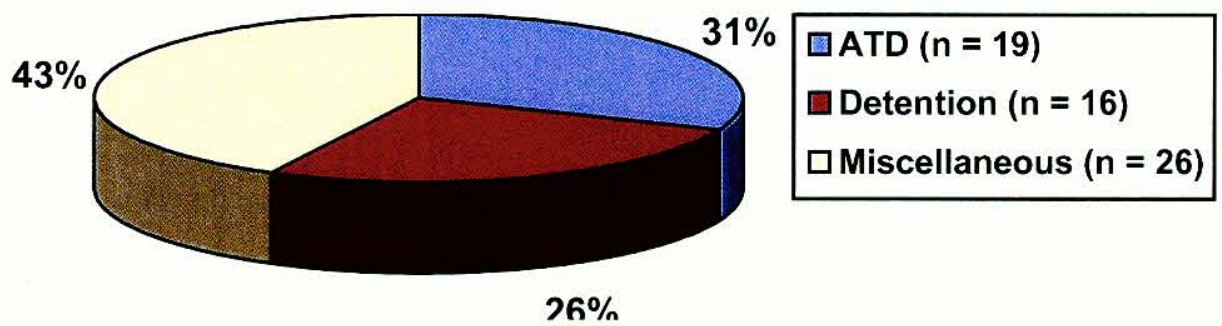

Figure 6. VCO status offender placements $(\mathrm{N}=61)$

Juvenile Detention Center reports indicated that 23 status offenders were securely detained for contempt of court for violating court-ordered conditions in the preceding 8 months of 2001 prior to implementation of the ATD program. Between September-December 2001, following implementation of the program, 12 status offenders were securely detained. In the first full-year following program implementation, the number of status offenders securely detained for increased by 41 percent $(N=59)$. This initial increase suggests that the ATD 
program had no impact on reducing status offender placements in secure detention. However, in 2003 the number of status offenders securely detained decreased and was comparable to those in $2001(N=35)$, although data were not reviewed beyond October, 2003. No demographic information concerning status offenders securely detained was available from this report. Figure 7 shows the total number of status offenders securely detained for contempt of court for violating a VCO from 2001 through October, 2003.

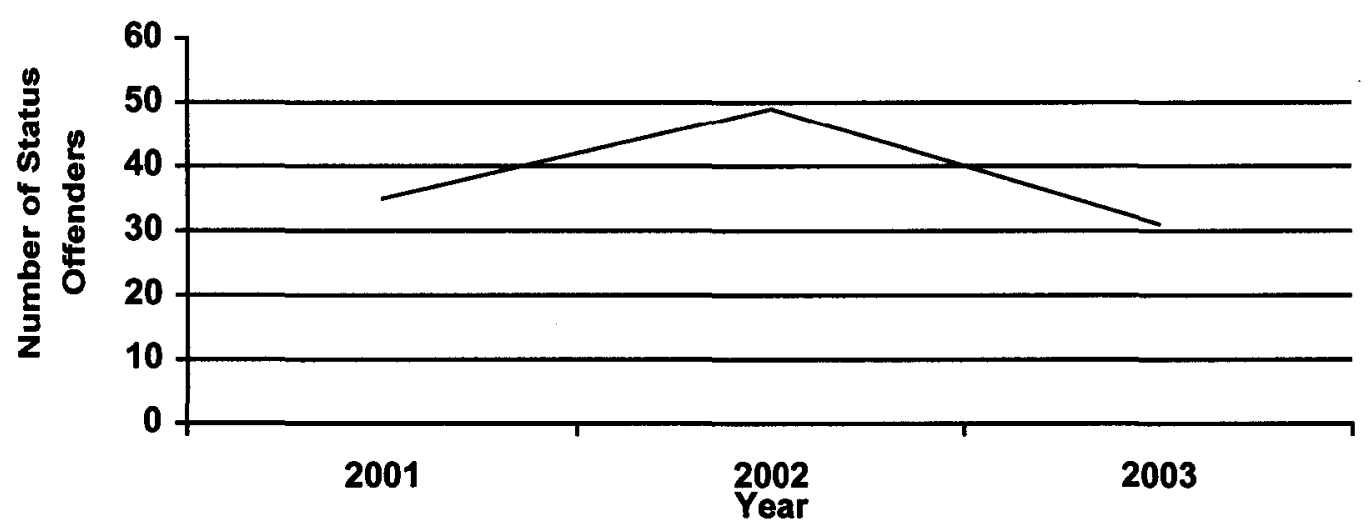

Figure 7. Number of status offenders detained for contempt by year ${ }^{16}$

\section{Alternatives to Detention.}

Between September 2001-June 2003, ATD program records reflected that 38 status offenders $(N=38)$ were placed through this program as a predispositional alternative following a charge of contempt. Of the youths placed, there were an equal number of females $(n=19,50.0 \%)$ and males $(n=19$, $50.0 \%$ ) placed. Minorities accounted for 52.6 percent of the ATD placements ( $n$ $=20)$, and Caucasians 47.3 percent $(n=18)$. The mean age was 15.13 years.

\footnotetext{
${ }^{16}$ Data available from the Kentucky Court of Justice, www.kycourts.net
} 
Of the underlying contempt offenses, habitual truancy accounted for 28.9 percent of the placements $(n=11)$; habitual runaway accounted for 26.3 percent of the placements $(n=10)$; failure to appear accounted for 26 percent of the placements $(n=10)$; and beyond control of a parent or school official accounted for 18.4 percent of the placements $(n=7)$. The ATD placements were used less frequently for status offenders as a final disposition $(N=7)$ than predispositional alternative.

\section{Placement Factors}

A number of factors appeared to influence placement decisions. Most significant were subjects' behavior and the availability of ATD placements equipped to handle youths with emotional and behavioral problems. Only two private agencies were contracted to provide ATD placements (Ed Necco and Associates and Kentucky United Methodist Homes) for status and delinquent juvenile offenders referred to the program in Fayette County. A facility managed by DJJ, the Bluegrass Regional Assessment Center (BRAC), was available but generally reserved for more problematic delinquent youths. These private programs were able to accept only a limited number of juvenile offenders referred by the ATD coordinator. Other factors that influenced placements for status offenders included previous failed ATD placements, juveniles' demeanor during judicial proceedings, recommendations from social workers or probation officers, parental requests, and judges' discretion. Based on review of Juvenile Court records it was determined that recommendations from agency personnel greatly influenced placement decisions. Judges observed recommendations 73.7 
percent of the time $(n=45)$. This observation was anticipated given statutory requirements for these agencies to submit recommendations to the court (See KRS § 610.265). It was unclear to what extent juveniles' demographics factored into placement decisions. Of the cases reviewed, a high percentage of referrals (78.6\%, $n=48$ ) was made by judges to the ATD coordinator.

The presence of emotional or behavioral issues was a factor frequently identified in court records that may have influenced placement decisions. Approximately 38 percent of the subjects $(n=23)$ referred to the ATD program had readily identifiable and documented mental health issues, making nonsecure placements difficult due to placement disruptions (Wade Carpenter, personal communication, February 13,2003$)$. However, the total number affected by mental health issues was likely more substantial; many individuals have not been diagnosed or provided treatment (Shelton, 2002). Conditions reported primarily from social workers via predispositional reports to the judge or from psychological reports entered into the court record included a range of mental health issues such as Attention Deficit Hyperactivity Disorder (ADHD), Attention Deficit Disorder (ADD), Oppositional Defiant Disorder (ODD), Conduct Disorder, Depressive Disorder, Bipolar Disorder, Substance Abuse or Polysubstance Abuse, Impulse Control Disorder, Adjustment Disorder, and Intermittent Explosive Disorder. Other issues noted typically included parent-child relational problems, and physical abuse or neglect of the child. These conditions are consistent with common mental illnesses among adolescents reported by Lexcen and Redding (2000). 
Although statutory requirements mandate use of least restrictive alternatives, it appeared that placement decisions were influenced by many factors such as mental health issues in addition to weighing judicial cooperation or safety of the public and youths. Because of inconsistent and incomplete documentation in both Juvenile Court and ATD program records, the total number of referrals during this period and case-specific details for every status offender could not be discerned; documentation varied among judges, and ATD records did not include information on all youths referred to the program.

A crosstabulation for the chi-square $\left(x^{2}\right)$ test of association was performed together with the Cramer's $V$ statistic to determine if there was any significant relationship between placement type and offender characteristics including ethnicity, gender, living arrangement, and school type attended. As seen in Table 3, weak, nonsignificant relationships were found indicating that placements were independent of these factors.

Table 3.

Crosstabulation for Placements by Offender Characteristics ( $N=61)$

\begin{tabular}{lcccc}
\hline Characteristics & $\underline{x^{2}}$ & $\underline{d f}$ & $\underline{\underline{p}}$ & $\underline{\underline{V}}$ \\
\hline Placement Type x Ethnicity & 3.797 & 2 & .150 & .249 \\
Placement Type x Gender & .011 & 2 & .994 & .014 \\
Placement Type x Living Arrangement & 2.552 & 2 & .279 & .205 \\
Placement Type x School Type Attended & 2.657 & 2 & .265 & .209 \\
\hline
\end{tabular}

The Kruskal-Wallis analysis of variance by ranks test was used to determine if significant differences existed between the placement groups based on offender characteristics including age (initial court contact and initial placement), 
grade, and number of placements. As seen in Table 4, a significant result was found $(H(2)=14.620, p<.01)$ indicating a difference between the groups in the number of placements. Although post hoc testing is not available for nonparametric procedures, results indicated that most subjects had miscellaneous placements (43\%) compared to ATD $(31 \%)$ or secure detention (26\%) placements. No significant differences existed between the groups based on age and grade.

Table 4.

Analysis of Variance by Ranks Between Placements for Age, Grade, and Number of Placements $(N=61)$

\begin{tabular}{lccc}
\hline Characteristics & $\underline{H}$ & $\underline{d f}$ & $\underline{p}$ \\
\hline Age-Court Contact & 2.436 & 2 & .296 \\
Age-Placement & .909 & 2 & .635 \\
Grade & 2.357 & 2 & .308 \\
\#Placements & 14.620 & 2 & $.001^{*}$ \\
\hline
\end{tabular}

Sig. $p \leq .01$

\section{Goal 2: The ATD program will ensure the court attendance of youths}

\section{(Judicial Cooperation).}

A nonequivalent, multiple-group pre/post-test design was used to compare three placement groups of status offenders: those with (a) ATD placements only, (b) secure detention only, and (c) other placements such as home detention, relative placement, or shelter care (miscellaneous group). For the miscellaneous group, placements in secure detention or through the ATD program may have also occurred, but were in addition to other placement options. Judicial cooperation was measured based on the number of contempt charges for failure 
to appear (FTA) for court proceedings. These placements are presented in Figure 8.

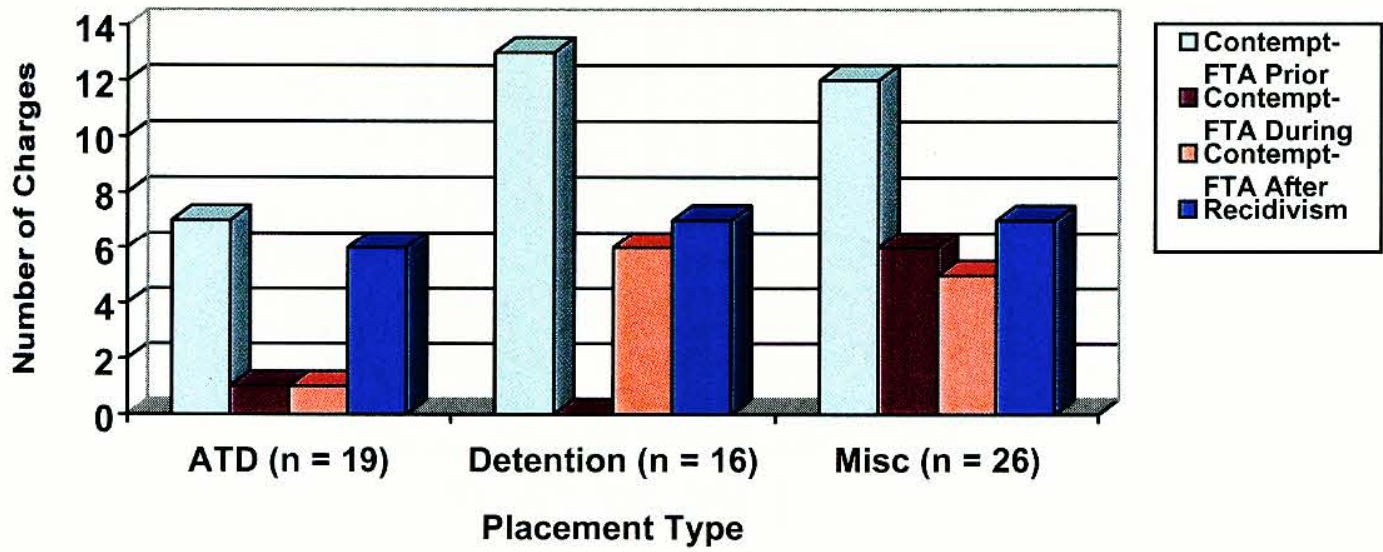

Figure 8 . Number of contempt-FTA charges and recidivism by placement type $(\mathrm{N}=61)$

As seen in Figure 8, noticeable differences existed between placements in the number of contempt-FTA charges and in recidivism based on these charges. To examine these differences, the Kruskal-Wallis analysis of variance by ranks test was used to determine whether significant differences existed in judicial cooperation as measured by the number of contempt-FTA charges adjudicated prior, during, and after initial placement. Differences in recidivism based on these charges were also determined. Based on the test statistic, significant results were found in the number of contempt-FTA charges during $(H(2)=6.138$, $p<.05)$ and after $(H(2)=8.122, p<.05)$ placements indicating that the placements differed from each other on these measures. Specifically, subjects with miscellaneous placements had more contempt charges during placements $(n=6)$ than those with ATD or secure detention ${ }^{17}$ placements $(n=1$ and $n=0$,

\footnotetext{
${ }^{17}$ The number of charges during secure detention placements was predictably low since Detention Center staff ensures youths appear for court proceedings.
} 
respectively). Subjects with secure detention and miscellaneous placements had more charges after placement ( $n=6$ and $n=5$, respectively) than those with ATD placements $(n=1)$. No significant differences were found in the number of contempt charges prior to placement or in recidivism indicating that the placements did not differ on these measures. Results are presented in Table 5. Table 5.

Analysis of Variance By Ranks Between Placements for Contempt-FTA Charges and Recidivism $(N=61)$

\begin{tabular}{lccc}
\hline Characteristics & $\underline{H}$ & $\underline{d f}$ & $\underline{\underline{p}}$ \\
\hline \#Contempt-FTA Prior & 3.242 & 2 & .198 \\
\#Contempt-FTA During & $6.138^{*}$ & 2 & .046 \\
\#Contempt-FTA After & $8.122^{*}$ & 2 & .017 \\
Recidivism & .198 & 2 & .906 \\
\hline
\end{tabular}

${ }^{*}$ Sig. $p \leq .05$

To determine the significance of relationships between variables included in this study, both the Spearman's rank-order and eta correlations were computed. Specifically, a Spearman's correlation was used to determine if significant relationships existed between offender characteristics including age (initial court contact and placement), grade, and number of placements and judicial cooperation as measured by the number of contempt-FTA charges prior, during, and after placement. These demographics were also correlated with recidivism (see Table 6). An eta correlation was used to determine if significant relationships existed between offender characteristics including gender, ethnicity, living arrangement, school type attended, and placement type and judicial cooperation as measured by the number of contempt-FTA charges prior, during, 
and after placement (see Table 7).

As seen in Table 6, significant, positive correlations were found between (a) age at initial placement and recidivism $(r h o(59)=.333, p<.05)$, and $(b)$ the number of contempt charges-FTA prior to placement and recidivism (rho(59) $=.634, p<.01)$ indicating that younger subjects at initial placement had higher recidivism and exhibited less judicial cooperation compared to older subjects. Additionally, subjects with more offenses prior to initial placement had higher recidivism and exhibited less judicial cooperation compared to those who offended less. No other significant relationships were found.

Table 6.

Intercorrelations Between Number of Contempt-FTA Charges, Recidivism, and Offender Characteristics $(N=61)$

\begin{tabular}{lcccc}
\hline Characteristics & \multicolumn{5}{c}{ \#Contempt Charges } & \\
\hline Age-Court Contact & .183 & -.045 & .069 & .049 \\
Age-Placement & .182 & -.069 & .120 & $.333^{*}$ \\
Grade & .094 & -.095 & .010 & .043 \\
\#Placements & .094 & .156 & .062 & -.049 \\
\#Contempt Prior & 1.000 & -.021 & .170 & $.634^{\star *}$ \\
\#Contempt During & -.021 & 1.000 & .080 & -.052 \\
\#Contempt After & .170 & .080 & 1.000 & -.054 \\
Recidivism & $.634^{* *}$ & -.052 & -.054 & 1.000 \\
\hline
\end{tabular}

${ }^{*}$ Sig. $p \leq .05$

${ }^{* *}$ Sig. $p \leq .01$

As seen in Table 7, very weak to weak relationships between these variables as indicated by eta-squared $\left(\eta^{2}\right)$ suggested that there was not a strong 
relationship between offender characteristics and judicial cooperation.

Table 7.

Intercorrelations Between Number of Contempt-FTA Charges and Offender Characteristics $(N=61)$

\begin{tabular}{lccccccc}
\hline & \multicolumn{3}{c}{ Prior } & \multicolumn{3}{c}{ \#Contempt Charges } & \multicolumn{2}{c}{ During } & \multicolumn{2}{c}{ After } \\
Characteristics & $\eta$ & $\eta^{2}$ & $\eta$ & $\eta^{2}$ & $\eta$ & $\eta^{2}$ \\
\hline Gender & .044 & .002 & .106 & .011 & .010 & .000 \\
Ethnicity & .166 & .028 & .022 & .000 & .125 & .016 \\
Living Arrangement & .078 & .006 & .186 & .035 & .109 & .012 \\
Placement Type & .194 & .040 & .320 & .102 & .377 & .142 \\
\hline
\end{tabular}

Eta was also used to examine these offender characteristics by placement type. As seen in Table 8, the relationships between these variables were also very weak to weak as indicated by eta-squared $\left(\eta^{2}\right)$. Therefore, offender characteristics and placement type were not strongly related to judicial cooperation.

Table 8.

Intercorrelations Between Number of Contempt-FTA Charges and Offender Characteristics by Placement Type $(N=61)$

\begin{tabular}{|c|c|c|c|c|c|c|}
\hline \multirow[b]{3}{*}{ Characteristics } & \multicolumn{6}{|c|}{ \#Contempt Charges } \\
\hline & \multicolumn{2}{|c|}{ Prior } & \multicolumn{2}{|c|}{ During } & \multicolumn{2}{|c|}{ After } \\
\hline & $\eta$ & $\eta^{2}$ & $\eta$ & $\eta^{2}$ & $\eta$ & $\eta^{2}$ \\
\hline \multicolumn{7}{|c|}{ Gender x Placement Type } \\
\hline ATD & .083 & .007 & .201 & .040 & .201 & .040 \\
\hline Detention & .073 & .005 & & & .016 & .000 \\
\hline Miscellaneous & .085 & .007 & .270 & .072 & .066 & .004 \\
\hline \multicolumn{7}{|c|}{ Ethnicity $\times$ Placement Type } \\
\hline ATD & .141 & .020 & .180 & .032 & .180 & .032 \\
\hline $\begin{array}{l}\text { Detention } \\
\text { Miscellaneous }\end{array}$ & $\begin{array}{l}.389 \\
085\end{array}$ & $\begin{array}{l}.151 \\
007\end{array}$ & 099 & .010 & $\begin{array}{l}.221 \\
365\end{array}$ & $\begin{array}{l}.050 \\
133\end{array}$ \\
\hline
\end{tabular}


Table 8. (Continued)

Intercorrelations Between Number of Contempt-FTA Charges and Offender Characteristics by Placement Type $(N=61)$

$$
\text { \#Contempt Charges }
$$

\begin{tabular}{|c|c|c|c|c|c|c|}
\hline \multirow[b]{3}{*}{ Characteristics } & & & & & & \\
\hline & \multicolumn{2}{|c|}{ Prior } & \multicolumn{2}{|c|}{ During } & \multicolumn{2}{|c|}{ After } \\
\hline & $\eta$ & $\eta^{2}$ & $\eta$ & $\eta^{2}$ & $\eta$ & $\eta^{2}$ \\
\hline \multicolumn{7}{|c|}{$\begin{array}{l}\text { Living Arrangement } x \\
\text { Placement Type }\end{array}$} \\
\hline ATD & 177 & .031 & .081 & .007 & .136 & .020 \\
\hline Detention & .092 & .010 & & & .289 & .083 \\
\hline $\begin{array}{l}\text { Miscellaneous } \\
\text { School Type Atten } \\
\text { Placement Type }\end{array}$ & .196 & .040 & .036 & .001 & .062 & .004 \\
\hline ATD & .015 & .000 & .141 & .020 & .394 & 160 \\
\hline Detention & 149 & .022 & a & & .163 & .030 \\
\hline Miscellaneous & .019 & .000 & .234 & .054 & .114 & .012 \\
\hline
\end{tabular}

${ }^{\mathrm{a} C o n s t a n t}$

Goal 3: The ATD program will ensure the safety of the public and youths (Public and Youth Safety).

To measure judicial cooperation, a nonequivalent, multiple-group pre/post test design was used to compare three placement groups of status offenders: those with (a) ATD placements only, (b) secure detention only, and (c) other placements such as home detention, relative placement, or shelter care (miscellaneous group). For the miscellaneous group, placement in secure detention, or through the ATD program may have also occurred but were in addition to other placement options. Public and youth safety was measured based on the number of status and delinquent charges.

To examine group differences, chart review of Juvenile Court records was conducted between September 2001-July 2003. As seen in Figure 9, noticeable differences existed between placements in the number of 
status/delinquent charges and in recidivism based on these charges.

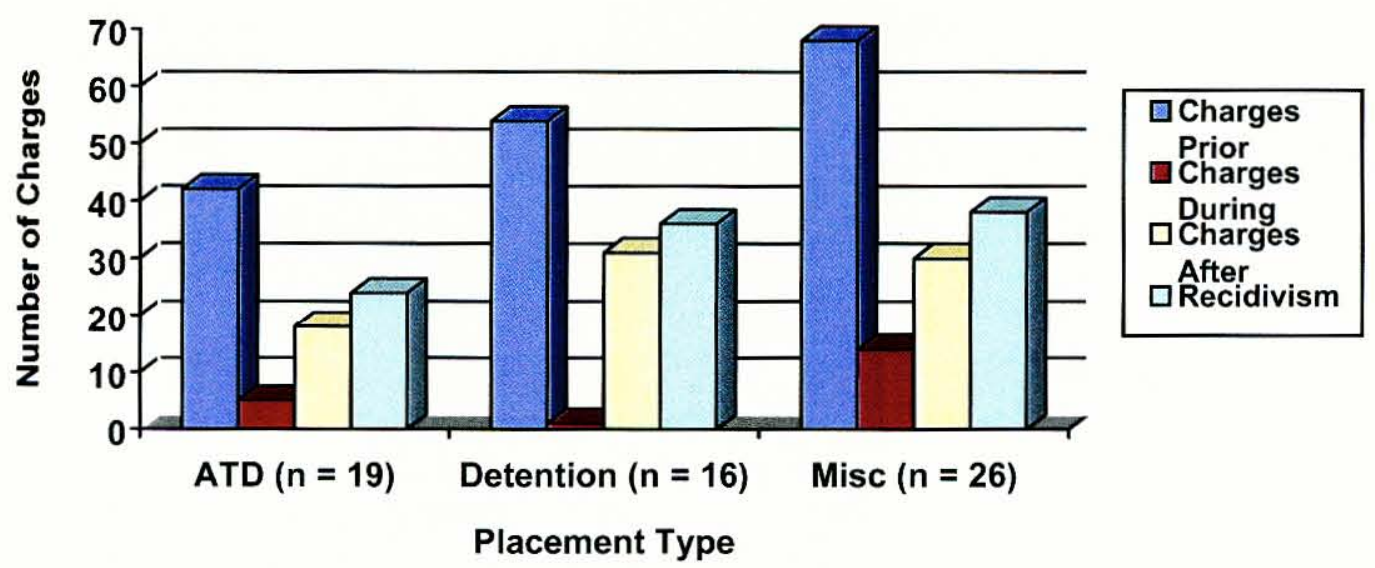

Figure 9. Number of status and delinquent charges and recidivism by placement type $(\mathrm{N}=61)$

The Kruskal-Wallis analysis of variance by ranks test was performed to determine whether significant differences existed between the placement groups in public and youth safety as measured by the number of status/delinquent charges adjudicated prior, during, and after initial placement. Differences between the groups in recidivism based on these charges were also determined. Significant results were found in the number of status/delinquent charges prior $(H(59)=9.465, p<.01)$, during $(H(59)=7.939, p<.01)$, and after $(H(59)=$ $11.632, p<.01)$ initial placement indicating differences between placements on these measures. Specifically, subjects with secure detention and miscellaneous placements had more status/delinquent charges prior to placement $(n=54$ and $n$ $=68$, respectively) than youths with ATD placements $(n=42)$. Youths with miscellaneous placements had more charges during placements $(n=14)$ than those with ATD and secure detention placements ( $n=5$ and $n=1$, respectively). Subjects with secure detention and miscellaneous placements had more charges 
after placement ( $n=31$ and $n=30$, respectively) than youths with ATD placements $(n=24)$. No significant differences were found between placement groups in recidivism. Results are presented in Table 9.

Table 9.

Analysis of Variance By Ranks Between Placements for Status/Delinquent Charges and Recidivism ( $N=61)$

\begin{tabular}{lccc}
\hline Characteristics & $\underline{x}^{2}$ & $\underline{d f}$ & $\underline{p}$ \\
\hline \#Status/Delinquent Prior & $9.465^{\star \star}$ & 2 & .009 \\
\#Status/Delinquent During & $7.939^{\star}$ & 2 & .019 \\
\#Status/Delinquent After & $11.632^{\star \star}$ & 2 & .003 \\
Recidivism & .790 & 2 & .674 \\
\hline
\end{tabular}

${ }^{*}$ Sig. $p<.05$

${ }^{* *}$ Sig. $p \leq .01$

To determine the significance of relationships between variables, both Spearman's rank-order and eta correlations were computed. Specifically, a Spearman's correlation was used to determine if significant relationships existed between offender characteristics including age (initial court contact and placement), grade, and number of placements and public and youth safety as measured by the number of status/delinquent charges prior, during, and after placement. These demographics were also correlated with recidivism (see Table 10). An eta correlation was used to determine if significant relationships existed between offender characteristics including gender, ethnicity, living arrangement, school type attended, and placement type and public and youth safety as measured by the number of status/delinquent charges prior, during, and after placement (see Table 11). 
As seen in Table 10, a significant, positive correlation was found between the number of status/delinquent charges prior to initial placement and recidivism $(r h o(59)=.322, p<.05)$ indicating that subjects with more offenses prior to initial placement had higher recidivism, thereby decreasing public and personal safety compared to those who offended less. No other significant relationships were found.

Table 10.

Intercorrelations Between Number of Status/Delinquent Charges, Recidivism, and Offender Characteristics $(N=61)$

\begin{tabular}{lcccc}
\hline \multirow{2}{*}{ Characteristics } & \multicolumn{5}{c}{ Prior } & During & $\underline{\text { After }}$ & $\underline{\text { Recidivism }}$ \\
\hline Age-Court Contact & .040 & .136 & -.006 & .011 \\
Age-Placement & .212 & .084 & .081 & .084 \\
Grade & -.070 & .115 & -.109 & -.065 \\
\#Status/Delinquent Prior & 1.000 & .084 & .242 & $.322^{*}$ \\
\#Status/Delinquent During & .084 & 1.000 & .208 & -.218 \\
\#Status/Delinquent After & .242 & .208 & 1.000 & -.188 \\
Recidivism & $.322^{*}$ & -.218 & -.188 & 1.000 \\
\hline
\end{tabular}

${ }^{\star}$ Sig. $p \leq .05$

As seen in Table 11, very weak to weak relationships between these variables as indicated by eta-squared $\left(\eta^{2}\right)$ suggested that there was not a strong relationship between offender characteristics and public and youth safety. 
Table 11.

Intercorrelations Between Number of Status/Delinquent Charges and Offender Characteristics $(N=61)$

\begin{tabular}{lccccccc}
\hline & \multicolumn{6}{c}{ \#Status/Delinquent Charges } \\
Characteristics & $\eta^{\stackrel{\text { Prior }}{n}}$ & \multicolumn{2}{c}{ During } & \multicolumn{2}{c}{ After } \\
Ethnicity & .125 & .016 & .134 & .018 & .145 & .021 \\
Gender & .091 & .008 & .011 & .000 & .017 & .000 \\
Living Arrangement & .121 & .015 & .108 & .012 & .075 & .006 \\
School Type Attended & .011 & .000 & .279 & .078 & .102 & .010 \\
Placement Type & .395 & .157 & .368 & .135 & .408 & .166 \\
\hline
\end{tabular}

Eta was also used to examine these offender characteristics by placement type. As seen in Table 12, the relationships between these variables were also very weak to weak as indicated by eta-squared $\left(\eta^{2}\right)$. Therefore, offender characteristics and placement type were not strongly related to public and youth safety.

Table 12.

Intercorrelations Between Number of Status/Delinquent Charges and Offender Characteristics by Placement Type $(N=61)$

\section{\#Status/Delinquent Charges}

\begin{tabular}{lcccccc} 
& \multicolumn{2}{c}{ Prior } & \multicolumn{2}{c}{ During } & \multicolumn{2}{c}{ After } \\
Characteristics & $\eta$ & $\eta^{2}$ & $\eta$ & $\eta^{2}$ & $\eta$ & $\eta^{2}$ \\
\hline Gender x Placement Type & & & & & & \\
$\quad$ ATD & .080 & .006 & .025 & .000 & .338 & .114 \\
$\quad$ Detention & .048 & .002 & .293 & .090 & .228 & .052 \\
$\quad$ Miscellaneous & .104 & .011 & .144 & .020 & .182 & .033 \\
Ethnicity x Placement Type & & & & & & \\
$\quad$ ATD & .012 & .000 & .287 & .082 & .049 & .002 \\
$\quad$ Detention & .153 & .023 & .174 & .030 & .174 & .030 \\
$\quad$ Miscellaneous & .234 & .055 & .168 & .030 & .007 & .000
\end{tabular}


Table 12. (Continued)

Intercorrelations Between Number of Status/Delinquent Charges and Offender Characteristics by Placement Type $(N=61)$

\#Status/Delinquent Charges

\begin{tabular}{lcccccc} 
& \multicolumn{2}{c}{ Prior } & \multicolumn{2}{c}{ During } & \multicolumn{2}{c}{ After } \\
Characteristics & $\eta$ & $\eta^{2}$ & $\eta$ & $\eta^{2}$ & $\eta$ & $\eta^{2}$ \\
\hline Living Arrangement $x$ & & & & & & \\
Placement Type & & & & & & \\
$\quad$ ATD & .055 & .003 & .205 & .042 & .136 & .020 \\
$\quad$ Detention & .182 & .033 & .124 & .015 & .124 & .015 \\
$\quad$ Miscellaneous & .114 & .013 & .060 & .004 & .144 & .021 \\
School Type X & & & & & & \\
Placement Type & & & & & & \\
$\quad$ ATD & .217 & .047 & .357 & .130 & .394 & .160 \\
$\quad$ Detention & .293 & .086 & .200 & .040 & .163 & .030 \\
$\quad$ Miscellaneous & .409 & .168 & .060 & .004 & .114 & .013 \\
\hline
\end{tabular}




\section{CHAPTER FIVE}

\section{DISCUSSION}

This study examined the efficacy of the Alternatives to Detention (ATD) program used for status offenders in Lexington, Fayette County, Kentucky. The study was a goals-based evaluation of the ATD program that sought to measure whether or not the program is meeting its predetermined goals, and to determine the appropriateness or inappropriateness of those goals. The following was assessed based on the program goals: (1) examine the extent to which the ATD program helps Fayette County comply with JJDPA and state mandates to use nonsecure detention alternatives for status offenders; (2) examine the effect of the ATD program on ensuring court appearances of status offenders; and (3) examine the effect of the ATD program on subsequent offending. The significance of the study is that it adds to the body of literature focusing on alternative programs for status offenders and deinstitutionalization efforts. This research is especially salient in a "get tough" era that also mandates deinstitutionalization. Therefore, there is a need to develop more effective responses to juvenile offending. As noted by Bilchik (1999), there is a need "to forge enlightened policies for our juvenile justice system... based on facts, not fears" (OJJDP, 1999). These facts, generated from research, may help determine if it is possible to have less offending without more punishment (Smith, 
1999).

The outcomes of this goals-based evaluation of the Alternatives to Detention (ATD) program were mixed. First, while the number of status offenders placed in secure detention decreased as mandated by JJDPA, the number of status offenders detained for contempt of court for violating valid court-ordered conditions (VCO) has remained constant. Presently, secure detention for violating a $\mathrm{VCO}$ is an exception permitted by JJDPA. Following the implementation of ATD program in Fayette County, the detention of status offenders increased the first year. Available data for the second year indicated detention rates more in line with the period prior to program implementation. Second, while judicial cooperation improved for youths with ATD placements during and after placements as measured by the number of contempt-FTA charges, this outcome was also observed for youths with secure detention and miscellaneous placements. While it was expected that these offenses would decrease during secure detention placements because detention staff ensure youths appear for court proceedings, other placement groups also had decreased contempt-FTA charges during placements. While there were fewer contempt-FTA charges after placement for youths with ATD placements, youths with secure detention and miscellaneous placements experienced the greatest decrease overall in these charges after placement. Third, results indicated that public and youth safety improved for youths with ATD placements as the number additional offenses, both status and delinquent, decreased during and after these placements. However, this finding was also noted for youths with detention and 
miscellaneous placements. While it was expected that these offenses would decrease during secure detention, other placement groups also had decreased charges during placements. Although there were fewer charges after placement for youths with ATD placements, youths with secure detention and miscellaneous placements experienced the greatest decrease overall in these charges after placement. Due to the small number of subjects in each placement group and low data variability, few statistically significant differences between placement groups were observed in the final analysis.

This goals-based study of the ATD program included review of both unit record and aggregate data to identify detention use trends (Goal 1), and employed a nonequivalent, multiple-group, pre/post-test design to evaluate judicial cooperation (Goal 2), and public and youth safety (Goal 3). Results of the study indicated that the ATD program was useful when used with status offenders as intended by the program goals. The findings also point out other themes identified in the literature concerning juvenile offenders. First, many preadolescents and early adolescents experience increasing difficulties as they transition into adulthood. The social, emotional, and behavioral challenges during this period are often manifested through offending (Lexcen \& Redding, 2000). A majority of the subjects in this study were young teens in middle school. Prior research has suggested that "the younger the age at which a youth consistently engages in problem or criminal behavior, the more likely it is that this behavior will persist into adolescence and adulthood" (Risler, Sutphen, \& Shields, 2000, p. 113). Therefore, interventions that target this age group are necessary 
to avert continued and perhaps more serious career offending. Second, a disproportionate number of minorities were classified as offenders. Prior research has examined this bias and suggests that policies and practices must be overhauled to ensure equity in the justice system (see, for example, Anderson, 1994; Belknap, Holsinger, \& Dunn, 1997; Bell, 2001; Leiber, 2002; Rhodes \& Fischer, 1993). Third, many of the status offenders also engaged in delinquent behavior. Studies have confirmed that juveniles commit a wide variety of offenses during their offending careers (Sheldon, Horvath \& Tracy, 1989), some escalating to more serious, delinquent offending (Benda, 1987, Thomas, 1976). Fourth, placements appeared to be influenced by the living arrangement of the subjects. Data indicated that juveniles who had living arrangements other than with at least one parent had more placements. This observation may be attributed to several explanations. For example, the parens patriae philosophy suggests the state should intervene when no adequate or appropriate caretaker is available to protect a child. This finding has been documented by Schutt and Dannefer (1988) who determined that the protectionist concerns of judges often lead to removal of children from families that are stressed. Fifth, decreased recidivism among the groups indicated that each of the interventions was useful. However, the significance of these findings is that unlike secure detention, interventions such as the ATD program can achieve similar results that are less restrictive and less costly. While this study only evaluated the impact of the ATD program when used as a predispositional alternative, the results are promising for its long-term effects on judicial 
cooperation as well as safety of the public and youths. These results, which indicate there can be less offending without more punishment, support further research to assess the impact of the program when used as a dispositional alternative. Discussion of the findings based on the specified program goals is warranted.

\section{Goal 1: The ATD program will reduce the placement of status offenders} in secure detention (Deinstitutionalization).

Review of Juvenile Detention Center, ATD program, and Juvenile Court records suggests that the placement of status offenders in secure detention has declined since the ATD program was implemented in Lexington, Fayette County, Kentucky in November, 2001. Based on Juvenile Detention Center records, no status offender has been securely detained contrary to the exceptions permitted by JJDPA since the ATD program was implemented. Although status offenders detained for contempt for violating Valid Court Orders (VCO), an exception permitted by JJDPA, sharply rose initially following implementation of the program, these detentions gradually declined. It is unclear to what extent the ATD program may have influenced this initial spike in detentions, but this observation may be attributed to an occurrence of net-widening and relabeling. As noted by Van Dusen (1981), this activity extends the client reach of the justice system by relabeling an individuals' behavior in some manner (e.g., status offender) to subject them to some form of system control. The use of secure detention under these circumstances remains questionable given the availability of less restrictive alternatives and federal and state mandates to use them. 
ATD placements consisted of foster care contracted through Ed Necco and Associates, and temporary shelter care contracted through United Methodist Homes (both private child care agencies). A third placement option operated by DJJ, Bluegrass Region Assessment Center (BRAC), had few status offender placements. Factors that typically influenced ATD placement decisions included previous failed placements (i.e., placement disruptions due to behavior problems), mental health issues, placement availability, nature of the offense, and legal history. Other factors such as variations in length of placement, placement location, and availability of services such as counseling were considerations whether or not to use detention alternatives (Wade Carpenter, personal communication, February 13,2003$)$. The ATD program has assisted this county in meeting deinstitutionalization goals for status offenders. Other conditions mandated by JJDPA such as sight and sound separation and disproportionate confinement were outside the scope of this study and, therefore, not considered. Despite the continued use of secure detention for contempt matters, this county remains in full-compliance with JJDPA mandates when based solely upon deinstitutionalization goals.

There are several critical areas requiring further research specific to this goal. First, the continued use of secure detention for status offenders found in contempt for violating a VCO poses uncertainty for the sustainability of the ATD program. As an exception permitted by JJDPA, incarceration of status offenders may again become viewed as more practical given issues such as resource allocation (i.e., funding, placement availability, human resources) or policy 
shifts familiar in juvenile justice. These are the perpetual quandaries noted by Bernard (1992) that have cycled in juvenile justice several times since its inception, thereby decreasing the effectiveness of the system. Second, as DJJ gradually assumes control of detention operations across the state (Fayette County currently maintains control of the Juvenile Detention Center), changes may impact the ATD program and detention use in general. Conflicts may arise between judges who have traditionally relied upon use of secure detention to control status offenders and agencies such as DJJ that are mandated to use less restrictive, nonsecure placements. According to Bazemore and Dicker (1996, p. 5), "among the numerous examples of juvenile justice policy reform efforts that were at least partially subverted by those responsible for implementation are the deinstitutionalization of status offenders...judges may use their influence...to actively support or oppose policy change, or they may attempt to subvert implementation if they perceive that reforms will result in unwarranted limits on their discretion."

Another area of concern is the predominant use of foster care for ATD placements that go largely unmonitored by the Juvenile Court. Based on the child welfare foster care model used historically for abused or neglected children, the ATD program in Fayette County places most status offenders referred by the courts into licensed, private child care foster homes. However, unlike the child welfare model that requires certain safeguards such as regular monitoring of the foster homes by social workers, no such protections are afforded to youths placed by the ATD program. Placement is based on referral by the judge 
as a predispositional alternative typically at a detention hearing or arraignment. While the foster homes may be monitored by caseworkers employed by the placement agency, there is no requirement for a Juvenile Court social worker or probation officer to monitor the juvenile or the placement. Therefore, protections against abuse or neglect, further unlawful behavior, or access to needed services such as counseling cannot be guaranteed. Interestingly, many juveniles state a preference for detention over a foster care placement. Perhaps they view foster care placement as more punitive than incarceration. This would be supported by findings of Wood and Grasmick (1999) who determined that prison inmates perceived alternative sanctions such as probation and electronic monitoring more punitive than incarceration, and that offenders preferred to serve out their sentences instead of participating in alternative sanctions. These issues should be explored further as the ATD program becomes established.

The long-term impact of institutionalization because of an increase in commitments is an area of concern among practitioners. Specifically, an unintended consequence of an out-of-home placement for juveniles through the ATD program is the more convenient pathway for commitment and long-term residential placement. With few placement options available to the courts prior to implementation of the ATD program in Fayette County, most youths who appeared in court were either placed into detention or returned home. In a few instances when DCBS assumed temporary custody, juveniles were placed into shelter care, or temporary custody was awarded to a relative for placement. Under these circumstances, the commitment process was often lengthy and 
delayed, even in instances when the best interest of the juvenile was commitment and placement. The ATD program affords the courts with an opportunity to quickly place a juvenile in an out-of-home placement without commitment. The long-term impact of these quick removals and placements on subsequent commitments and/or long-term institutionalization should be explored.

A mandate of the ATD program is to also provide least restrictive placements for nonviolent public offenders or delinquents. In Fayette County current detention protocol currently requires separation of status offenders from delinquents. However, as many of the ATD program resources used with this population are also used with status offenders, the effects of co-placement needs further assessment. Deinstitutionalization equates to separation of status offenders from more serious delinquents.

Goal 2: The ATD program will ensure the court attendance of youths (Judicial Cooperation).

To measure Goal 2, a nonequivalent, multiple-group, pre/post-test design was used to compare three placement groups of status offenders including those with: (a) ATD placements only; (b) secure detention only; and (c) other placements such as shelter care or home detention (miscellaneous category). The miscellaneous group may also have included ATD or secure detention placements. The design was selected based on placement options typically available to judges. For Goal 2, judicial cooperation was determined based on the number of contempt-FTA charges adjudicated for subjects prior, during, and 
after the initial placement intervention.

Several analyses were conducted in this study to assess the relationships between variables, and to assess placement group differences. Results indicated that judicial cooperation increased during and after placement for subjects in the three placement groups based on decline in the number of contempt-FTA charges. Specifically, the ATD and detention groups had the greatest decrease in these charges during placements, and the secure detention and miscellaneous placements had the greatest decrease after placement. However, these differences were not significant. Similarly, there was no significant difference between the placements in recidivism. Although Goal 2 of the predispositional ATD program does not claim to influence judicial cooperation of juveniles after placement, this finding indicates that there was a residual effect based on placement. Further examination of these relationships in future studies would be useful to determine the long-term implications of the ATD program and other placement options in ensuring judicial cooperation.

Results indicated few significant relationships between the variables. Age (initial court contact and initial placement), grade, and number of placements did not have a significant effect on judicial cooperation. Similarly, there were no significant relationships between judicial cooperation prior and during placement, nor during and after placement. However, a significant relationship did exist between judicial cooperation prior to and after placement. This indicates that judicial cooperation prior to placement influenced judicial cooperation after placement. Subjects who exhibited judicial cooperation prior to placement 
tended to exhibit it after placement. This was supported by a significant finding in recidivism.

The eta statistic was used to assess judicial cooperation by comparing the number of contempt-FTA charges, and offender characteristics including ethnicity, gender, living arrangement, school type attended, and placement type. Weak associations were found between the variables, indicating there were no significant relationships between them and judicial cooperation. Weak associations remained despite the introduction of a third variable or control.

Goal 3: The ATD program will ensure the safety of the public and youths (Public and Youth Safety).

A nonequivalent, multiple-group, pre/post-test design was also used to compare the three placement groups to measure Goal 3. For Goal 3, public and youth safety was measured by the number of status and delinquent offenses adjudicated for subjects prior, during, and after the initial placement intervention.

Results indicated that public and youth safety increased for subjects in the three placement groups during and after placement based on a decline in the number of status/delinquent charges. Specifically, the detention and miscellaneous groups had the greatest decrease in charges during placements, while the miscellaneous group had the greatest decrease after placement. However, these differences were not significant. Similarly, there was no significant differences between the placements in recidivism. As with Goal 2, this goal does not claim to influence public and youth safety after placement, but this finding indicates that there was a residual effect based on placement type. 
Further examination of these relationships in future studies would be useful to determine the long-term implications of the ATD program and other placement options in ensuring public and youth safety.

Results indicated several statistically significant relationships between the variables. While age (initial court contact and initial placement) or grade did not have a significant effect on public and youth safety, the number of placements did have a significant effect on public and youth safety during placements. Specifically, a considerable decrease in number of placements and offending occurred during placements. However, the number of placements was not significantly related to public and youth safety prior to or after placement. Similarly, there were no significant relationships between public and youth safety prior to and during placement, nor during and after placement. However, a significant relationship did exist between public and youth safety prior to and after placement. This indicates that public and youth safety prior to placement influenced public and youth safety after placement. Subjects who committed status/delinquent offenses prior to placement tended to commit these offenses after placement. This was supported by a significant finding in recidivism.

The eta statistic was used to assess public and youth safety by comparing the number of status and delinquent charges and offender characteristics including ethnicity, gender, living arrangement, school type attended, and placement type. Weak associations were found between the variables, indicating there were no significant relationships between them and public and youth safety. Weak associations remained despite the introduction of a third 
variable or control.

\section{ATD Recommendations}

This study also included recommendations to further develop the ATD program based on its specified goals. These recommendations include the following: (a) increase utilization of program placements to further decrease status offenders detained for contempt; (b) increase availability of placements to handle difficult youths; (c) minimize placement disruptions; (d) implement a modern records management system; and (e) increase interagency cooperation through improved communication.

To further develop the ATD program consistent with its goals, the continued use of secure detention for status offenders found in contempt must be reevaluated. Presently, detention of status offenders found in contempt is a permissible exception to deinstitutionalization based on federal and state mandates. Despite legal requirements and efforts of justice system personnel to advocate for less restrictive placements for status offenders, judges in Fayette County routinely incarcerate these youths. Until policymakers legislate changes completely prohibiting use of secure detention of status offenders, social workers, probation officers, and others involved must continue to advocate for more therapeutic interventions. This advocacy should be extended to youths who are difficult to place because of severe emotional and/or behavioral issues. Presently, these factors and others such as a lack of available placements equipped to handle these youths, result in an over-reliance on secure detention. More placement options with access to services will be more therapeutic and 
likely decrease placement disruptions.

Currently, Fayette County is limited in ATD resources given the numbers of offenders involved in the court system. A limited number of placements and one ATD coordinator whose responsibilities include both status offenders and delinquents and coordination of the program in other counties decreases the usefulness of this program. Similarly, as the ATD program further develops, records management and communication efforts with justice system personnel will likely become increasingly unmanageable. Based on the difficulties in tracking placements and placement decisions during this study, it is recommended that the program modernize its records management system and communication procedures. Many agencies including those in criminal justice currently use electronic registries for diagnosis, tracking, research, and case management activities. An electronic database such as those used by DJJ (JORI, Juvenile Offender Referral Information), or DCBS (TWIST, The Worker's Information System) would greatly improve these efforts. Improving records management improves policy planning, coordination, and service delivery as recognized by the United States Department of Justice ${ }^{18}$. Similarly, communication between the ATD program and agencies involved with these youths must be improved. Presently, communication is inconsistent or unreliable following an ATD placement. This is exacerbated by placements often located in rural areas outside Fayette County. Written reports or assessments for the court and agency personnel are integral for coordination and service delivery. These

\footnotetext{
${ }^{18}$ See Criminal Justice Records Improvement Program, available at http://www.opm.state.ct.us/pdpd1/justice/cji.htm
} 
critical areas deserve consideration if the ATD program is to move forward.

\section{Study Limitations}

There are several caveats that should be considered in the interpretation of this study. First, the research design was not rigorous. While this study employed a design more stringent than the one-group, pre/post-test design frequently used in program evaluations, it lacked both randomization and a control group present in true experimental designs. Thus, the nonequivalent group design used in this study is especially susceptible to certain threats to internal validity that affect generality of the study conclusions or its external validity (Anastas \& MacDonald, 1994; Campbell \& Stanley, 1963; Trochim, 2002).

Five internal validity threats should be considered when assessing the outcomes of this study including selection, history, maturation, statistical regression, and the combined effects of these interactions (e.g., selectionmaturation). A selection threat may have occurred because the subjects were not randomly assigned to the groups. Therefore, the groups may have been different prior to the study, which could affect the outcome of the study. A history threat may have occurred because the subjects could have reacted to an event unrelated to the interventions, or because an event occurred for one group and not for others. A maturation threat may have occurred because one group matured or aged at a rate different than the comparison groups, creating an impression of a program effect that did not exist. A statistical regression threat may have occurred based on the selection of subjects with extreme scores 
or characteristics. Marked changes for groups may have resulted due to a tendency to regress to the mean. A combined interaction effect may have occurred due to an effect between the selection of comparison groups and a second internal validity threat that may have led to confounding outcomes, and an erroneous interpretation that the treatment or intervention caused the effect. The researcher must account for these threats when explaining study outcomes. The groups selected for this study were as similar as possible (i.e., based on offender characteristics, offender classification, offense type, offense history, placement history, etc.) absent any randomization. Subjects for each placement group were matched based on these characteristics. The pretest distribution of scores or means for each group were used to assess if the groups differed as an indication of a selection threat. In this study, while the number of contempt-FTA charges prior to placement were similar among the three placement groups, status/delinquent charges prior to placement did not. As the findings of this study indicated that placement options were used differentially for status offenders due to factors such as severity of mental health issues or disruptive behavior, it is likely that the groups differed and selection threats cannot be ruled out for having influenced the outcomes. In other words, judges' familiarity with individual offender issues likely factored into subsequent placement decisions.

While the internal validity threat, history, does not appear to have factored into the outcomes based on improvements observed from pretest to post-test for each of the three placement groups, the effects of history cannot be completely ruled out. However, the brevity of the study period likely lessened the effects of history on the outcomes. 
Maturation may have contributed to the outcomes between the placement groups. Findings of this study indicated that age of the offender differentially affected placement factors including number of placements and type of placement. For example, subjects with secure detention placements tended to be younger and had more placements than subjects with ATD placements. This suggests that being an older, more mature youth may have contributed to the outcome and not the intervention (e.g., aging-out factor).

Statistical regression cannot be ruled out as a contributor to the outcomes. Since the ATD program placement group had a lower pretest mean in the number of contempt-FTA, and status and delinquent charges compared to the comparison placement groups, secure detention and miscellaneous groups, it is possible that the ATD group regressed upwards on the post-test. Similarly, since the comparison groups had higher pretest means for these charges, it is possible these groups regressed downwards on the post-test. In other words, each of the groups appears to regress toward the mean, and therefore, statistical regression cannot be ruled out as a contributor to the outcomes.

An external validity threat, multiple treatment interference, should be noted based on the inclusion of the miscellaneous placement group used for comparison. Multiple treatment interference suggests that as multiple treatments are given to the same subjects, it is difficult to control for the effects of prior treatments. Therefore, the outcomes may be attributed to the prior treatments and not the intervention being tested. Since the miscellaneous group may have also included other placement interventions including secure detention and/or 
ATD program placements, the outcomes may have been affected by all of the placement interventions that had been used for these status offenders.

Second, systematic sampling could not be used as the study included the entire population of available status offender cases for the specified study period. Therefore, the number of subjects included was small. Two important considerations regarding sample size noted by Hill (1998) are relevant to this study. Large samples are essential when (1) the total sample is to be subdivided into subsamples to be compared with one another, and (2) there is a wide range of variables and characteristics to be considered, creating a risk of missing or misrepresenting those differences. Thirty subjects per group is often cited as the minimum. The total number of subjects included in this study was 61 and likely did not meet this threshold. However, for correlational research, also a component of this study, Hill recommends at least 30 subjects to establish relationships. The total number of subjects appears adequate for these comparisons.

Third, this goals-based study of the ATD program relied solely upon offending to evaluate program outcomes based on stated program goals. Reoffending should be considered in context with other indicators of program success. Future studies should give consideration to the qualitative aspects of subjects' experiences, and their first-hand accounts of program successes and failures. The strength of qualitative research is its "utility of inductive, exploration...in finding new avenues of investigation and in guarding against the researcher's choice of measures that may limit the findings...it demonstrates the 
importance of looking beyond simplistic, linear, models to the subjective experiences and contexts of the participants..." (Kidd, 2002, ๆ The present study).

Fourth, since evaluation of the specific interventions available and/or used with each ATD placement were not within the scope of this study, distinctions between ATD placements could not be made. It is likely that juveniles' successes or failures are tied to differences within each program or placement, as well as individual circumstances (e.g., severe mental health problems). Therefore, examination of individual ATD placements and more in-depth analysis of individual factors would be useful to determine which services are most useful for this population.

Fifth, inconsistent and incomplete documentation prohibited a more thorough analysis of the ATD program. These problems include variations among judges' documentation efforts, lack of consistent and recorded feedback between the ATD program and court concerning subjects' placements, lack of an ATD database early in the program's implementation, and inability of the ATD coordinator to be present during all court proceedings due to ATD responsibilities in other counties. Inability to inspect all cases initially identified for this study also affected the final analysis.

Sixth, since deinstitutionalization affects both status offenders and nonviolent delinquents, further research concerning the usefulness of the ATD program and other alternatives with nonviolent delinquents should be conducted. Similarly, additional research should be conducted to assess the ATD program statewide. 
This analysis was beyond the scope of the present study.

\section{Summary and Conclusion}

Policymakers and practitioners continue to debate the issue of what programs or services are effective in controlling juvenile offending. Although serious offending has declined in the past decade, rates of offending remain persistently high. This is particularly evident in the number of status cases that are processed annually in the Juvenile and Family Courts.

Status offenders present unique challenges to an already overburdened juvenile justice system. Many status offenders are victims of maltreatment (Sullivan \& Knutson, 2000; Swanston, Parkinson, O'Toole, Plunkett, Shrimpton, \& Oates, 2003) and many have serious mental health or substance abuse issues (Lexcen \& Redding, 2000; Shelton, 2002). Due to these challenges, Holden and Kapler (1995, p. 8) have noted that, "the status offender is one of the most difficult juvenile offenders to place and the least amenable to community-based intervention." As a consequence, a large number of status offenders eventually require long-term residential treatment (J. Gibbs, ${ }^{19}$ personal communication, January 15,2004$)$. Although these challenges and the revolving door have led some to argue that the Juvenile Court system is not appropriate to address status behaviors, the "jury" remains at an impasse as to what is the most appropriate response. Whether one views these challenges as a status offense dilemma (Abadinsky, 1976), double paradox (Weijers, 1999), or cycle (Bernard, 1992), the overwhelming response is that further research is necessary to

\footnotetext{
${ }^{19}$ Jane Gibbs is the Family Court and Juvenile Court liaison for the Department for Community Based Services in Fayette County.
} 
determine which programs or services can be effective and cost-efficient (Boone, 1997).

This study examined the efficacy of the Alternatives to Detention (ATD) program used with status offenders in Lexington, Fayette County, Kentucky. Results indicated that Fayette County remains in full-compliance with deinstitutionalization mandates for status offenders. However, these findings do not account for the continued use of secure detention for status offenders who are detained for contempt after violating Valid Court Orders (VCO). Presently, federal and state mandates do not consider the VCO exception when determining states' compliance. Status offenders securely detained because of this exception has remained constant since the implementation of the ATD program.

While it was anticipated that the ATD program would be as useful as the more restrictive secure detention and more useful than other placement options in ensuring judicial cooperation and public and youth safety, findings indicated that improvements were made across all placement options. Judicial cooperation increased from youths during and after placements as the number of contempt charges for failure to appear (FTA) decreased for all three placement options. Similarly, public and youth safety improved during and after placements as the number of status and delinquent charges decreased for all three placement options. These decreases reflected less reoffending or recidivism. These findings do support the assumption that less-restrictive, lesscostly placement interventions can be useful for some status offenders. 
However, these findings cannot be generalized to all status offenders because the data suggest that many chronic status offenders were unsuccessful in nonsecure placements as indicated by their lack of judicial cooperation and/or increased risks to the public and their safety from reoffending. In these instances, the ATD coordinator, caseworkers, and judges have continued to rely upon use of secure detention to ensure "protection of the child or community" as permitted by state statute (K.R.S. $\S 630.080(1)$. Secure detention will likely continue to be used based on the "severity of the problems confronted by [these] children and their families..." (Asarnow, Aoki, \& Elson, 1996, p. 213), especially when services are unavailable or ineffective. However, there is no quick fix for these behaviors, especially those of chronic status offenders.

Although the results of the study did not indicate any significant difference between the ATD program placements and other placement options on judicial cooperation or public and youth safety, the results do not suggest that these placements were unsuccessful. The results do suggest that the more restrictive and costly secure detention intervention had no more of a deterrent effect than other alternative placement options. Therefore, judicial cooperation and public and youth safety can be provided by means other than secure detention. These results indicate that the ATD program is meeting its predetermined goals and that these goals are appropriate based on current federal and state mandates and the special needs of status offenders. 


\section{REFERENCES}

Abadinsky, H. (1976). The status offense dilemma: Coercion and treatment. Crime and Delinquency, 22, 456-460.

Agnew, R., Brezina, T., Wright, J. P., \& Cullen, F. T. (2002). Strain, personality traits, and delinquency: Extending general strain theory. Criminology, 40, 43-72.

Albonetti, C. A., \& Hepburn, J. R. (1997). Probation revocation: A proportional hazards model of the conditioning effects of social disadvantage. Social Problems, 44, 124-139.

Alder, C. (1984). Gender bias in juvenile diversion. Crime and Delinquency, 30, 400-414.

Allison, K. W., Crawford, I., Leone, P. E., Trickett, E., Perez-Febles, A., Burton, L. M., \& LeBlanc, R. (1999). Adolescent substance use: Preliminary examinations of school and neighborhood context. American Journal of Community Psychology, 27, 111-140.

Anastas, J. W., \& MacDonald, M. L. (1994). Research design for social work and the human services. New York: Lexington Books.

Anderson, G. M. (1994). Juvenile justice and the double standard. America, 170, 13-16.

Annie E. Casey Foundation. (1999, Fall/Winter). Juvenile jailhouse rocked. 
Reforming detention in Chicago, Portland, and Sacramento. Retrieved

February 13, 2004, from http://www.aecf.org/initiatives/jdai/download.htm Annie E. Casey Foundation. (2002). Juvenile Detention Alternatives Initiative.

Retrieved November 4, 2002, from http://www.aecf.org/initiatives/jdai/

Asarnow, J. R., Aoki, W., \& Elson, S. (1996). Children in residential treatment:

A follow-up study. Journal of Clinical Child Psychology, 25, 209-214.

Bakal, Y. (1998). Reflections: A quarter century of reform in Massachusetts

youth corrections. Crime and Delinquency, 44, 110-116.

Barnes, P. G. (1996). It may take a village...or a specialized court to address

family problems. American Bar Association Journal, 82, 22-24.

Barton, B. B., \& Butts, J. A. (1990). Viable options: Intensive supervision programs for juvenile delinquents. Crime and Delinquency, 36, 238-256.

Bazemore, G. (1994). Understanding the response to reforms limiting

discretion: Judges' views of restrictions on detention intake. Justice

Quarterly, 11, 429-452.

Bazemore, G. (2001). Young people, trouble, and crime: Restorative justice as

a normatic theory of informal social control and social Agree. Youth \&

Society, 33, 199-226.

Bazemore, G., \& Dicker, T. J. (1996). Implementing detention intake reform.

The Prison Journal, 76, 5-21.

Beger, R. R. (1994a). Illinois juvenile justice: An emerging dual system. Crime and Delinquency, 40, 54-69.

Beger, R. R. (1994b). The consistently inconsistent application of contempt 
power in juvenile courts. Journal of Crime and Justice, 17, 93-106.

Belknap, J., Holsinger, K., \& Dunn, M. (1997). Understanding incarcerated girls:

The results of a focus group study. Prison Journal, 77, 381-405.

Bell, J. R. (2001). Unjust in the much: Disproportionality in the juvenile justice system. Guild Practitioner, 58, 84-92.

Belou, E. (2004). History of family court. Retrieved January 14, 2005, from http://familyrightsassociation.com

Benda, B. B. (1987). Comparison of rates of recidivism among status offenders and delinquents. Adolescence, 22, 445-458.

Bernard, T. J. (1992). The cycle of juvenile justice. New York: Oxford University Press.

Bilchik, S. (1999). Foreward. In Juvenile Offenders and Victims: 1999 National Report (NCJ Publication No. 178257). Washington, DC: U.S. Department of Justice.

Birkbeck, C., \& LaFree, G. (1993). The situational analysis of crime and deviance. Annual Review of Sociology, 19, 113-138.

Bishop, D. M., \& Frazier, C. E. (1996). Race effects in juvenile justice decisionmaking: Findings of a statewide analysis. Journal of Criminal Law and Criminology, 86, 392-414.

Boisvert, M. J., \& Wells, R. (1980). Toward a rational policy on status offenders. Social Work, 25, 230-235.

Bonta, J. (2000). A quasi-experimental evaluation of an intensive rehabilitation supervision program. Criminal Justice and Behavior, 27, 312-330. 
Boone, H. (1997). Saving kids from the slammer: What are the costs and benefits? Spectrum, 70, 5-8.

Bourque, B.B., Cronin, R.C., Pearson, F. R., Felker, D.B., Han, M., \& Hill, S. M. (1996). Boot camps for juvenile offenders: An implementation evaluation of three demonstration programs. Washington, DC: National Institute of Justice.

Brezina, T. (1998). Adolescent maltreatment and delinquency: the question of intervening processes. Journal of Research in Crime and Delinquency, 35, 71-100.

Bullis, M., Yovanoff, P., \& Havel, E. (2004). The importance of getting started right: Further examination of the facility-to-community transition of formerly incarcerated youth. The Journal of Special Education, 38, 80-95.

Campbell, D. T., \& Stanley, J. C. (1963). Experimental and quasi-experimental designs for research. Chicago: Rand-McNally.

Carney, M. M., \& Buttell, F. (2003). Reducing juvenile recidivism: Evaluating the wraparound services model. Research on Social Work Practice, 13, 551 568.

Castellano, T.C., \& Soderstrom, I. R. (1992). Therapeutic wilderness programs and juvenile recidivism: A program evaluation. Journal of Offender Rehabilitation, 17, 19-46.

Center for Peacekeeping and Conflict Studies. (2003). Restorative Justice Project. Fresno, CA: Author.

Chess, C. (2000). Evaluating environmental public participation: Methodological 
questions. Journal of Environmental Planning and Management, 43, 769785.

Colley L. L., \& Culbertson, R. G. (1988). Status offender legislation and the courts. Journal of Offender Counseling, Services \& Rehabilitation, 12, 4156.

Crowe, A. H. (2000). Jurisdictional technical assistance package for juvenile corrections report. Washington, DC: U.S. Department of Justice, Office of Justice Programs, Office of Juvenile Justice and Delinquency Prevention.

Curra, J. (1996). The contours of crime. In Exploring the frontier of the future: How Kentucky will live, learn, and work. Frankfort, KY: Kentucky Long-Term Policy Research Center.

Dallal, G. E. (2000). Nonparametric statistics. Retrieved July 24, 2004, from http://www.statsoft.com

DeJong, L. (1997). Survival analysis and specific deterrence-integrating theoretical and empirical models of recidivism. Criminology, 35, 561-575.

Delaware Statistical Analysis Center. (1999). Evaluation of the Delaware Juvenile Drug Court Diversion Program. Wilmington: Delaware Criminal Justice Council.

DeMelo, D. M. (1999). Criminological theory. Retrieved January 12, 2005, from http://home.comcast.net/ ddemelo/crime/crimetheory.html

Deschenes, E. P., \& Greenwood, P. W. (1996). Alternative placements for juvenile offenders: Results from the evaluation of the Nokaomis Challenge Program. The Journal of Research in Crime and Delinquency, 35, 267-294. 
Diem, K. G. (2002, December). Using research methods to evaluate your extension program. Journal of Extension, 40. Retrieved July 23, 2003, from http://www.joe.org/joe/2002december/a1.html

Diloreto, R. (2002). Alternatives to detention for youths. The Advocate, 24, 4546. Retrieved March 9, 2004, from http://dpa.state.ky.us/library/advocate/july02/alternatives.html

Driver, F. (1993). Power and pauperism: The workhouse system, 1834-1884. New York: Cambridge University Press.

Ed Necco and Associates. (2002). Juvenile detention alternatives. Keeping our youth and communities safe [Brochure]. South Point, OH: Author.

Eddy, M. J., Reid, J. B., \& Fetrow, R. A. (2000). An elementary school-bases prevention program targeting modifiable antecedents of youth delinquency and violence: Linking the interests of families and teachers (LIFT). Journal of Emotional and Behavioral Disorders, 8, 165-176.

Elrod, H. P., \& Minor, K. I. (1992). Second wave evaluation of a multi-faceted intervention for probationers. International Journal of Offender Therapy and Comparative Criminology, 36, 247-262.

Fagan, J., \& Forst, M. (1996). Risks, fixers, and zeal: Implementing experimental treatments for violent juvenile offenders. The Prison Journal, $76,22-59$.

Famularo, R., Fenton, T., Kinscherff, R., Barnum, R., Bolduc, S.M., \& Bunschaft, D. (1992). Differences in neuropsychological and academic achievement between adolescent delinquents and status offenders. American Journal of 
Psychiatry, 149, $1252-1257$.

Famularo, R., Kinscherff, R., Fenton, T., \& Bolduc S.M. (1990). Child maltreatment histories among runaway and delinquent children. Clinical Pediatrics, 29, 713-718.

Federal Bureau of Investigation. (2000). Uniform Crime Reports. Retrieved April 19, 2002, from http://www.fbi/gov/00cius.htm

Federle, K. H. (2000). The institutionalization of female delinquency. Buffalo Law Review, 48, 881-908.

Feld, B. C. (1997). Abolish the juvenile court: Youthfulness, criminal responsibility, and sentencing policy. Journal of Criminal Law and Criminology, 88, 68-136.

Feld, B. C. (1999). Transformation of the juvenile court part II: Race and the "crack down" on youth crime. Minnesota Law Review, 84, 327-395.

Feldman, L., Males, M., \& Schiraldi, V. (2001). A tale of two jurisdictions: Youth crime and detention rates in Maryland and the District of Columbia.

Washington, DC: Building Blocks for Youth. Retrieved April 23, 2003, from http://www.buildingblocksforyouth.org

Fendrich, M., \& Archer, M. (1998). Long-term rearrest rates in a sample of adjudicated delinquents: Evaluating the impact of alternative programs. Prison, 78, 68-136.

Garcia, C. A. (2004). Realistic expectations: Constructing a mission-based evaluation model for community corrections. Criminal Justice Policy Review, $15,251-270$. 
Garson, G. D. (2005). Statnotes: An online textbook. Retrieved February 8, 2005, from http://uww2.chass.ncsu.edu/garson/pa765/statnote.htm

Gibbons, D. C. (1999). Changing law-breakers-What have we learned since the 1950s? Crime and Delinquency, 45, 272-293.

Gibbs, J. J., Giever, D., \& Martin, J. S. (1998). Parental management and selfcontrol: An empirical test of Gottfredson and Hirschi's general theory. Journal of Research in Crime and Delinquency, 35, 40-71.

Gibeaut, J. (1997). ABA backs unified family courts. ABA Journal, 83, 58-59. Gibson, C. L., Wright, J. P., \& Tibbetts, S. G. (2000). Empirical assessment of the generality of the general theory of crime: The effects of low self-control on social development. Journal of Crime and Justice, 23, 109-134.

Gilman, D. (1976). How to retain jurisdiction over status offenders-Change without reform in Florida. Crime and Delinquency, 22, 48-51.

Gordon, J. A., Moriarty, L. J., \& Grant, P. H. (2000). Impact of a juvenile residential treatment center on minority offenders. Journal of Contemporary Criminal Justice, 16, 194-208.

Gorod, B. (2000). The significance of risk: An examination of deprivation and delinquency in the lives of status offenders. Retrieved November 15, 2003, from http://www.childwelfare.net/activities/interns2000/BrianneGorod2/html Gottfredson, M. R., \& Hirschi, T. (1990). A general theory of crime. Stanford, CA: Stanford University Press.

Greenwood, P. (1994). What works with juvenile offenders: A synthesis of the literature and experience. Federal Probation, 58, 63-68. 
Greenwood, P. W., Model, K. E., Rydell, C. P., \& Chiesa, J. (1996). Diverting children from a life of crime: What are the costs and benefits? Santa Monica, CA: RAND.

Greenwood, P. W., \& Turner, S. (1987). The VisionQuest Program: An evaluation. Santa Monica, CA: RAND.

Greenwood, P. W., \& Turner, S. (1993). Evaluation of the Paint Creek Center: A residential program for serious delinquents. Criminology, 31, 263-279.

Greve, W. (2001). Imprisonment of juveniles and adolescents: Deficits and demands for developmental research. Applied Developmental Science, 5, 21-37.

Hagan, M. P., Cho, M. E., Jensen, J. A., \& King, R. P. (1997). An assessment of the effectiveness of an intensive treatment program for severely mentally disturbed juvenile offenders. International Journal of Offender Therapy and Comparative Criminology, 41, 340-349.

Harris, P. W. (1999). Differentiating delinquent youth for program planning and evaluation. Criminal Justice and Behavior, 26, 403-435.

Harris, P. W., Welsh, W. N., \& Butler, F. (2000). A century of juvenile justice. Criminal Justice, 1, 359-425.

Hill, R. (1998). What sample size is "enough" in internet survey research? Interpersonal Computing and Technology Journal, 6. Retrieved July 23, 2003, from http://jan.ucc.nau.edu

Hoffman, J. P. (2003). A contextual analysis of differential association, social control, and strain theories of delinquency. Social Forces, 81, 753-786. 
Holden, G. W., \& Kapler, R. A. (1995). Deinstitutionalizing status offenders: A record of progress (NCJ Publication No. 152979, pp. 3-10). Washington, DC: U.S. Department of Justice.

Hull, J. D. (1994, November). Running scared. Time, 144, 92-100.

Hund, A. A. Y. (1998). The reduction of status offenses through increased attachment design. Retrieved October 3, 2002, from http://www.siue.edu/ jfarley/hund495.htm

In re Gault, 387 U.S. 1 (1967).

In re Winship, 397 U.S. 358 (1970).

Ireland, T. O., Smith, C. A., \& Thornberry, T. P. (2002). Developmental issues in the impact of child maltreatment on later delinquency and drug use. Criminology, 40, 359-396.

Jackson, J. L., de Keijser, J. W., \& Michon, J.A. (1995). A critical look at research on alternatives to custody. Federal Probation, 59, 43-53.

Johnson, L. M., Simons, R.L., \& Conger, R. D. (2004). Criminal justice system involvement and continuity of crime: A longitudinal analysis. Youth and Society, 36, 3-29.

Jonson-Reid, M., \& Barth, R. P. (2000). From placement to prison: The path to adolescent incarceration from child welfare supervised foster care or group care. Children and Youth Services Review, 22, 493-517.

Joshi, P. K., \& Rosenburg, L. (1997). Children's behavioral response to residential treatment. Journal of Clinical Psychology, 53, 567-574. Josi, D. A., \& Sechrest, D. K. (1999). A pragmatic approach to parole aftercare: 
Evaluation of a community reintegration program for high-risk youthful offenders. Justice Quarterly, 16, 51-81.

Juvenile Delinquency Prevention and Control Act, 42 U.S.C. $§ 3871$ et seq. (1968).

Juvenile Justice and Delinquency Prevention Act, 42 U.S.C. $\$ 5601$ et seq. (1974).

Juvenile Research and Statistics Association. (2003). Alternatives to secure confinement/detention. Retrieved November 22, 2003, from http://www.jrsa.org/jjec/programs/alternatives/index.html

Kakar, S. (1996). Child abuse and juvenile delinquency: A prospective study. Australian and New Zealand Journal of Criminology, 29, 47-57. Kalishman, S. (2002). Evaluating community-based health professions education programs. Education for Health, 15, 228-240.

Katner, D. R. (2000). Raising mental health issues-other than insanity-in juvenile delinquency defense. Journal of Criminal Law, 28, 73-95.

Katsiyannis, A., Zhang, D., Barrett, D. E., \& Flaska, T. (2004). Background and psychosocial variables associated with recidivism among adolescent males: A 3-year investigation. Journal of Emotional and Behavioral Disorders, 12, 23-30.

Kelley, T. M. (1983). Status offenders can be different: A comparative study of delinquent careers. Crime and Delinquency, 29, 365-380.

Kelley, T. M., Kennedy, D.B., \& Homant, R. J. (2003). Evaluation of an individualized treatment program for adolescent shoplifters. Adolescence, 
$38,725-734$.

Kentucky Court of Justice. (2003). Statewide district court data. Retrieved August 11, 2003, from http://www.aoc.state.ky.us

Kentucky Department of Juvenile Justice. (2002). Alternatives to secure detention. Retrieved April 23, 2003 from http://dj.state.ky.us/ATD.htm Kentucky Department of Juvenile Justice. (2003). Standards of Practice $\$ 1102$. Frankfort, KY: author.

Kentucky Department of Public Advocacy. (2000). Excerpts from the 1999 Kentucky Juvenile Justice Advisory Committee Annual Report. The Advocate, 22, 30. Retrieved August 12, 2002, from http://dpa.state.ky.us/library/advocate/maroo/toc.html

Kentucky Unified Juvenile Code, Chpt. 600-645, K.R.S. § 600.010 et seq.

Kidd, S. A. (2002). Suicide and prostitution among street youth: A qualitative analysis. Retrieved October 7, 2004, from http://www.findarticles.com Kierkus, C.A., \& Baer, D. (2002). A social control explanation of the relationship between family structure and delinquent behaviour. Canadian Journal of Criminology, 44, 425-459.

Kowalski, M., \& Caputo, T. (1999). Recidivism in youth court: An examination of the impact of age, gender, and prior record. Canadian Journal of Criminology, 41, 57-84.

Krisberg, B. (1995). The legacy of juvenile corrections. Corrections Today, 57, 122-126.

Krisberg, B., \& Austin, L. (1993). Reinventing juvenile justice. Newbury Park, 


\section{CA: Sage.}

Kurtz, D. P., Giddings, M. M., \& Sutphen, R. (1993). A prospective investigation of racial disparity in the juvenile justice system. Juvenile and Family Court Journal, 44, 43-59.

LeBlanc, M., \& Biron, L. (1980). Status offenses: A legal term without meaning. Journal of Research in Crime and Delinquency, 17, 114-125.

Leiber, M. J. (2002). Disproportionate minority confinement (DMC) of youth: An analysis of state and federal efforts to address the issue. Crime and Delinquency, 48, 3-47.

Lemmon, J. H. (1999). How child maltreatment affects dimensions of juvenile delinquency in a cohort of low-income urban youths. Justice Quarterly, 16, 357-377).

Levitt, S. D. (1998). Juvenile crime and punishment. The Journal of Political Economy, 106, 1156-1185.

Lexcen, F., \& Redding, R. E. (2000). Mental health needs of juvenile offenders. Juvenile Justice Fact Sheet. Charlottesville: Institute of Law, Psychiatry, and Public Policy, University of Virginia. Retrieved March 15, 2003, from http://ilppp.virgina.edu

Lindner, C. (1981). The utilization of day-evening centers as an alternative to secure detention of juveniles. Journal of Probation and Parole, 13, 12-18. Lipsey, M. W. (2001). RE: Unresolved problems and unfinished business. American Journal of Evaluation, 22, 325-329.

Lipsey, M. W., Wilson, D. B., \& Cothern, L. (2000). Effective intervention for 
serious juvenile offenders. Juvenile Justice Bulletin (NCJ Publication No.

181210, pp. 1-8). Washington, DC: U.S. Department of Justice.

Logan, C. H., \& Rausch, S. P. (1985). Why deinstitutionalizing status offenders

is pointless. Crime and Delinquency, 31, 501-517.

Loughran, E. J. (1997). The Massachusetts experience: A historical review of reform in the Department of Youth Services. Social Justice, 24, 170-187.

Lyons, J. S., Libman-Mintzer, L. N., Kisiel, C. L., \& Shallcross. H. (1998).

Understanding the mental health needs of children and adolescents in residential treatment. Professional Psychology, 29, 582-588.

MacDonald, J. M., \& Chesney, L. M. (2001). Gender bias and juvenile justice revisited: A multiyear analysis. Crime and Delinquency, 47, 173-195.

MacKenzie, D. L. (1999). Commentary: The effectiveness of aftercare programs-Examining the evidence. Juvenile Justice Bulletin (NCJ Publication No.175715, pp. 1-24). Washington, DC: U.S. Department of Justice.

MacKenzie, D. L., \& Brame, R. (2001). Community supervision, prosocial activities, and recidivism. Justice Quarterly, 18, 429-449.

MacKenzie, D. L., \& Souryal, C. (1994). Multisite evaluation of shock incarceration. Washington, DC: U.S. National Institute of Justice. Maloney, D., Romig, D., \& Armstrong, T. (1988). Juvenile probation: The balanced approach. Reno, NV: National Council of Juvenile and Family Court Judges.

Markowitz, M. W., \& Jones-Brown, D. (2000). System in black and white: 
Exploring the connections between race, crime, and justice. Westport, CT: Praeger.

Martin, L. H., \& Snyder, P. R. (1976). Jurisdiction over status offenders should not be removed from the juvenile court. Crime and Delinquency, 22, 44-47. Matthews, H. T. (2000). Status offenders: Our children's constitutional rights versus what's right for them. Southern University Law Review, 27, 201-213. Matthews, R., \& Pitts, J. (1998). Rehabilitation, recidivism, and realism. The Prison Journal, 78, 390-405.

Mazerolle, P., Brame, R., Paternoster, R., Piquero, A., \& Dean, C. (2000). Onset age, persistence, and offending versatility: Comparisons across gender. Criminology, 38, 1143-1172.

McCord, J., Widom, C. S., \& Crowell, N. A. (Eds.). (2001). Panel on juvenile crime: Prevention, treatment, and control. Washington, DC: National Academy Press.

McKeiver v. Pennsylvania, 403 U.S. 528 (1976).

McNamara, C. (1998). Basic guide to program evaluation. Retrieved November 25, 2002, from http://www.mapnp.org/library/evaluatn/fnl_eval.htm

Miller, J. G. (1991). Last one over the wall-The Massachusetts experiment in closing reform schools. Columbus: Ohio State University Press.

Minor, K. I., Hartmann, D. J., \& Terry, S. (1997). Predictors of actions and recidivism. Crime and Delinquency, 43, 328-344.

Minor, K. I., Wells, J. B., Soderstrom, I. R., Bingham, R., \& Williamson, D. (1999). Sentence completion and recidivism among juveniles referred to 
teen court. Crime and Delinquency, 45, 467-480.

Monahan, J. (1994). The causes of violence. The FBI Law Enforcement Bulletin, 63, 11-16.

Morse, S. J. (1997). Immaturity and irresponsibility. Criminal Law and Criminology, 88, 15-67.

Murray, C. A., \& Cox, L. A. (1979). Beyond probation: Juvenile corrections and the chronic delinquent. Beverly Hills, CA: Sage.

Myner, J., Santman, J., Cappelletty, G. G., \& Perlmutter, B. F. (1998). Variables related to recidivism among juvenile offenders. International Journal of Offender Therapy and Comparative Criminology, 42, 65-81.

National Council on Crime and Delinquency. (1999). Evaluation of the Cook County Juvenile Sheriff's Work Alternative Program. Chicago: Illinois Criminal Justice Information Authority.

Nelson, G. M. (1982). Status offenders, delinquents, and Title XX. Social Work, $27,348-353$.

Norkus, Z. (2000). Max Weber's interpretive sociology and rational choice approach. Sociology, 12, 259-283.

O'Conner, J. M., \& Treat, L. K. (1996). Getting smart about getting tough: Juvenile justice and the possibility of progressive reform. American Criminal Law Review, 33, 1299-1344.

Office of Juvenile Justice and Delinquency Prevention. (2000). Juvenile court statistics. Washington, DC: Author.

Ohlin, L. E. (1998). The future of juvenile justice policy and research. Crime 
and Delinquency, 44, 143-154.

Olsson, K. S. (1996). The juvenile justice dilemma. Corrections Today, 58, 4852.

O'Mahoney, D. (2000). Young people, crime, and criminal justice: Patterns and prospects for the future. Youth and Society, 32, 60-80.

Oregon Youth Authority. (2002). Juvenile recidivism: Oregon's statewide report on juvenile recidivism 1996-2000. Salem, OR: Author.

Pabon, E. (1983). The case for alternatives to detention. Juvenile and Family Court Journal, 34, 37-46.

Pandiani, J. A. (1998). Using incarceration rates to measure mental health program performance. The Journal of Behavioral Health Services and Research, 25, 300-312.

Patrick, S., Marsh, R., Bundy, W., Mimura, S., \& Perkins, T. (2004). Control group study of juvenile diversion programs: An experiment in juvenile diversion-The comparison of three methods and a control group. Social Science Journal, 41, 129-136.

Patton, M. J. (1982). Practical evaluation. Beverly Hills, CA: Sage.

Petersilia, J. (1995). A crime control rationale for reinvesting in community corrections. Prison Journal, 75, 479-497.

Petersilia, J. (1996). Recidivism. In. M. D. McShane \& F. P. Williams III (Eds.), Encyclopedia of American prisons (pp. 382-385). New York: Garland.

Peterson, C. A. (2002). Reflections on the challenges of program evaluation. Topics in Early Childhood Education, 22, 82-86. 
Petrosino, A., Turpin-Petrosino, C., \& Finckenauer, J. O. (2000). Well-meaning programs can have harmful effects! Lessons from experiments of programs such as Scared Straight. Crime and Delinquency, 46, 354-379.

Pillick, A. M. (1985). Child welfare: The contempt power of family court used to incarcerate chromic status offenders. Children's Legal Rights Journal, 6, 913.

Pinderhughes, H. (1997). Race in the hood: Conflict and violence among urban youth. Minneapolis: University of Minnesota Press.

Platt, A. M. (1977). The child savers: The invention of delinquency. Chicago: University of Chicago Press.

Poulin, M. E., Harris, P. W., \& Jones, P. R. (2000). The significance of definitions of success in program evaluation. Evaluation Review, 24, 516537.

Poulin, M., \& Orchowsky, S. (2003). Juvenile justice program evaluation. An overview ( $2^{\text {nd }}$ ed.). Washington, DC: Juvenile Justice Evaluation Center.

Pranis, K. (1998). Promising practices in community justice: Restorative justice. In K. Dunlap (Ed.), Community justice concepts and strategies (pp. 37-57). Lexington, KY: American Probation and Parole Association.

President's Crime Prevention Council. (1997). Comprehensive Planning Techniques. Retrieved April 24, 2003, from http://www.nal.usda.gov/pavnet/whitehouse/catalog/comp-06.html Presser, L., \& Van-Voorhis, P. (2002). Values and evaluation: Assessing processes of restorative justice programs. Crime and Delinquency, 48, $162-$ 
188.

Priest, S. (2001). A program evaluation primer. Journal of Experiential Education, 24, 34-41.

Puzzanchera, C., Stahl, A., Finnegan, T.A., Tierney, N., \& Snyder, H. N. (in press). Juvenile Court Statistics 2000. Washington, DC: Office of Juvenile Justice and Delinquency Prevention. Retrieved February 4, 2005, from http://ojjdp.ncjrs.org/ojstatbb/court/faqs.asp

Quist, R. M., \& Matshazi, D. G. M. (2000). The child and adolescent functional assessment scale (CAFAS): A dynamic predictor of juvenile recidivism. Adolescence, 35, 181-193.

Rankin, J. H., \& Wells, L. E. (1985). From status to delinquent offenses:

Escalation? Journal of Criminal Justice, 13, 171-180.

Rausch, S. (1983). Court processing versus diversion of status offenders: A test of deterrence and labeling theories. Journal of Research in Crime and Delinquency, 20, 39-54.

Redding, R. E. (2000). Barriers to meeting the mental health needs of offenders in the juvenile justice system. Juvenile Justice Fact Sheet. Charlottesville: Institute of Law, Psychiatry, and Public Policy, University of Virginia. Retrieved March 13, 2003 from http://www.ilppp.virginia.edu/Publications_and_Reports/BarrMeet.html

Reid, W. J. (2004). Do some interventions work better than others? A review of comparative social work experiments. Social Work, 28, 71-82.

Riley, D. B., Greif, G. L., Caplan, D. L., \& MacAulay, H. K. (2004). Common 
themes and treatment approaches in working with families of runaway youths. American Journal of Family Therapy, 32, 139-154.

Rhodes, J. E., \& Fischer, K. (1993). Spanning the gender gap: Gender

differences in delinquency among inner-city adolescents. Adolescence, 28, 879-890.

Risler, E. A., Sutphen, R., \& Shields, J. (2000). Preliminary validation of the juvenile first offender risk assessment index. Research on Social Work Practice, 10, 111-126.

Ristau, S. (2001). Building organizational capacity in outcomes evaluation: A successful state association model. Families in Society, 82, 555-560.

Robinson, G., \& Arnold, T. (2000). Change in laws impacting juveniles-An overview. The Advocate, 22, 14-15. Retrieved November 4, 2002, from http://dpa.state.ky.us/library/advocate/july00/Juvenile.htm

Rojek, D. G., \& Erickson, M. L. (1982). Delinquent careers: A test of the career escalation model. Criminology, 20, 5-28.

Ross, T., Armstrong, M., \& Conger, D. (2002). Bridging child welfare and juvenile justice: Preventing unnecessary detention of foster children. Child Welfare, 81, 471-495.

Rosenblatt, J. A., Rosenblatt, A., \& Biggs, E. E. (2002). Criminal behavior and emotional disorder: Comparing youth served by the mental health and juvenile justice systems. The Journal of Behavioral Health and Research, $27,227-238$.

Rossi, P. H., Freeman, H. E., \& Lipsey, M. W. (1999). Evaluation: A systematic 
approach ( $3^{\text {rd }}$ ed.). Beverly Hills, CA: Sage.

Rossner, L. S. (1988). Juvenile secure detention. Journal of Offender

Counseling, Services, and Rehabilitation, 12, 57-77.

Roy, S. (1995). Juvenile restitution and recidivism in a midwestern county.

Federal Probation, 59, 55-62.

Roy, S. (1997). Five years of electronic monitoring of adults and juveniles in

Lake County, Indiana: A comparative study on factors related to failure.

Journal of Crime and Justice, 20, 141-160.

Rubin, H. T. (1977). The 's search for identity and responsibility.

Crime and Delinquency, 23, 1-13.

Russell, R., \& Sedlak, U. (1993). Status offenders: Attitudes of child welfare practitioners toward practice and policy issues. Child Welfare, 72, 13-19.

Sanders, J. R. (2001). A vision for evaluation. American Journal of Evaluation, $22,363-366$.

Sarri, R. C. (1983). Gender issues in juvenile justice. Crime and Delinquency, $29,381-397$.

Schneider, A. L. (1984). Divesting status offenders from Juvenile Court jurisdiction. Crime and Delinquency, 30, 347-370.

Schutt, R. K., \& Dannefer, D. (1988). Detention decisions in juvenile cases: JINS, JD's, and gender. Law and Society Review, 22, 509-520.

Schwartz, I. M., Jackson-Beeck, M., \& Anderson, R. (1984). The "hidden" system of juvenile control. Crime and Delinquency, 30, 371-385.

Scott, E. S., \& Steinberg, L. (2003). Blaming youth. Texas Law Review, 81, 
799-841.

Sexton, E. T. (1998). Harmed children: Delinquency, child abuse, and school. Reclaiming Children and Youth, 7, 95-99.

Shaw, C. R., \& McKay, H. D. (1942). Juvenile delinquency in urban areas.

Chicago: University of Chicago Press.

Sheldon, R. G. (1999). Detention diversion advocacy: An evaluation. Juvenile Justice Bulletin. Washington, DC: U.S. Department of Justice.

Sheldon, R. G., Horvath, J. A., \& Tracy, S. (1989). Do status offenders get worse? Some clarification on the question of escalation. Crime and Delinquency, 35, 202-216.

Shelton, D. (2002). Failure of mental health policy-incarcerated children and adolescents. Pediatric Nursing, 22, 278-281.

Shore, H. (2000). The idea of juvenile crime in $19^{\text {th }}$ century England. History Today, 50, 21-28.

Sickmund, M. (2000). Offenders in juvenile court, 1997. Juvenile Justice Bulletin (NCJ Publication No. 181204, pp. 1-15). Washington, DC: U.S. Department of Justice.

Sickmund, M. (2003). Juveniles in court. Juvenile Offenders and Victims National Report Series Bulletin (NCJ Publication No. 195420, pp. 2-31). Washington, DC: U.S. Department of Justice.

Skonovd, N., \& Krause, W. (1991). The regional youth educational facility promising short-term institutional and aftercare program for juvenile court wards. In T. Armstrong (Ed.), Intensive interventions with high risk youths: 
Promising approaches in juvenile probation and parole (pp. 395-421). Monsey, NY: Criminal Justice Press.

Smith, A., \& Stern, S. B. (1997). Delinquency and antisocial behavior: A review of family processes and intervention research. Social Services Review, 71, $382-421$.

Smith, D. J., (1999). Less crime without more punishment. Edinburgh Law Review, 3, 294-316.

Snyder, H. N., \& Sickmund, M. (1999). Juvenile courts and juvenile crime. In Juvenile Offenders and Victims: 1999 National Report (pp. 141-183). Pittsburgh, PA: National Center for Juvenile justice.

Spergel, I. A., Reamer, F. G., \& Lynch, J. O. (1981). Deinstitutionalization of status offenders: Individual outcome and system effects. Journal of Research in Crime and Delinquency, 18, 4-33.

St. C. Levy, K. (1997). The contribution of self-concept in the etiology of adolescent delinquent. Adolescence, 32, 671-687.

Stahl, A., L., Kang, W., \& Wilt, D. (2003). Easy Access to State and County Juvenile Court Case Counts 2000. Washington, DC: Office of Juvenile Justice and Delinquency Prevention. Retrieved on February 4, 2005, from http://ojjdp.ncjrs.org/ojstatbb/court/faqs.asp

Stahl, A. L., Sickmund, M., Finnegan, T. A., Snyder, H. N., Poole, R. S., \& Tierney, N. (1999). Juvenile Court Statistics 1996. Washington, DC: Office of Juvenile Justice and Delinquency Prevention.

Steinberg, L., \& Cauffman, E. (1999). A developmental perspective on serious 
juvenile crime: When should juveniles be treated as adults? Federal Probation, 63, 52-57.

Steinhart, D. J. (1996). Status offenses. The Juvenile Court, 6, 86-99.

Stewart, M. J., Vockell, E. L., \& Ray, R. E. (1986). Decreasing court appearances of juvenile status offenders. Social Casework: The Journal of Contemporary Social Work, 67, 74-79.

Sullivan, P., \& Knutson, J. (2000). The prevalence of disabilities and maltreatment among runaway children. Child Abuse and Neglect, 24, 275289.

Swanston, H. Y., Parkinson, P. N., O'Toole, B. I., Plunkett, A.M., Shrimpton, S., \& Oates, R. K. (2003). Juvenile crime, aggression, and delinquency after sexual abuse. British Journal or Criminology, 43, 729-249.

Terry-McElrath, Y., McBride, D., Vanderwaal, C., \& Ruel, E. (2002). Impact of a juvenile residential treatment center on minority offenders. Corrections Today, 64, 78-87.

Thomas, C. W. (1976). Are status offenders really so different? A comparative and longitudinal assessment. Crime and Delinquency, 22, 438-455.

Trochim, W. M. K. (2002). Research methods knowledge base. Retrieved December 3, 2002, from http://trochim.omni.cornell.edu/kb/quasnegd.htm U.S. Department of Education, National Center for Education Statistics. (1998). Unit record versus aggregate data: Perspectives on postsecondary education data collection, retention, and release. Washington, DC: Council of the National Postsecondary Education Cooperative Working Group. 
Van Dusen, K. T. (1981). Net widening and relabeling. American Behavior Scientist, 24, 801-811.

Van-Voorhis, P., Mathers, R. A., \& Garner, C. C. (1988). The impact of family structure and quality on delinquency: A comparative assessment of structural and functional factors. Criminology, 26, 235-261.

Wade, B. (1998). Keeping kids out of court: Three case studies illustrate some of the latest efforts to reduce recidivism within their communities. American City and County, 113, 26-34.

Waggoner, K. J. (1996). The project on human development in Chicago neighborhoods. The FBI Law Enforcement Bulletin, 65, 28-34.

Weijers, I. (1999). The double paradox of juvenile justice. European Journal on Criminal Policy and Research, 7, 329-351.

Whitbeck, L. B., Hoyt, D. R., \& Yoder, K. A. (1999). A risk-amplification model of victimization and depressive symptoms among runaway and homeless adolescents. American Journal of Community Psychology, 27, 273-296.

Wickipedia Foundation. (2004). Wickipedia online free encyclopedia. Retrieved January 7, 2005, from http://en.wikipedia.org/wiki/Deterrence

Wilson, J. Q. (1975). Thinking about crime. New York: Basic Books.

Wilson, J. Q. (1983). Thinking about crime: The debate over deterrence. The Atlantic, 252, 72-87.

Wood, P. B., \& Grasmick, H. G. (1999). Toward the development of punishment equivalencies: Male and female inmates rate the severity of alternative sanctions compared to prison. Justice Quarterly, 16, 19-50. 
Worthen, B.R. (2001). Whither evaluation? That all depends. American Journal of Evaluation, 22, 409-419.

Wright, A., \& Jaworsky, J. L. (1998). Koch Crime Institute white paper report. The standardization of juvenile offender program evaluation. Retrieved December 9, 2004, from http://kci.org/publication/white_paper/program_eval//solution.htm

Wright, J. P., Cullen, F. T., \& Miller, J. T. (2001). Family social capital and delinquent involvement. Journal of Criminal Justice, 29, 1-9.

Wyman, J. R. (1997). Drug abuse among runaway and homeless youths calls for focused outreach solutions. Retrieved April 4, 2002, from http://www.nida.nih.gov

Yamaguchi, K. (1998). Rational-choice theories of anticipatory socialization. Rationality and Society, 10, 163-200.

Yoder, K. A., Whitbeck, L. B., \& Hoyt, D. R. (1999). Event history of antecedents to running away from home and being on the streets. American Behavioral Scientist, 45, 51-66.

Zimring, F. E. (2000). The common thread: Diversion in juvenile justice. California Law Review, 88, 2477-2495.

Zingraff, M. T., Leiter, J., Myers, K. A., \& Johnsen, M. (1993). Child maltreatment and youthful problem behavior relationship. Criminology, 31, 173-202. 
APPENDIXA

Risk Screening Instrument 
Juvenile's Name

Sex: $M \square F \square$ Age:

Race/Ethnicity:

Most Serious Current Charge:

OtherCharges:
CDW Referral No

County:

Admission Date/Time:

\section{IT IS THE POLICY OF DJJ THAT STATUS OFFENDERS WILL NOT BE SECURELY DETAINED}

A. Automatic Secure Detention: If the juvenile meets any of the criteria included in this section, the juvenile is not eligible for alternative placement. Check the appropriate box and sign your name at the bottom. You do not need to complete the remainder of the form.

․ Capital offense, Class A Felony, Class B Felony

$\square \quad$ Fugitive from another jurisdiction on a public offense with a formal hold request from the other jurisdiction

$\square$ The juvenile was 14 or older at the time of the alleged commission of a felony in which a firearm was used in the commission of the offense

The juvenile is currently on probation/parole as a youthful offender or out on bond as an accused youthful offender

$\square \quad$ The juvenile is a traffic offender 16 years of age or older

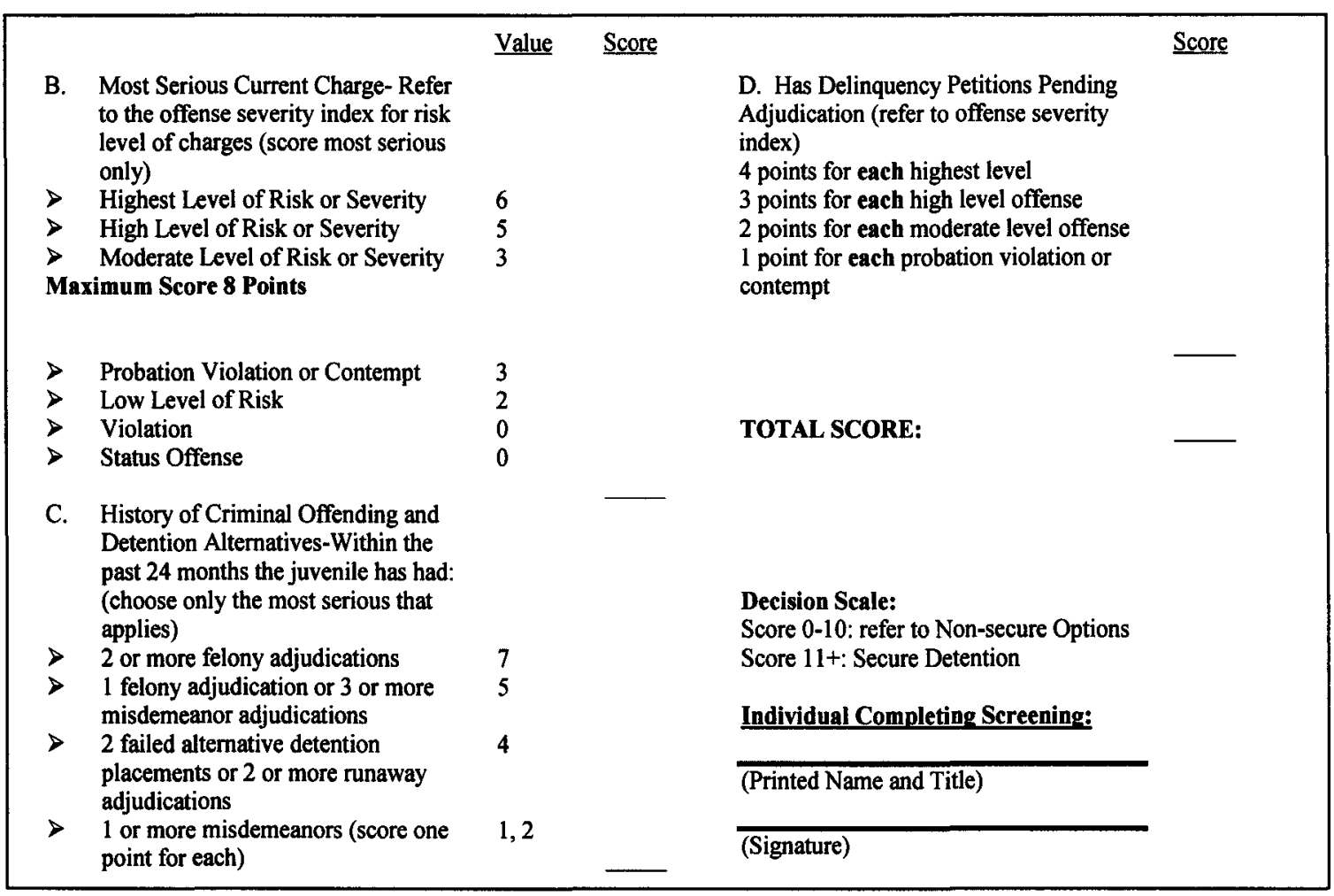

Administrative Override: (Requires Supervisory Approval) Reason:

Name and Title of Supervisor:

Signature of Supervisor: Date: 


\section{APPENDIXB}

Offense Risk or Severity Index 
Kentucky Department of Juvenile Justice

Offender Risk or Severity Index

Low Level Risk- Any offense not specifically listed as Highest, High, Moderate or as a Contempt or Probation Violation and not under the nonoffender or status codes below shall be categorized as a Low Level of Risk, and shall be assigned a value of 2 on the screening instrument.

Nonoffense and Status Offense Codes- Nonoffense and Status Offenses shall be assigned a value of 0 .

\begin{tabular}{|l|l|l|}
\hline CHARGE & UOR & KRS \\
\hline Runaway & 2800 & $630.020(1)$ \\
\hline Beyond Control & 2801 & $630.020(2)$ \\
\hline Habitual Truant & 2802 & $630.020(3)$ \\
\hline $\begin{array}{l}\text { Emergency Admit-Mental } \\
\text { Hospital }\end{array}$ & 2803 & 645.120 \\
\hline $\begin{array}{l}\text { Involuntary Commitment- } \\
\text { Mental Hospital }\end{array}$ & 2804 & 645.150 \\
\hline $\begin{array}{l}\text { Temporary Custody- } \\
\text { Nonoffender }\end{array}$ & 2810 & 620.090 \\
\hline $\begin{array}{l}\text { Emergency Custody- } \\
\text { Nonoffender }\end{array}$ & 2811 & 620.060 \\
\hline $\begin{array}{l}\text { Dependency- } \\
\text { Nonoffender }\end{array}$ & 2813 & 620.070 \\
\hline Neglect-Nonoffender & 2814 & 620.070 \\
\hline Abuse-Nonoffender & 2815 & 620.070 \\
\hline
\end{tabular}


APPENDIX C

Codebook of Variables 


\section{CodeBook}

\begin{tabular}{|l|l|l|l|}
\hline Nominal Level Variables & \multicolumn{3}{l|}{} \\
\hline Ethnicity & 1 = African American & 2 = Caucasian & 3 = Hispanic \\
\hline & 4 = Bi-Racial & $5=$ Other & \\
\hline Gender & 1 = Female & 2 = Male & \\
\hline Living Arrangement & 1 = Both Parents & $2=$ Mother & $3=$ Father \\
\hline & 4 = Relative & $5=$ Other & \\
\hline Placement Type & 1 = ATD & $2=$ Detention & $\begin{array}{l}3= \\
\text { Miscellaneous }\end{array}$ \\
\hline School Type Attended & 1 = Traditional & $2=$ Alternative & $\begin{array}{l}99=\text { Not } \\
\text { Enrolled }\end{array}$ \\
\hline
\end{tabular}

Ordinal Level Variables

\begin{tabular}{|l|l|}
\hline \multicolumn{2}{|l|}{ Interval/Ratio Level } \\
\cline { 1 - 2 } Variables & \\
\hline Grade & $1-12$ \\
\hline Age Initial Court Contact & $1-99$ Years \\
\hline Age Initial Placement & $1-99$ Years \\
\hline \# Placements & $1+$ \\
\hline $\begin{array}{l}\text { \#Contempt-FTA Charges } \\
\text { Prior, During, \& After }\end{array}$ & $0+$ \\
\hline $\begin{array}{l}\text { \#Status \& Delinquent } \\
\text { Charges Prior, During, \& } \\
\text { After }\end{array}$ & $0+$ \\
\hline $\begin{array}{l}\text { Offense Difference } \\
\text { (Recidivism) \#Charges } \\
\text { Prior minus After }\end{array}$ & $0+$ \\
\hline
\end{tabular}


CURRICULUM VITAE

Arthur Hayden, MSW, MS

Cabinet for Health and Family Services

2050 Creative Drive Suite 160

Lexington KY 40505

arthur.hayden@ky.gov

\section{EDUCATION}

\section{University of Kentucky/University of Louisville}

Ph.D. in Social Work

May, 2005

\section{Eastern Kentucky University}

M.S.-Criminal Justice (Juvenile Services \& Corrections)

December, 1998

\section{University of Kentucky \\ M.S.W.-Social Work \\ May, 1997}

Kentucky State University

BA-Criminal Justice

December, 1992

\section{EMPLOYMENT}

Cabinet for Health and Family Services

Department for Community Based Services

Lexington, KY 40508

Social Services Clinician

May, 1994-Present

HOPE Center

Lexington, KY 40508

Substance Abuse \& Recovery Counselor (MSW Practicum)

August, 1996-May, 1997 


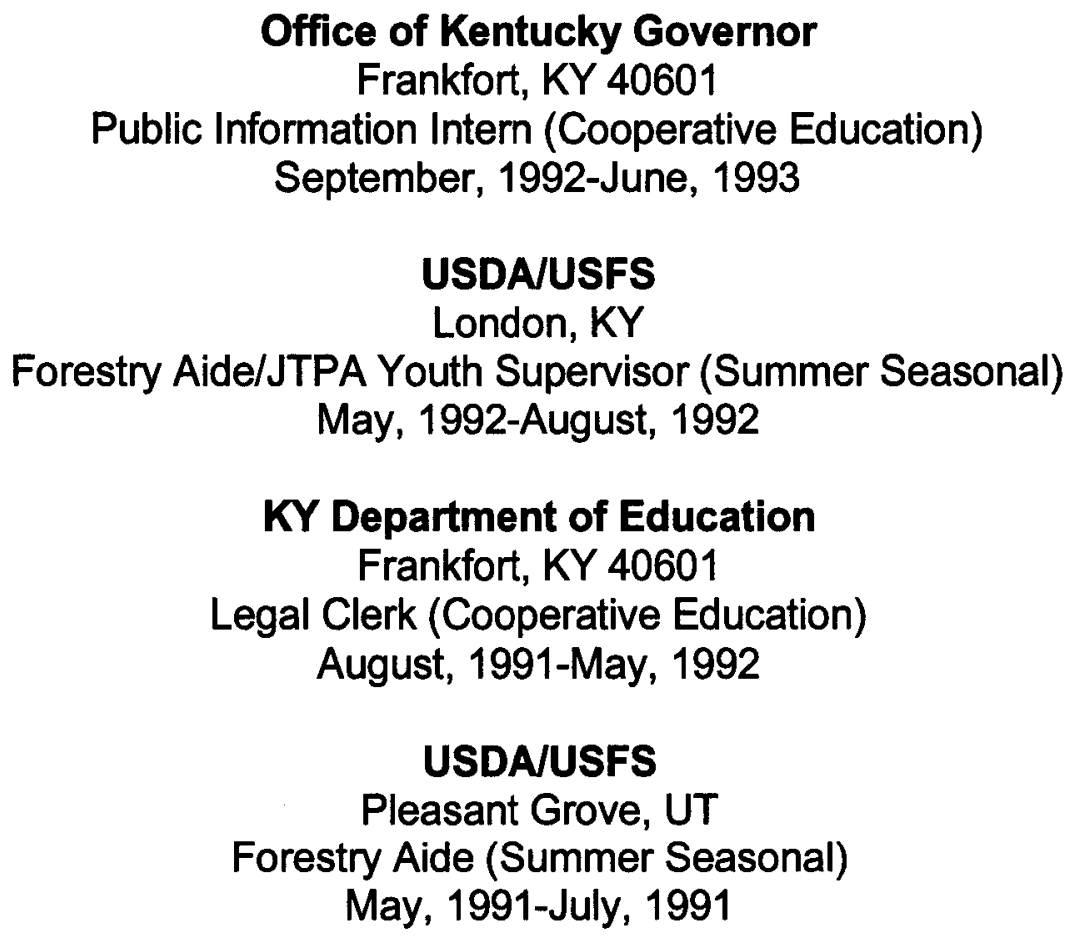

\section{University of Louisville}

Kent School of Social Work

SW-669: Research Design II

Spring, 2005

\section{University of Kentucky}

College of Social Work

SW-751: Research Design \& Implementation II

Spring, 2005

\section{University of Louisville} Kent School of Social Work SW-668: Research Design I Fall, 2004

\section{University of Kentucky}

College of Social Work

SW-750: Research Design \& Implementation I

Fall, 2004 


\section{University of Kentucky \\ College of Social Work \\ SW-444: Educational Practicum I \\ Fall, 2003 \\ University of Kentucky \\ College of Social Work \\ SW-124: Introduction to Social Work \\ Fall, 2001}

\section{RESEARCH}

Detention Alternatives for Status Offenders (Dissertation), 2005

Drug Courts for Status Offenders, 2002

Child Custody Allocation in Domestic Violence Cases (NERI, 2001)

Probation and Residential Treatment Outcomes, 2000

Probation Outcomes, 1998

\section{SAMPLE OF}

TRAININGS

ATTENDED

CAPTASA Annual Conference, 2004

KYCPE Annual Conference, 2004

HIPAA, 2003

Truancy Symposium, 2003

Trainings Attended: 78

Hours Trained: 460.75

\section{REFERENCES}

Dr. Ruth Huber

Director, Social Work Ph.D. Program

University of Louisville

Louisville, KY 40292

(502) 852-5555

ruth.huber@louisville.edu 
Dr. Dana Sullivan

Research Professor

University of Louisville

Louisville, KY 40292

(502) 852-5555

dana.sullivan@louisville.edu

Vivian Schneider, M.A.

Supervisor, Juvenile Services Unit

CHFS/DCBS

Lexington, KY 40505

Vivian.schneider@ky.gov 